\title{
Avaliação da Resistência Adesiva e da Microinfiltração Marginal em Restaurações de Porcelana Fixadas com Três Sistemas de Dupla Polimerização
}

\section{ROGÉRIO FULGÊNCIO PINHEIRO}

Tese apresentada à Faculdade de Odontologia de Bauru, da Universidade de São Paulo, como requisito para obtenção do título de Doutor em Odontologia, área de Dentística - opção Dentística Restauradora. 


\section{Avaliação da Resistência Adesiva e da Microinfiltração Marginal em Restaurações de Porcelana Fixadas com Três Sistemas de Dupla Polimerização}

\section{ROGÉRIO FULGÊNCIO PINHEIRO}

Tese apresentada à Faculdade de Odontologia de Bauru, da Universidade de São Paulo, como requisito para obtenção do título de Doutor em Odontologia, área de Dentística - opção Dentística Restauradora.

Orientador: Prof. Dr. Mário Honorato da Silva e Souza Júnior

\section{BAURU}




\section{Avaliação da Resistência Adesiva e da Microinfiltração Marginal em Restaurações de Porcelana Fixadas com Três Sistemas de Dupla Polimerização}

\section{ROGÉRIO FULGÊNCIO PINHEIRO}

Tese apresentada à Faculdade de Odontologia de Bauru, da Universidade de São Paulo, como requisito para obtenção do título de Doutor em Odontologia, área de Dentística - opção Dentística Restauradora.

(Edição Revista)

Orientador: Prof. Dr. Mário Honorato da Silva e Souza Júnior

\section{BAURU}




\section{Pinheiro, Rogério Fulgêncio}

P655a Avaliação da resistência adesiva e da microinfiltração marginal em restaurações de porcelana fixadas com três sistemas de dupla polimerização. / Rogério Fulgêncio Pinheiro. -- Bauru, 1999. 127 p. : il. ; $30 \mathrm{~cm}$.

Tese. (Doutorado) -- Faculdade de Odontologia de Bauru. USP.

Orientador: Prof. Dr. Mário Honorato da Silva e Souza Júnior. 


\section{ROGÉRIO FULGÊNCIO PINHEIRO}

Nascimento

Filiação

$1986-1989$

1990

1991

1992

$1993-1995$

1994

1995

$1997-1998$

da

RJ

$1995-1999$
02 maio de 1965

Rio de Janeiro - RJ

Ronaldo Walter Pinheiro

Lúcia Olívia Fulgêncio Pinheiro

Curso de Odontologia - Faculdade de Odontologia da Universidade Gama Filho - Rio de Janeiro - RJ.

2 으 Tenente Dentista do Exército Brasileiro.

Curso de especialização em Dentística - Faculdade de Odontologia de Bauru, USP.

Professor Assistente da Disciplina de Clínica Integrada da Faculdade de Odontologia da Universidade de Nova Iguaçu - RJ.

Curso de Pós-graduação em Dentística, em nível de Mestrado, na Faculdade de Odontologia de Bauru, USP.

Professor Assistente da Disciplina de Dentística da Faculdade de Odontologia da Universidade Gama Filho, RJ.

Professor de Curso de

Especializacão em Dentística da Faculdade de Odontologia da Universidade Gama Filho, RJ

Coordenador do Curso de Especialização em Dentística Pontifícia Universidade Católica,

Curso de Pós-graduação em Dentística, ao nível de Doutorado, na Faculdade de Odontologia de Bauru, USP. 
Associações

ABO - Associação Brasileira de Odontologia - Secção Rio de Janeiro.

ABOPREV - Associação Brasileira de Odontologia Preventiva.

APG - Associação de Pós-Graduandos.

SBPqO - Sociedade Brasileira de Pesquisas odontológicas.

IADR - International Association for Dental Research 
À minha avó Maria José,

exemplo de que na vida é preciso compreensão, apoio e simplicidade para se ir longe;

\section{À Evelise,}

minha companheira durante estes anos, pelas lembranças dos grandes momentos de cumplicidade e por ter deixado muitas saudades;

com carinho, dedico este trabalho. 
Agradecimentos

A Deus, pela presença constante;

Aos meus pais Ronaldo e Lúcia, pelo dom da vida; 
Ao Prof. Dr. Mário Honorato da Silva e Souza Júnior, com quem tive o prazer de conviver e ser orientado.

Sua orientação segura e eficiente resultou, não somente neste trabalho, mas em um referencial no ensino e na pesquisa odontológica;

meu muito obrigado. 
Ao Prof. Dr. José Mondelli, baluarte da Odontologia, que através da maneira simples e dedicada com que abraça seus objetivos, resultou no meu grande respeito e admiração;

Ao Prof. Dr. Carlos Eduardo Francischone, mestre e exemplo de dedicação à Odontologia e ao próximo.

Seus ensinamentos como meu orientador no Mestrado e em outros trabalhos colaboraram muito para a minha formação;

Meu agradecimento especial. 
Aos professores do Departamento de Dentística da Faculdade de Odontologia de Bauru - USP, Profs. Drs. José Mondelli, Aquira Ishikiriama, Maria Fidela de Lima Navarro, José Carlos Pereira, João Lúcio Coradazzi, Carlos Eduardo Francischone, Eduardo Batista Franco, Mário Honorato de Silva e Souza Júnior, Ricardo Marins de Carvalho, Rafael Lia Mondelli, pela cumplicidade na minha formação de docente, pesquisador e profissional da odontologia. Vocês me mostraram o exemplo de trabalho de uma equipe que luta pelo ensino e pela pesquisa no Brasil;

muito obrigado. 
À Daniele Crepaldi e ao Wilton, meus primeiros orientados, que foram de importância crucial na execução

da parte prática deste trabalho; 
Aos amigos do curso de Mestrado Adriana, Alberto, Alexandra, Angela, Carol, Geraldo, Ingrid, Régia, Regina, Sílvia; Jorge, João, Mário pela amizade em uma fase muito importante;

Aos amigos do curso de Doutorado, Adriana, Angela, Cecília, Fafá, Joãozinho, Margareth, Renata e Regina, por aumentarem esta amizade;

Ao Dr. Halim; Haline e Hugo pela grata convivência;

À Denise e ao Paulão por continuarmos a luta pelo ensino;

Ao Elio, Vladimir, Damé e Eduardo, com quem tive o prazer de conviver e trabalhar; 
À Faculdade de Odontologia de Bauru - USP, através de seu Diretor, Prof. Dr. Aymar Pavarini e seu Vice-Diretor, Prof. Dr. Clóvis Monteiro Bramante;

Ao presidente da Comissão de Pós-Graduação da FOB - USP, Prof. Dr. Luiz Fernando Pegoraro pela oportunidade concedida;

Ao Coordenador do Curso de Pós-Graduação em Dentística (Doutorado) da FOB - USP, Prof. Dr. José Carlos Pereira pela confiança depositada e oportunidade concedida;

À Chefe do Departamento de Dentística da FOB - USP, Prof ${ }^{a}$. Dr ${ }^{a}$. Maria Fidela de Lima Navarro pelo exemplo de dedicação à pesquisa;

À Universidade Gama Filho, onde dei os meus primeiros passos na Odontologia, pelo incentivo à minha carreira;

À Universidade de Nova Iguaçu pelo início da minha carreira docente e apoio durante esses anos;

Ao CNPq pela bolsa de estudos concedida; 
Ao Prof. Dr. José Roberto Pereira Lauris que não mediu esforços na orientação da análise estatística;

À Beth, pelo carinho e apoio durante estes anos;

Ao Nelson, meu "orientador técnico" pelo capricho na realização das incrustações e pela amizade;

Aos funcionários do Departamento de Dentística, D. Rosinha, Rosa, Zuleica, Nelson, Seu Dito, Júnior, Vanessa, Heloísa e Angela, pela agradável convivência nestes anos;

Ao Edimauro, que não mediu esforços na utilização do microscópio;

Aos funcionários da APG, Salvador, André e Silmara, pela constante boa vontade;

Aos funcionários da Pós-Graduação, Aninha, Cleuza, Dionílio, Heloísa, Neide, Sandra, Jane, Débora e Aurélio pela amizade e incansável dedicação;

Aos funcionários da Biblioteca, em especial à Cybelle pela atenção que dedicou a esta pesquisa;

Ao Valdir pelo empenho na revisão do texto;

Ao Neimar e à Teca pelo auxílio na confecção das ilustrações;

Ao Roberto pela formatação do texto; 
Aos meus Tios Abel e Carlinhos pelo exemplo profissional e pela solidariedade;

Aos meus "amigos do Rio", os bons e velhos amigos, que torceram por mim durante estes anos; incentivo;

Ao Dr. José Eustáquio, a quem tenho grande admiração, pela amizade e

Ao Prof. Dr. Orlando Chevitarese, um grande mestre da Vida;

Ao meu amigo Prof. Carlos Zarro Portela e demais professores da UNIG, companheiros de trabalho, que acreditaram em mim e me apoiaram mesmo de longe;

Ao Coordenador do Curso de Odontologia da Universidade Gama Filho, Prof. Dr. Mário João e demais professores, com quem tenho o prazer de trabalhar e conviver;

Ao Prof. Dr. Wilson Chagas de Araújo, pela confiança depositada;

Ao Dr. Santa Rosa, pelas nossas conversas semanais; 
Aos alunos, sem os quais o professor não teria razão de existir;

Aos pacientes pela confiança depositada durante o curso; trabalho,

A todos que acreditaram em mim e assim colaboraram na realização deste meu muito obrigado. 


\section{SUMÁRIO}

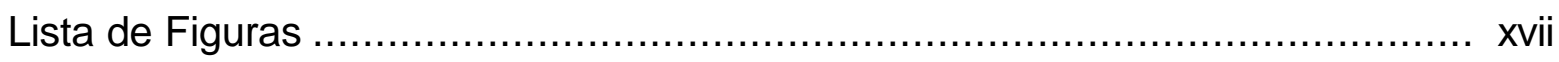

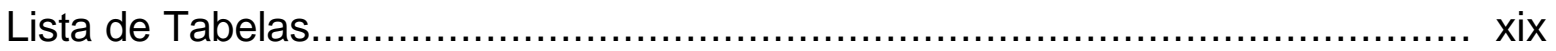

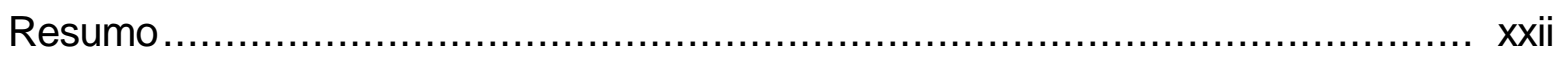

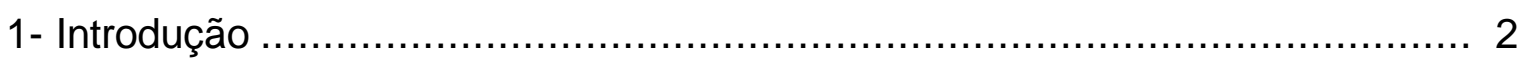

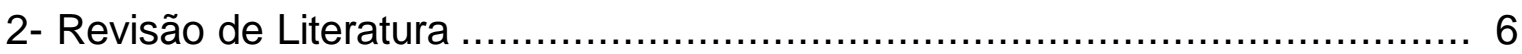

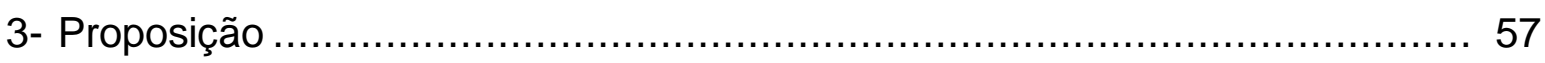

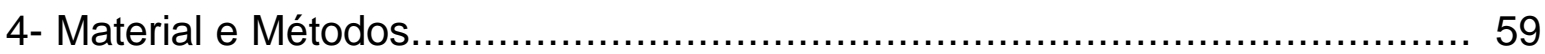

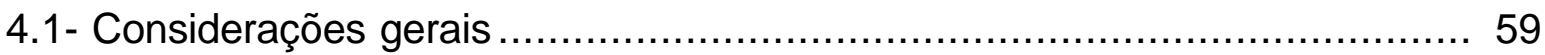

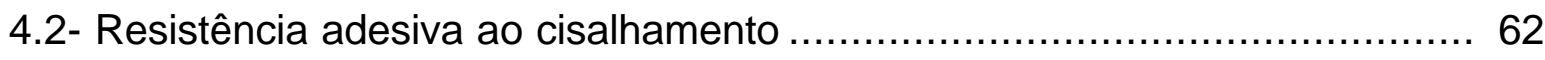

4.2.1- Obtenção dos corpos-de-prova.......................................... 62

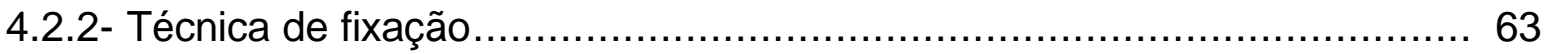

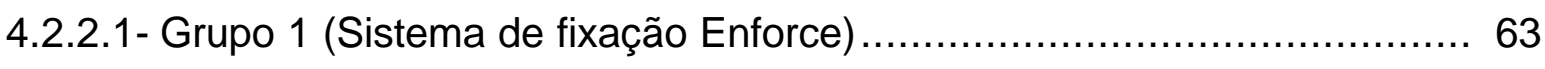

4.2.2.2- Grupo 2 (Sistema de fixação Scotchbond Resin Cement/Scotchbond

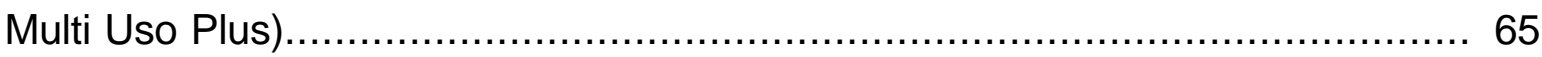

4.2.2.3- Grupo 3 (Sistema de fixação Variolink Professional Set) .................. 66

4.2.3- Testes de resistência adesiva ............................................. 67

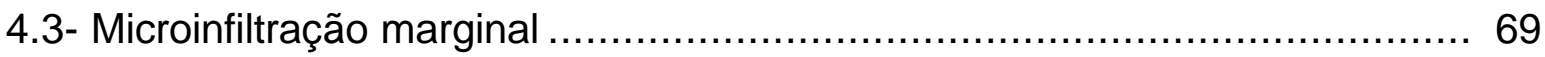

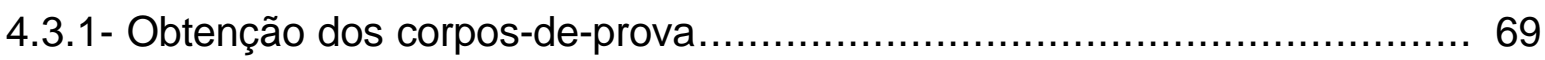

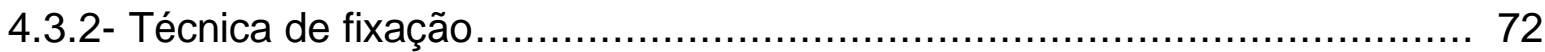

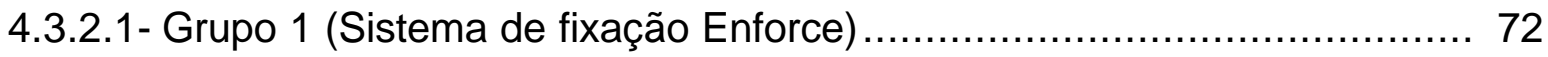

4.3.2.2- Grupo 2 (Sistema de fixação Scotchbond Resin Cement/Scotchbond

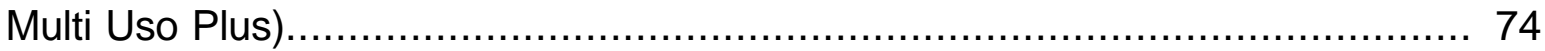

4.3.2.3- Grupo 3 (Sistema de fixação Variolink Professional Set) ................. 75

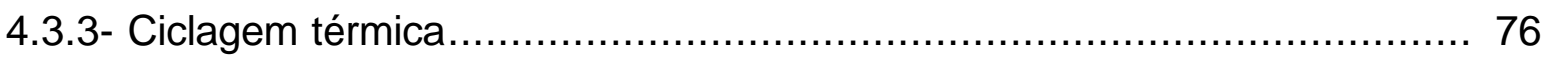

4.3.4- Seccionamento dos dentes e método de avaliação ............................ 78 


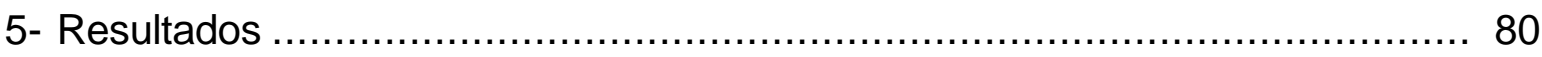

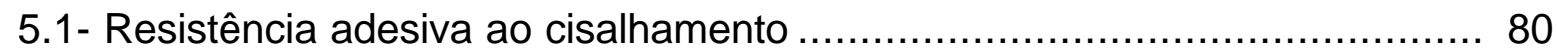

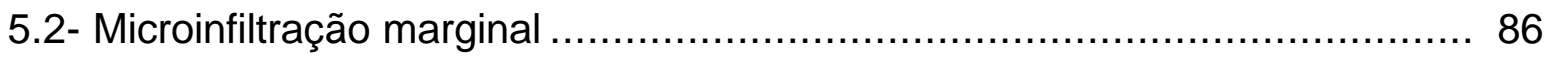

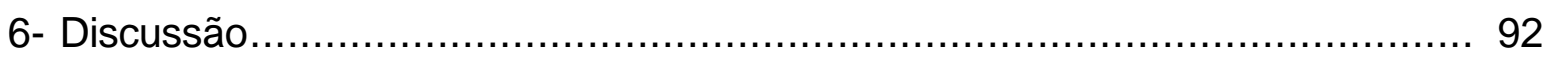

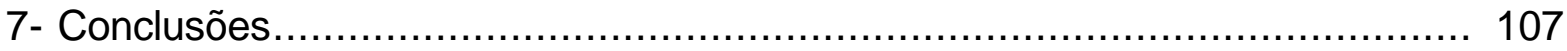

Referências Bibliográficas.......................................................... 109

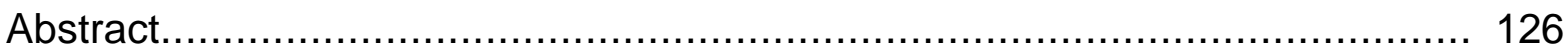




\section{LISTA DE FIGURAS}

Figura 1 - Sistemas de fixação adesiva de dupla polimerização. A - Sistema de Fixação Enforce; B - Sistema de fixação Scotchbond Multi-Uso Plus/Scotchbond Resin Cement; C - Sistema de Fixação Variolink Professional Set. 61

Figura 2 - Corpo-de-prova fixado ao cilindro de PVC com resina acrílica quimicamente polimerizável.

Figura 3 - Cilindro de porcelana fixado à dentina do espécime. 65

Figura 4 - Corpo-de-prova fraturado após a aplicação da força de cisalhamento na base adesiva.

Figura 5 - Cavidade MOD para incrustação de porcelana realizada em um prémolar superior. A - vista oclusal; B - vistal proximal.

Figura 6 - Incrustação de porcelana fixada com agente de fixação resinoso de dupla polimerização

Figura 7 - Corpo-de-prova coberto com esmalte de unha deixando apenas $1 \mathrm{~mm}$ livre em torno da restauração. 
Figura 8 - Representação gráfica dos valores médios dos corpos-de-prova submetidos à força de cisalhamento.

Figura 9 - Exemplos de modos de fratura dos corpos-de-prova submetidos à força de cisalhamento. A - fratura adesiva entre a dentina e o agente de fixação; B - fratura adesiva entre o agente de fixação e a porcelana; $\mathrm{C}$ - fratura mista..

Figura 10 - Índices de infiltração marginal dos espécimes fixados com 3 sistemas de fixação adesiva de dupla polimerização: A - índice 0; B - índice 1; C - índice 2; D - índice 3.

Figura 11 - Representação gráfica dos valores percentuais dos índices de infiltração marginal dos 3 grupos experimentais (\%). 89 


\section{LISTA DE TABELAS}

Tabela 1 - Sistemas de fixação adesiva avaliados e seus respectivos fabricantes e números de lote.

Tabela 2 - Valores individuais em $\mathrm{Kg} / \mathrm{cm}^{2}$ e $\mathrm{MPa}$ dos corpos-de-prova submetidos ao teste de resistência adesiva ao cisalhamento.

Tabela 3 - Valores médios e desvios-padrão dos grupos submetidos ao teste de resistência adesiva ao cisalhamento.

Tabela 4 - Resultados de análise de variância a um critério (ANOVA) aplicado aos valores obtidos após o teste de resistência adesiva ao cisalhamento.

Tabela 5 - Resultados do teste de comparações múltiplas (Student-NewmanKeuls) entre os grupos experimentais submetidos ao teste de resistência adesiva ao cisalhamento $(p<0,05)$

Tabela 6 - Valores percentuais do modo de fratura ocorrido nos corpos-deprova submetidos à resistência adesiva ao cisalhamento (\%)......

Tabela 7 - Índices individuais de infiltração marginal dos espécimes fixados com 3 sistemas de fixação adesiva de dupla polimerização 
Tabela 8 - Análise de variância não paramétrica, método Kruskal-Wallis dos índices de infiltração marginal dos espécimes fixados com 3 sistemas de fixação adesiva de dupla polimerização

Tabela 9 - Teste de Miller para comparações individuais entre os grupos.

Tabela 10 - Valores percentuais dos índices de infiltração marginal dos espécimes fixados com 3 sistemas de fixação adesiva de dupla polimerização (\%)................................................................ 89 
RESUMO 


\section{RESUMO}

Avaliaram-se a resistência adesiva, por meio de testes de cisalhamento de porcelana aderida à dentina, e a microinfiltração marginal em incrustações de porcelana fixadas com três sistemas de fixação resinosos de dupla polimerização. Os sistemas utilizados foram o Enforce, Scotchbond Resin Cement/Scotchbond Multi-Uso Plus e Variolink Professional Set.

Na primeira parte desta pesquisa, 30 molares humanos extraídos foram incluídos em cilindros de PVC e a superfície oclusal abrasionada até a exposição da dentina. Cilindros de porcelana foram confeccionados, jateados com óxido de alumínio com partículas de $50 \mu \mathrm{m}$ e em seguida, condicionados com ácido fluorídrico a $8 \%$ por quatro minutos. Os corpos-de-prova foram divididos aleatoriamente em três grupos e fixados com os respectivos sistemas de fixação. Todos os espécimes foram armazenados em água a $37^{\circ} \mathrm{C}$ por 24 horas e o teste de resistência adesiva ao cisalhamento conduzido em uma máquina de testes universal Kratos. Os valores obtidos foram tabulados e submetidos à análise estatística. $\mathrm{O}$ modo de fratura dos espécimes também foi determinado.

$\mathrm{Na}$ segunda parte do experimento, cavidades mesioclusodistais para incrustações de porcelana foram preparadas em 30 pré-molares humanos extraídos, mantendo-se o término cervical em esmalte. Estas cavidades foram moldadas e as incrustações de porcelana confeccionadas sobre o modelo refratário. As restaurações foram posicionadas sobre os respectivos dentes, os ajustes internos realizados e os espécimes divididos aleatoriamente em três grupos. Todas as incrustações tiveram sua superfície interna condicionada com ácido fluorídrico a 8\% por quatro minutos e foram fixadas com os respectivos sistemas de fixação. Os 
corpos-de-prova foram armazenados em água destilada a $37^{\circ} \mathrm{C}$ por 24 horas, cobertos com esmalte de unha deixando livre $1 \mathrm{~mm}$ em torno das margens da restauração e termociclados. Depois, os espécimes foram imersos em fucsina básica a $0,5 \%$ por 24 horas, lavados e seccionados no sentido mesiodistal, obtendo-se três secções de cada espécime. Os índices de infiltração marginal foram atribuídos por meio de uma lupa estereoscópica com aumento de 40X por três examinadores previamente calibrados. Foi estabelecido o critério de infiltração máxima do corante em cada corpo-de-prova de acordo com os seguintes escores: 0- nenhuma infiltração; 1- infiltração na parede gengival; 2- infiltração na parede axial; 3infiltração na parede axial e em direção à polpa. Os dados obtidos foram analisados estatisticamente.

Com base na análise dos resultados foi possível concluir que não houve diferença estatisticamente significante na resistência adesiva ao cisalhamento entre os sistemas de fixação Enforce e Scotchbond Resin Cement/Scotchbond Multi-Uso Plus, porém estas foram estatisticamente superiores ao sistema de fixação Variolink Professional Set. O modo de fratura dos corpos-de-prova submetidos à força de cisalhamento foi predominantemente mista para os sistemas de fixação Enforce e Scotchbond Resin Cement/ Scotchbond Multi-Uso Plus, enquanto o Sistema de fixação Variolink Professional Set apresentou fratura adesiva entre a dentina e o sistema de fixação em todos os espécimes. Embora nenhum dos sistemas de fixação utilizados tenha sido capaz de impedir a infiltração marginal, os sistemas Enforce e Scotchbond Resin Cement/ Scotchbond Multi-Uso Plus se comportaram de forma similar e estatisticamente superior ao sistema Variolink Professional Set. 
1-INTRODUÇÃO 


\section{1- INTRODUÇÃO}

As restaurações de porcelana odontológica são consideradas uma alternativa restauradora para dentes extensamente destruídos, onde a estética é requisitada. Pelo seu processo evolutivo percebe-se um significante avanço nesta tecnologia, principalmente nos últimos anos. Em parte, este desenvolvimento foi uma consequência da maior importância que as pessoas atribuíram à estética em geral nas últimas décadas e particularmente à dentária ${ }^{20}$. Outro fator que contribuiu para o aprimoramento destes materiais foi o desenvolvimento de sistemas adesivos mais efetivos.

O primeiro marco na utilização de restaurações estéticas adesivas na região posterior ocorreu, no entanto, com as resinas compostas. Era um fascínio para os pacientes terem restaurações não metálicas e uma tentação para muitos clínicos, o que resultou no seu uso indiscriminado. Conseqüentemente, muitas restaurações falharam precocemente devido à recidiva de cárie, perda de forma anatômica, desgastes oclusais acentuados, infiltração marginal e alteração de cor $^{95}$. Critérios para sua utilização foram então, estabelecidos, suas propriedades melhoradas e o seu uso indiscriminado, controlado. Paralelamente, a evolução dos sistemas cerâmicos permitiu que as incrustações de porcelana se tornassem uma alternativa viável à gama de opções restauradoras de uso indireto.

O sucesso das incrustações de porcelana é dependente, entre outros fatores, da efetividade do agente de fixação que promove uma adesão entre a restauração e a estrutura dentária, compensando a friabilidade da porcelana ${ }^{7}$, além de melhorar a adaptação marginal final ${ }^{38}$. Para assegurarmos uma completa polimerização dentro de um tempo clínico viável, os agentes de fixação resinosos de dupla polimerização são os materiais de eleição ${ }^{10,110}$. Eles apresentam polimerização física, por meio da 
luz halógena, e química, induzida por aquela, favorecendo sua completa polimerização mesmo nas porções mais profundas, onde a luz pode não alcançar. Porém, estes agentes de fixação apresentam uma contração de polimerização, que pode resultar na formação de fendas marginais e conseqüente microinfiltração. Quando isto ocorre, há a passagem de bactérias, fluidos, moléculas e íons entre a restauração e a parede cavitária ${ }^{39,42,63}$. REES; JACOBSEN ${ }^{66}$ e SCHMALZ; FEDERLIN; $\mathrm{REICH}^{77}$ sugeriram que as incrustações poderiam ter uma fenda marginal máxima de $100 \mu \mathrm{m}$. Recentemente, $\mathrm{ROCHA}^{71}$ observou uma discrepância marginal média em incrustações de porcelana de $68,27 \mu \mathrm{m}$. Quando há a fenda, esta poderia ser selada por meio de sistemas adesivos e agentes de fixação, evitando ou reduzindo a infiltração marginal e suas conseqüências.

A microinfiltração marginal tem sido associada à sensibilidade pós-operatória, manchamento marginal, patologia pulpar e cárie secundária, sendo esta a principal razão para a substituição de restaurações ${ }^{93}$. Dentre os fatores que podem contribuir para a infiltração marginal em restaurações adesivas, pode-se ressaltar a pouca estabilidade dimensional, deficiência na resistência adesiva, contração de polimerização, alto coeficiente de expansão térmica e solubilidade química do agente cimentante ${ }^{96}$, fatores estes, exacerbados quanto maior for a espessura do agente de fixação.

RETIEF; MANDRAS; RUSSELL ${ }^{69}$ estudaram a relação entre a resistência ao cisalhamento e a microinfiltração em sistemas adesivos e concluíram que uma resistência de $21 \mathrm{MPa}$, poderia resistir as forças de contração durante a polimerização. Sabe-se que os resultados laboratoriais não podem ser extrapolados diretamente para a realidade clínica. Porém, a eficiência adesiva do sistema de fixação às estruturas dentárias e à superfície da porcelana, a estabilidade 
dimensional do sistema de fixação frente a estresses como a variação de temperatura, e ainda sua capacidade de impedir ou dificultar a penetração de fluidos pela interface dente/restauração são dados importantes que, sem dúvida, quando analisados conjuntamente com outros já descritos na literatura ${ }^{9,29,53,65,75,77,84,85,86,94}$, ajudarão a, pelo menos, prever o tipo de comportamento clínico destas restaurações. 
2-REVISÃO DE LITERATURA 


\section{2- REVISÃO DE LITERATURA}

O efeito das variações de temperatura na estabilidade dimensional de vários materiais restauradores foi estudado por NELSEN; WOLCOTT; PAFFENBARGER ${ }^{57}$ em 1952. Os autores ${ }^{57}$ verificaram que as alterações térmicas podem levar a uma troca de fluidos entre o dente e a restauração. Esta infiltração ocorreria como conseqüência das diferenças entre o coeficiente de expansão térmica da estrutura dentária e do material restaurador.

A técnica do condicionamento ácido do esmalte para aumentar a retenção de restaurações de resina acrílica ao esmalte foi introduzida por BUONOCORE ${ }^{8}$, em 1955. Ele comparou a adesão da resina acrílica ao esmalte condicionado com dois agentes condicionadores. Concluiu que o tratamento da superfície do esmalte com ácidos aumentou a retenção destas resinas, sendo que a utilização do ácido fosfórico a $85 \%$ por 30 segundos proporcionou uma maior retenção. Este fato seria, segundo o autor ${ }^{8}$, importante para o sucesso das restaurações, permitindo realizar preparos mais conservadores, além de proteger as cavidades de classe III e V contra a cárie secundária.

A união de adesivos à porcelana foi estudada inicialmente por PAFFENBARGER; SWEENEY; BOWEN ${ }^{60}$, em 1967, utilizando o agente de ligação silano para aumentar a união entre os dentes de porcelana e a base de resina acrílica das próteses totais. Após a realização de testes de resistência à tração, os autores $^{60}$ verificaram que seu emprego dispensava o uso de retenções adicionais como pinos metálicos, resultando em dentes mais resistentes e estéticos. 
KIDD $^{42}$, em 1976, realizou uma revisão de literatura sobre microinfiltração. Destacou que esta seria decorrente da falta de vedamento marginal das restaurações, resultando na passagem de bactérias, fluidos, substâncias químicas, moléculas e íons através da interface dente/restauração. Isto poderia acarretar em descoloração marginal, sensibilidade pós-operatória e cárie secundária. Ressaltou também, que os testes de avaliação da microinfiltração seriam muito importantes para o prognóstico do comportamento dos materiais restauradores.

DAVIDSON; DE GEE; FEILZER ${ }^{17}$, em 1984, investigaram a contração de polimerização linear e volumétrica da resina composta em função do tempo de polimerização. Utilizaram neste experimento uma resina composta quimicamente ativada e uma resina composta fotoativada. Na primeira parte da pesquisa, espécimes de dentina bovina foram confeccionados e conectados ao dispositivo de tração. O sistema adesivo foi aplicado e a resina composta inserida. Iniciou-se então, a polimerização, que era registrada em diferentes períodos. Na segunda parte do experimento, 24 cavidades de classe $\mathrm{V}$ foram preparadas em dentes bovinos. $\mathrm{O}$ esmalte foi condicionado e o sistema adesivo aplicado para que as cavidades fossem restauradas. Os dentes foram armazenados em água por 48 horas, seccionados e imersos em solução de azul de metileno. Os espécimes seccionados foram examinados num estereomicroscópio. Os resultados demostraram que a contração de polimerização linear era restrita a uma direção quando uma boa união resina composta/dentina era formada. Porém, quando a resina estivesse unida a várias paredes, as forças de contração poderiam superar a força de união. 
Em 1987, FEILZER; DE GEE; DAVIDSON²4 investigaram a influência da configuração da cavidade sobre o estresse que ocorre na interface adesiva durante a polimerização de uma resina composta. Em um dispositivo constituído de discos paralelos com diversos diâmetros, foram colocadas diferentes espessuras de resina composta. A contração da resina foi medida por meio de um dispositivo de tração acoplado a um dos discos fornecendo um registro constante do estresse gerado. Assim, os autores ${ }^{24}$ observaram que a preservação da interface adesiva depende, entre outros fatores, da configuração tridimensional da restauração, ou seja, quanto maior a quantidade de superfícies aderidas em relação a superfícies livres maior seria o estresse.

Em 1989, ABBATE; TJAN; FOX ${ }^{1}$ compararam a adaptação marginal de quatro sistemas para confecção de coroas totais: (1) coroa total metalocerâmica com margens em metal; (2) coroa total metalocerâmica com margem vestibular em porcelana; (3) coroa total de porcelana obtida com o sistema Cerestore; (4) coroa total de porcelana obtida com o sistema Dicor. Quarenta dentes foram preparados e divididos em quatro grupos. Estes foram moldados e os troquéis foram obtidos para a confecção das restaurações. Após sua confecção, cada restauração foi cimentada ao respectivo preparo com cimento fosfato de zinco. Os corpos-de-prova foram imersos em resina epóxica e seccionados no sentido vestibulolingual. A espessura do cimento foi medida nas margens lingual e vestibular e os dados analisados estatisticamente. Os resultados mostraram que as discrepâncias marginais variaram de $56 \mu \mathrm{m}$ à $81 \mu \mathrm{m}$, sendo o Sistema Cerestore o que apresentou as menores fendas marginais e o sistema Dicor o que apresentou os maiores valores, apesar de não apresentarem diferenças estatisticamente significante entre si. 
SHORTALL et al. ${ }^{78}$, em 1989, utilizando preparos classe II em molares, estudaram a infiltração marginal em restaurações de resina composta de uso direto, incrustações de porcelana e restaurações de resina composta de uso indireto. Os dentes foram preparados e restaurados com os diferentes materiais. Foram realizadas as medidas de microinfiltração e pôde-se observar que as restaurações indiretas fixadas com resina composta promoveram um selamento marginal superior quando comparada às restaurações diretas de resina composta. Também concluiuse que as incrustações de porcelana apresentavam uma maior incidência de excesso cervical do agente cimentante que as restaurações indiretas de resina composta.

As conseqüências da contração de polimerização das resinas compostas foram estudadas por FEILZER; DE GEE; DAVIDSON²5, em 1989. Os autores ${ }^{25}$ comentaram que a contração gerada nas paredes cavitárias aumenta numa relação direta com o fator $\mathrm{C}$. Ressaltaram que a contração volumétrica, que é normalmente distribuída em três dimensões, é gradualmente convertida em uma única direção quando o fator $\mathrm{C}$ aumenta, como acontece com finas camadas de resina composta. Assim, na cimentação de incrustações ou coroas isto poderia resultar em sensibilidade pós-operatória, falha coesiva do agente de fixação, discrepâncias marginais ou perda da retenção. Segundo os autores ${ }^{25}$, estaria errado o conceito de que a contração de polimerização de finas camadas do agente de fixação resinoso causaria apenas pequenas conseqüências. 
Em 1990, MAHLER ${ }^{49}$ redigiu uma contestação ao trabalho de FEILZER; DE GEE; DAVIDSON ${ }^{25}$ afirmando que o estresse gerado pela contração de polimerização do agente de fixação resinoso é cerca de $7 \mathrm{MPa}$, uma magnitude menor que o das restaurações diretas de resina composta, que se situa em torno de $53 \mathrm{MPa}$. Justificou que diferenças entre fatores como a viscosidade do cimento e da resina composta, alterações no módulo de elasticidade durante a polimerização e os ângulos internos da cavidade poderiam reduzir a magnitude do estresse calculado.

Em 1990, ARIYATNAM et al. ${ }^{5}$ verificaram a variação na espessura do agente de fixação resinoso. Para tanto, cavidades mesioclusodistais (MOD) foram preparadas em 25 pré-molares e molares. Após a moldagem e obtenção dos modelos, foram confeccionadas incrustações de resina composta e estas foram fixadas nas respectivas cavidades. As análises dos dentes seccionados revelaram uma considerável variação na espessura do agente de fixação resinoso. Esta variação ocorreu entre 10 e $90 \mu \mathrm{m}$ e foi menos espessa e mais uniforme nas margens cavo-superficiais das superfícies oclusais. Os autores ${ }^{5}$ também relataram que a técnica de manipulação e aplicação do agente de fixação pode ter influência na formação de porosidades e bolhas.

PASHLEY ${ }^{61}$, em 1990, fez algumas considerações clínicas sobre a microinfiltração. Dentre elas, enfatizou que o entendimento da permeabilidade dentinária seria fundamental e diretamente relacionada à quantidade, à espessura e à localização da dentina exposta, e que os estudos laboratoriais de penetração de corante seriam testes que visualizam a quantidade de penetração, o que pode ou não ocorrer in vivo. Afirmou que esta discrepância poderia resultar em pouca 
correlação entre a quantidade de microinfiltração in vitro e o sucesso clínico do material restaurador, pois a microinfiltração que ocorre in vivo seria menor que a obtida em testes laboratoriais. Salientou que apesar de muito importante, estes testes não podem ser extrapolados diretamente para situações clínicas, uma vez que se torna difícil simular a natureza dinâmica do complexo dentinopulpar.

Em 1990, WARREN ${ }^{103}$ mediu a dureza de espécimes de resina composta, fotopolimerizados durante 40 e 60 segundos, através de discos de porcelana com várias espessuras. Foram confeccionados três discos de porcelana com 1, 2 e 3mm de espessura e espécimes de resina composta com $0,2 \mathrm{~mm}$ de espessura. Cada disco de porcelana foi colocado sobre o espécime de resina. A extremidade de um aparelho fotopolimerizador foi então, posicionada sobre o disco de porcelana e acionado por 40 segundos. Em seguida, removeu-se o disco e a resina foi polimerizada sem a interferência da porcelana. O mesmo procedimento foi realizado com tempo de polimerização de 60 segundos. Os espécimes foram então, imersos em água por 24 horas e submetidos ao teste de dureza de Vickers. Os resultados indicaram que os valores de dureza diminuíram com o aumento da espessura da porcelana, para ambos os tempos de polimerização. $\mathrm{O}$ aumento do tempo para 60 segundos, aumentou significantemente o valor médio da dureza para os espécimes de 1 e $2 \mathrm{~mm}$ de espessura, mas não foi significante para os espécimes de $3 \mathrm{~mm}$. $\mathrm{O}$ autor $^{103}$ sugeriu um aumento no tempo de polimerização, principalmente quando a porcelana tiver mais de $1 \mathrm{~mm}$ de espessura. Ademais, ressaltou que em tais situações o uso de um agente de fixação de dupla polimerização pode oferecer algumas vantagens. 
CHARLTON; MOORE ${ }^{15}$, em 1991, avaliaram o efeito do envelhecimento na resistência ao cisalhamento de dois adesivos (Imperva Bond e Prisma Universal Bond 3) à dentina. Para tanto, utilizaram 40 discos de dentina confeccionados a partir de molares humanos extraídos. Estes foram divididos em quatro grupos de dez espécimes cada, sendo dois grupos testados após cinco minutos e os grupos restantes armazenados, termociclados e testados após duas semanas. As falhas foram avaliadas microscopicamente e classificadas em adesivas, coesivas ou mistas. Os autores ${ }^{15}$ concluíram que a resistência ao cisalhamento foi maior para o Imperva Bond tanto para os tempos de cinco minutos quanto duas semanas. Para ambos os agentes adesivos, a resistência adesiva após duas semanas mostrou-se maior que em cinco minutos.

HASEGAWA; BOYER; CHAN ${ }^{35}$, em 1991, conduziram um estudo in vitro a fim de determinar a dureza de três sistemas de fixação resinosos de dupla polimerização, e também, determinar a efetividade das cunhas refletivas em promover a polimerização destes sistemas na margem cervical. Incrustações de resina composta foram fixadas em molares extraídos com os sistemas Dual Cement, Dicor Cement e Duo Cement. Cunhas refletivas também foram utilizadas na embrasura de metade dos espécimes. Os autores ${ }^{35}$ concluíram que os tempos de exposição à luz recomendados pelos fabricantes para a polimerização dos agentes de fixação foram insuficientes para compensar a interposição do dente e do material restaurador. Dois sistemas comportaram-se primariamente como materiais fotopolimerizáveis, com rápida polimerização inicial e altamente sensíveis à luz. O terceiro sistema apresentou-se principalmente como um material quimicamente 
ativado, com menor polimerização inicial e sensibilidade à luz. A cunha refletiva teve pequeno efeito na polimerização dos agentes de fixação.

Em 1991, PASHLEY; PASHLEY ${ }^{63}$ teceram alguns comentários relevantes sobre a estrutura e a função da dentina, assim como as implicações clínicas da permeabilidade dentinária na Odontologia restauradora. Comentaram que a dentina pode se comportar como uma barreira ou como um componente permeável do complexo dentinopulpar, dependendo de algumas variáveis, tais como o diâmetro e o número de túbulos por $\mathrm{mm}^{2}$. Afirmaram que nos testes in vitro para análise da microinfiltração que utilizam penetração de corante, a permeabilidade dentinária é constante, ao contrário do que ocorre in vivo, onde a pressão pulpar mantém o movimento do fluido dentinário em direção contrária à polpa. Este fato poderia reduzir as conseqüências clínicas da microinfiltração e desta forma, os testes in vitro poderiam ser considerados testes mais severos.

Devido à variabilidade nas metodologias existentes entre os laboratórios e a dificuldade em comparar os resultados, em 1991, RETIEF ${ }^{68}$ realizou uma revisão de literatura e propôs alguns parâmetros para sua padronização. Ressaltou que os testes laboratoriais são freqüentemente realizados para avaliar a eficácia de um sistema restaurador experimental ou para predizer o comportamento clínico de um sistema comercial. Comentou que os testes mais utilizados são a avaliação da resistência adesiva (resistência à tração e ao cisalhamento), da microinfiltração e da fenda marginal. $\mathrm{O}$ autor $^{68}$ comentou que $\mathrm{O}$ meio de armazenamento ideal dos espécimes seria o soro fisiológico e enfatizou a importância de padronizar as dimensões do preparo cavitário devido à grande diferença no diâmetro e densidade 
dos túbulos dentinários. Para os testes de resistência ao cisalhamento, disse que a área adesiva a ser testada deveria apresentar $3 \mathrm{~mm}$ de diâmetro e a força deveria ser aplicada na base adesiva numa velocidade de $0,5 \mathrm{~mm} / \mathrm{min}$. Para os testes de microinfiltração, relatou que as restaurações deveriam ser acabadas após 15 minutos e armazenadas em água destilada por 24 horas antes da termociclagem. Esta, por sua vez, deveria completar 500 ciclos entre banhos com temperatura variando de entre $50^{\circ} \mathrm{C}$ e $8^{\circ} \mathrm{C}$ e tempo de imersão máximo de 15 segundos, já que as alterações térmicas intra-orais não ocorrem por longos intervalos de tempo.

No mesmo ano, SORENSEN et al. ${ }^{88}$ avaliaram a resistência ao cisalhamento de nove tipos de porcelana à resina composta variando o tratamento de superfície. Quarenta discos de porcelana foram confeccionados, divididos em quatro grupos de dez espécimes cada e submetidos aos seguintes tratamentos: (1) controle, sem tratamento; (2) somente aplicação de silano; (3) condicionamento com ácido fluorídrico a $20 \%$ por três minutos; (4) condicionamento com ácido fluorídrico por três minutos e aplicação de silano. Os espécimes de porcelana foram então, aderidos aos discos de resina composta e fotopolimerizados. As amostras resultantes foram armazenadas em água a $37^{\circ} \mathrm{C}$ por sete dias, termocicladas e submetidas ao teste de cisalhamento. Os resultados mostraram que, com exceção das porcelanas HiCeram e G-Cera, o condicionamento aumentou significantemente a resistência adesiva da resina à porcelana, quando comparada ao grupo controle. Duas porcelanas (VMK 68 e Mirage) obtiveram um aumento substancial dos valores de adesão com a aplicação do silano. Nenhuma das porcelanas testadas apresentou um aumento significante da resistência com a aplicação de silano em superfícies não condicionadas. Na avaliação dos espécimes somente condicionados, as porcelanas 
Cerinate, Optec e Mirage apresentaram os maiores índices de resistência ao cisalhamento, e todos os seus espécimes fraturaram coesivamente tanto com condicionamento (Optec e Cerinate) quanto com condicionamento e silanização (Optec e Mirage). Deste modo, concluiu-se que o tratamento com ácido foi mais efetivo para as porcelanas com feldspato, com exceção da porcelana G-Ceram, mas não foi para as porcelanas com alto conteúdo de alumina, que parecem ser resistentes ao ataque químico.

Em 1991, SORENSEN; KANG; AVERA ${ }^{87}$ estudaram os efeitos do tratamento de superfície da porcelana sobre a microinfiltração na interface porcelana/resina composta. Espécimes de porcelana foram confeccionados e divididos em quatro grupos que receberam os seguintes tratamentos: (1) controle; (2) silanização; (3) condicionamento com ácido fluorídrico a $20 \%$ por três minutos; (4) condicionamento com ácido fluorídrico a $20 \%$ e silanização. A resina composta foi aplicada à superfície tratada dos espécimes de porcelana e fotopolimerizada. Os espécimes foram armazenados em água a $37^{\circ} \mathrm{C}$ por sete dias e termociclados. Para a avaliação da microinfiltração, os espécimes foram imersos em uma solução de $50 \%$ de nitrato de prata por 45 minutos, lavadas, colocadas em uma solução reveladora e expostos a uma lâmpada fluorescente por oito horas. A microinfiltração nos espécimes foi medida com um microscópio óptico. Segundo os resultados, nenhum dos grupos foi capaz de impedir a infiltração marginal e houve diferenças significantes entre as diferentes porcelanas. Tanto o condicionamento quanto à silanização aumentaram a durabilidade da adesão resina composta/porcelana durante a ciclagem térmica. 
HAYAKAWA et al. ${ }^{36}$, em 1992, investigaram a influência do tratamento da superfície da porcelana e da aplicação do silano na adesão entre a resina composta e a porcelana. Discos de porcelana foram confeccionados e submetidos a um dos três procedimentos: (1) polimento com lixa abrasiva; (2) condicionamento com ácido fosfórico por 60 segundos; (3) condicionamento com ácido fluorídrico por 30 segundos. O agente silano foi utilizado conforme as recomendações do fabricante e a resina composta aplicada e polimerizada. Os espécimes foram armazenados em água a $37^{\circ} \mathrm{C}$ por 24 horas e testados na máquina de testes. Concluiu-se que os espécimes condicionados com ácido fluorídrico tiveram uma resistência adesiva maior que aqueles simplesmente polidos ou condicionados com ácido fosfórico. Os autores $^{36}$ também concluíram que a utilização do agente silano resultou em uma maior resistência adesiva devido à reação química entre a superfície da porcelana e o agente silano.

KANCA III ${ }^{40}$, em 1992, avaliou a resistência adesiva do sistema All-Bond à dentina seca ou úmida. Foram obtidos cinco grupos de dez espécimes cada, confeccionados a partir de dentes humanos. Cada espécime foi desgastado até a exposição da dentina. Em três grupos a dentina foi condicionada por 30 segundos usando ácido fosfórico a 10\%. Após a lavagem, a dentina foi seca por três e dez segundos com jatos de ar ou apenas removendo o excesso de ar com papel absorvente. Os outros dois grupos foram condicionados por 15 segundos com ácido fosfórico a $37 \%$. Um grupo foi seco com ar por dez segundos e o outro teve apenas o excesso de água removido. O grupo controle, de espécimes em esmalte, foi condicionado com ácido fosfórico a 37\% por 15 segundos, lavado e secado por dez segundos com jatos de ar. O sistema All-Bond foi utilizado e a resina composta 
inserida e fotopolimerizada. O teste de resistência adesiva ao cisalhamento foi realizado após 24 horas em uma máquina de testes universal Instron. Os resultados mostraram uma maior resistência adesiva à dentina úmida, principalmente quando foi utilizado o ácido fosfórico a 37\%.

KARAAGACLIOGLU; ZAIMOGLU; AKOREN ${ }^{41}$, em 1992, compararam o selamento marginal de cavidades de classe II restauradas com incrustações de porcelana e de resina composta. Foram preparadas 80 cavidades mesioclusais e distoclusais com término cervical em cemento. Metade destes preparos foram restaurados com a porcelana odontológica Ceramco II e a outra metade com o sistema de resina composta SR Isosit. Um cimento de ionômero de vidro foi aplicado nas cavidades mesioclusais e as incrustações foram fixadas com sistema resinoso Ultrabond. Após a termociclagem, os dentes foram imersos em uma solução de fucsina básica por 24 horas, lavados, seccionados e a extensão da infiltração marginal avaliada. Os autores ${ }^{41}$ observaram que a microinfiltração na interface das incrustações foi inevitável, mas sua magnitude foi afetada pelo tipo de material forrador. Uma comparação entre as incrustações de porcelana e as de resina composta, indicou uma melhor adaptação marginal das restaurações de porcelana.

Em 1992, KREJCI; KREJCI; LUTZ ${ }^{44}$ realizaram uma avaliação clínica de um ano e meio de incrustações de porcelana. Dez pacientes com boa higiene oral e saúde periodontal foram selecionados. Cada paciente recebeu uma incrustação intracoronária em um pré-molar. Todas as restaurações foram moldadas com silicona de adição e examinadas no microscópio eletrônico de varredura. Decorridos um ano e meio, os dez pacientes retornaram para avaliação. As restaurações foram 
examinadas clinicamente, e em adição, outro grupo de réplicas foi realizado para ser analisado no microscópio eletrônico de varredura, juntamente com o primeiro grupo. Os autores ${ }^{44}$ concluíram que após este período as restaurações apresentaram um bom comportamento clínico, embora algumas falhas fossem observadas ao exame microscópico. Apesar da excelente adaptação marginal obtida imediatamente após a fixação das incrustações, fraturas marginais foram observadas no controle de um ano e meio.

Em 1992, LACY et al. ${ }^{46}$ investigaram o comportamento de diversos sistemas adesivos no selamento marginal de coroas totais de porcelana e de resina composta. Cento e oitenta dentes foram preparados e divididos em nove grupos a serem tratados com diferentes sistemas adesivos, sendo seis grupos com término cervical em esmalte, dois em dentina e um em cimento de ionômero de vidro. As coroas foram fixadas com agente de fixação resinoso e os espécimes armazenados em água por quatro dias. Após, realizou-se a termociclagem e a imersão dos espécimes em solução de nitrato de prata a 50\%. Os corpos-de-prova corados foram seccionados e analisados em um microscópio. Não se observou infiltração marginal nos espécimes com término cervical em esmalte, sendo que o mesmo não ocorreu com o término cervical em dentina ou em cimento de ionômero de vidro.

LU et al. ${ }^{48}$, em 1992, investigaram o efeito de vários tratamentos de superfície sobre a resistência adesiva na interface resina/porcelana utilizando dois agentes de fixação resinosos e dois agentes silanizadores. Também examinaram a morfologia da superfície da porcelana após o condicionamento com ácido fluorídrico e a natureza das falhas após a aplicação de uma força de cisalhamento. Cinqüenta e 
seis discos de porcelana foram confeccionados e divididos em quatro grupos: (1) grupo controle; (2) condicionamento com ácido fluorídrico a $20 \%$ por dois minutos e meio; (3) silanização com Porcelain Repair Primer + Bondlite e Scotchprime + Scotchbond 2; (4) condicionamento + silanização com Porcelain Repair Primer. Outros 56 discos de porcelana foram aderidos aos discos já tratados e o conjunto foi submetido ao teste de resistência ao cisalhamento. Algumas amostras foram observadas microscopicamente e verificaram-se superfícies uniformemente porosas nas porcelanas condicionadas. Baseado nos resultados, concluiu-se que o tratamento da porcelana, com condicionamento e/ou silanização, aumentou consideravelmente sua adesão com o agente de fixação resinoso.

No mesmo ano, REES; JACOBSEN ${ }^{66}$ utilizaram o método do elemento finito a fim de verificar a contração do agente de fixação em torno de incrustações de Classe I confeccionadas com resina composta e porcelana. A partir de análises realizadas, pôde-se constatar uma contração em torno de 7\%, com valores na ordem de 410MPa. Os resultados comparando as incrustações de resina composta com as de porcelana mostraram que esta última tende a produzir uma ligeira, porém maior força de contração, gerando assim, uma maior tensão na interface dente/agente de fixação. A máxima resistência a tração medida foi de $21 \mathrm{MPa}$, sendo que em muitos casos ela foi maior que $10 \mathrm{MPa}$.

SAUNDERS; MUIRHEAD ${ }^{76}$, em 1992, avaliaram a microinfiltração em restaurações de classe $\mathrm{V}$ com término cervical em dentina, restauradas com resina composta, utilizando dois sistemas adesivos (Syntac Bond e Denthesive). Foram preparadas cavidades em 40 pré-molares e restauradas com duas técnicas: (1) 
inserção de incremento único; (2) inserção incremental. Os espécimes foram armazenados em água deionizada a $37^{\circ} \mathrm{C}$ por seis semanas, termociclados $\mathrm{e}$ imersos em solução de azul de metileno por 24 horas. Em seguida, foram lavados e seccionados para a análise da microinfiltração marginal. Os autores ${ }^{76}$ observaram $^{2}$ que ambos os sistemas adesivos utilizados não foram capazes de impedir a infiltração na interface dente/restauração.

Em 1992, SORENSEN et al. ${ }^{89}$ compararam a adaptação marginal de dois sistemas para confecção de coroa total de porcelana e avaliaram a relação entre adaptação marginal e microinfiltração. Vinte incisivos centrais foram divididos em dois grupos: (1) coroa total de porcelana obtida sobre lâmina de platina; (2) coroa total de porcelana sobre refratário. As coroas foram adaptadas aos preparos e fixadas com resina composta. Os espécimes foram então, armazenados em água por 21 dias, termociclados e imersos em solução de nitrato de prata a 50\%. Estes foram seccionados e examinados quanto à desadaptação marginal. A microinfiltração marginal também foi avaliada por três examinadores calibrados. As conclusões deste trabalho mostraram que a discrepância marginal média do grupo 1 $(182 \mu \mathrm{m})$ foi significantemente menor que a do grupo $2(292 \mu \mathrm{m})$. A microinfiltração foi mais crítica na interface dente/resina composta que na interface porcelana resina/composta, não havendo porém, relação entre discrepância marginal vertical e quantidade de microinfiltração.

SWIFT JUNIOR; TRIOLO JUNIOR ${ }^{92}$, em 1992, compararam a resistência adesiva ao cisalhamento do sistema adesivo Scotchbond Multi-Purpose ao esmalte e à dentina na presença ou na ausência de umidade. Espécimes de esmalte e 
dentina foram preparados e condicionados com ácido maleico a 10\%, sendo que metade dos espécimes foram secos com ar e a outra metade teve os excessos de água removidos com um papel absorvente. Após, o sistema adesivo foi utilizado e uma resina composta foi aplicada e polimerizada. Os espécimes foram termociclados e a resistência adesiva determinada em uma máquina de testes universal Instron. Os resultados mostraram um melhor comportamento deste sistema quando utilizado no esmalte e na dentina úmidos. Os autores ${ }^{92}$ ressaltaram que o sistema Scotchbond Multi-Purpose é uma solução aquosa sem componentes voláteis e que a natureza hidrofílica do "Primer" seria fundamental para sua efetividade na presença de umidade.

Em 1992, TAYLOR; LYNCH ${ }^{93}$ realizaram uma revisão de literatura abordando as diversas metodologias sobre microinfiltração. Destacaram que os estudos in vitro com penetração de corantes, principalmente a fucsina básica, são os mais comumente utilizados. Dentre as vantagens e desvantagens de cada técnica, enfatizaram o problema da subjetividade e da falta de padronização entre as metodologias que dificultaria a comparação com outros trabalhos.

Em 1992, VAN MEERBEEK et al. ${ }^{99}$ investigaram a interface existente entre a superfície dentinária previamente tratada e o sistema adesivo. Foram confeccionados discos de dentina medindo aproximadamente 1,0 a $1,5 \mathrm{~mm}$ de espessura, obtidos a partir de terceiros molares humanos extraídos. Para cada grupo avaliado, utilizaram-se cinco corpos-de-prova. Estes foram abrasionados com lixa de granulação 600 a fim de obter uma "smear layer" padronizada. Vários sistemas adesivos foram utilizados de acordo com as recomendações dos 
respectivos fabricantes e sobre estes aplicou-se uma resina composta de baixa viscosidade. Os corpos-de-prova foram seccionados perpendicularmente e preparados para a análise no microscópio eletrônico de varredura. Dentre as diversas observações realizadas pelos autores ${ }^{99}$, pode-se destacar que a união dos sistemas adesivos que promovem uma desmineralização da dentina é principalmente micromecânica e a formação da camada híbrida depende da desmineralização e impregnação da dentina pelo do "primer". Os autores ${ }^{99}$ também relataram que a camada híbrida pode ter um potencial protetor à passagem de toxinas e microorganismos e conseqüentemente melhorar o desempenho clínico das restaurações.

WENDT; MCINNES; DICKINSON ${ }^{105}$, em 1992, avaliaram a influência da termociclagem na microinfiltração marginal. Cinqüenta dentes humanos receberam preparos MOD e foram restaurados com resina composta. Os espécimes foram divididos em cinco grupos aleatoriamente: (1) imersão em fucsina básica a 0,5\% por 24 horas sem termociclagem; (2) termociclagem e imersão em fucsina básica a 0,5\% por 24 horas; (3) termociclagem em fucsina básica a 0,5\%; (4) e (5) mesmo tratamento dos grupos 1 e 2 respectivamente, com exceção do tempo de imersão em fucsina que foi reduzido a quatro horas. Todos os espécimes foram montados em uma base de resina acrílica, seccionados no sentido oclusogengival e analisados num estereomicroscópio quanto à penetração do corante. Os autores ${ }^{105}$ não encontraram diferença significante entre os grupos em que se realizou a termociclagem seguida da imersão em corante e os grupos em que a termociclagem foi realizada concomitantemente com a imersão na fucsina. 
ZAIMOGLU; KARAAGAÇLIOGLU; ÜÇTASLI ${ }^{108}$, em 1992, avaliaram a microinfiltração em facetas de porcelana aderidas à superfície vestibular de incisivos centrais superiores com margens cervicais em esmalte e dentina. A efetividade de agentes de fixação resinosos fotopolimerizáveis e de dupla polimerização sobre a microinfiltração também foi analisada. Dois tipos de preparos foram realizados em 40 incisivos centrais superiores extraídos, sendo que metade apresentava um chanfrado de $0,5 \mathrm{~mm}$ em esmalte e a outra metade, $0,5 \mathrm{~mm}$ em dentina. Os dentes foram divididos em oito grupos experimentais com cinco dentes cada. Os sistemas de fixação resinosos utilizados foram o Porcelite e Porcelite Dual Cure. Depois da confecção das facetas, com dois tipos de porcelana, sua superfície interna foi condicionada com ácido fluorídrico e silanizada. As facetas foram fixadas com os respectivos agentes de fixação de acordo com as instruções de cada fabricante. Os espécimes foram armazenados em água a $37^{\circ} \mathrm{C}$ por 14 dias, termociclados e imersos em uma solução aquosa de fucsina básica $0,5 \%$ por 24 horas. Cada dente foi seccionado longitudinalmente para avaliação da infiltração em quatro interfaces: (1) região cervical - dente/resina; (2) região cervical - porcelana/resina; (3) região incisal - dente/resina; (4) região incisal - porcelana/resina. De acordo com os resultados, não houve diferença estatisticamente significante na infiltração entre as duas porcelanas com qualquer um dos agentes de fixação. Contudo, um índice maior de microinfiltração foi encontrado nas interfaces dentina/resina, comparado com as interfaces esmalte/resina.

Em 1992, ZUELLIG-SINGER; KREJCI; LUTZ ${ }^{110}$ avaliaram a adesão de incrustações de resina composta e de porcelana à dentina. Foram preparadas cavidades MOD em 24 molares humanos, sendo que a margem cervical de uma 
caixa proximal se localizava em esmalte e a outra em dentina. As restaurações foram fixadas com sistemas de fixação resinosos, com diversos tipos de polimerização (fotopolimerizável, quimicamente polimerizável ou de polimerização dupla). Os espécimes foram ciclados mecanicamente e as interfaces dente/agente de fixação e agente de fixação/incrustação foram analisadas no microscópio eletrônico de varredura. Os autores ${ }^{110}$ observaram uma união mais uniforme ao esmalte que à dentina. $O$ uso de sistemas resinosos de dupla polimerização melhorou a adaptação marginal, quando comparado ao sistema resinoso fotopolimerizável.

BLAIR et al. ${ }^{7}$,em 1993, investigaram o efeito da utilização de três agentes de fixação resinosos, associados ou não a sistemas adesivos, na microinfiltração marginal. Preparos de classe $V$ foram realizados na superfície vestibular e lingual de 60 molares humanos. Todos os preparos apresentavam a margem oclusal localizada em esmalte e a margem cervical em dentina ou cemento. As cavidades foram moldadas e as incrustações realizadas com o sistema Dicor. Todas as incrustações foram fixadas e no grupo controle utilizou-se o cimento fosfato de zinco. Os espécimes foram armazenados em água destilada à temperatura ambiente por uma semana e em seguida termociclados. Os ápices foram selados e os espécimes cobertos com esmalte de unha deixando $1 \mathrm{~mm}$ livre em torno da restauração. Em seguida, estes foram imersos em fucsina básica a 1\% por 24 hora. Os corpos-deprova foram limpos, seccionados no sentido oclusogengival e examinados no microscópio óptico com aumento de dez vezes. Pôde-se observar que, apesar de todos os sistemas de fixação apresentarem alguma infiltração marginal, o uso de sistemas adesivos foi decisivo na sua redução. 
CARDASH et al. ${ }^{10}$, em 1993, investigaram o efeito da cor da porcelana na polimerização dos agentes de fixação resinosos fotopolimerizáveis e de dupla polimerização. Discos de porcelana com dimensões padronizadas de $10 \mathrm{~mm}$ de diâmetro e $2 \mathrm{~mm}$ de espessura foram confeccionados em diversos matizes. Um agente de fixação resinoso fotopolimerizável e outro de dupla polimerização foram inseridos em matrizes e cobertos com os discos de porcelana. Foram utilizados dois espécimes para cada combinação do matiz da porcelana, tipo de ativação da resina e tempo de exposição à fonte polimerizadora. A dureza Knoop foi medida e os resultados submetidos à análise estatística. Os autores ${ }^{10}$ concluíram que uma espessura de $2 \mathrm{~mm}$ de uma porcelana matizada afeta a microdureza de uma resina composta fotopolimerizada e que valores maiores foram encontrados quando se utilizou uma resina de dupla polimerização.

Em 1993, DONOVAN; CHEE $^{20}$ teceram alguns comentários a respeito das restaurações indiretas em dentes posteriores. Dentre eles, ressaltaram a importância da integridade marginal na longevidade das restaurações prevenindo a microinfiltração que poderia resultar em cárie secundária. Ademais, comentaram que apesar da boa adaptação conseguida com as incrustações de porcelana, o selamento é dependente de uma interação de vários materiais e substratos que não seriam completamente compreendidos. A sensibilidade técnica para a confecção destas restaurações também poderia ser responsável pelo alto índice de fraturas da porcelana e uma tendência à microinfiltração nas margens cervicais.

A composição de 14 sistemas de fixação resinosos de dupla polimerização foi estudada por IONOKOSHI et al. ${ }^{38}$, em 1993. Eles fizeram algumas considerações e 
ressaltaram que o formato das partículas inorgânicas era irregular em dez marcas comerciais. O agente de fixação experimental 3M Luting Composite apresentou partículas esferoidais que permitiam uma película menor de $25 \mu \mathrm{m}$. Quanto ao

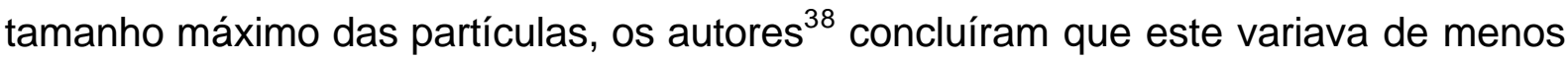
de $1 \mu \mathrm{m}$ até $250 \mu \mathrm{m}$, sendo que sua distribuição nem sempre era homogênea em alguns produtos. Sugeriram então, que deveriam ser feitas especificações para os sistemas de fixação resinosos de dupla polimerização.

Em 1993, KREJCI; LUTZ; REIMER ${ }^{45}$ avaliaram a adaptação marginal de quatro sistemas para confecção de incrustações de porcelana (Dicor, Dicor MGC, Biodent, Cerec Vita MKI). Para tanto, 24 primeiros molares foram fixados em uma base e divididos em quatro grupos aleatórios. Foram realizados preparos intracoronários tipo MOD, sendo a margem cervical mesial localizada em esmalte e a margem cervical distal localizada em dentina. As restaurações foram confeccionadas, condicionadas, silanizadas e fixadas com um sistema resinoso de dupla polimerização. Foram feitas réplicas para a análise da adaptação marginal no microscópio eletrônico de varredura. As restaurações foram então, submetidas a situações que simulassem as condições clínicas, como a desintegração química,

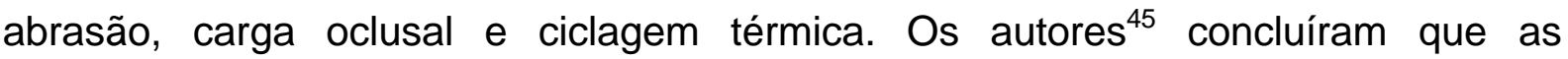
restaurações apresentaram uma boa adaptação marginal inicial em esmalte, embora não houvesse selamento dentinário sem o uso dos adesivos dentinários. As variações térmicas, mecânicas e químicas causaram deterioração das margens.

Em 1993, MCINTYRE ; BOCHIECHIO ${ }^{51}$ determinaram se a equiparação entre o coeficiente de expansão do revestimento refratário e da porcelana poderia 
melhorar a adaptação marginal de incrustrações. Foram utilizados os sistemas refratários Fortune e Polyvest e a porcelana VMK 68. Um preparo para incrustação intracoronária foi confeccionado sobre o primeiro pré-molar superior esquerdo, que foi moldado com silicona de adição. Obteve-se então, um modelo metalizado que, por sua vez, foi moldado 30 vezes para a confecção dos modelos de trabalho. Quinze espécimes foram confeccionados pelo mesmo sistema revestimento/porcelana e quinze por sistemas diferentes, porém, de acordo com as recomendações do fabricante. As restaurações, após sua conclusão, foram adaptadas ao modelo mestre e a fenda marginal foi registrada no microscópio Unitron. As superfícies avaliadas foram a vestibular, lingual e proximais mesial e distal. Os resultados foram submetidos à análise estatística e pôde-se concluir que quando se utilizou o mesmo sistema revestimento/porcelana, as fendas marginais foram menores.

Ao comentar a importância da adaptação marginal na longevidade de uma restauração, MOLIN; KARLSSON ${ }^{55}$, em 1993, avaliaram quantitativamente e compararam entre si, a adaptação marginal de quatro tipos de incrustações, sendo um de ouro e três de porcelana. Neste estudo, foram selecionados 20 pacientes, sendo que no total foram restaurados 35 pré-molares e 45 molares. Após o preparo, moldagens totais foram realizadas com silicona. Modelos de gesso foram obtidos e as incrustações de porcelana confeccionadas de acordo com três técnicas diferentes: Sistema de porcelana sobre refratário (Mirage), Sistema CAD-CAM (Cerec) e Sistema de porcelana fundida e injetada (IPS Empress). As incrustações de ouro foram confeccionadas pela técnica da cera perdida. Quando as restaurações retornaram do laboratório, foram obtidas moldagens da fenda existente 
entre a superfície interna da incrustação e a superfície do gesso. O mesmo procedimento foi realizado na cavidade oral, obtendo-se a réplica do espaço entre a incrustação e 0 dente. As réplicas dos espécimes foram seccionadas vestibulolingualmente e mesiodistalmente, resultando em quatro partes. As medidas foram observadas no microscópio com aumento de 50 vezes e os resultados mostraram que a menor discrepância marginal foi registrada para as incrustações de ouro na margem oclusal e a maior discrepância na margem cervical das incrustações do sistema Cerec. Quando submetidos à análise de variância, a ordem decrescente de discrepância marginal foi incrustações de ouro < Mirage/Empress < Cerec.

ØILO ${ }^{58}$, em 1993, ressaltou a importância de alguns testes laboratoriais como os de resistência adesiva, microinfiltração e medição de fendas marginais para o desenvolvimento dos materiais restauradores. Enfatizou que os testes de resistência à tração e ao cisalhamento são os testes laboratoriais mais utilizados e que os resultados obtidos são dependentes do tipo de teste aplicado, tipo e qualidade da dentina, condições de armazenamento dos espécimes, além das propriedades manipulativas do material.

PASHLEY et al. ${ }^{64}$, em 1993, compararam a morfologia de dois tipos de dentina, coberta ou não com "smear layer", antes e após o condicionamento ácido, a fim de identificar porosidades que permitiriam a infiltração da resina durante os procedimentos de adesão. Foram obtidos corpos-de-prova a partir de terceiros molares. Estes foram fraturados com auxílio de cinzéis ou preparados com uma ponta diamantada. Metade de cada corpo-de-prova foi condicionada por 30 
segundos com ácido fosfórico a 37\%, lavada e então, seca com ar ou mantida úmida. Na análise da microscopia eletrônica de varredura, pôde-se verificar que o condicionamento aumentou o diâmetro dos túbulos dentinários e a porosidade. Os espécimes secos apresentaram colapso das fibras colágenas. Este efeito foi mais acentuado nos espécimes que apresentavam smear layer antes do condicionamento.

ANAGNOSTOPOULOS; ELIADES; PALAGHIAS ${ }^{4}$, em 1993 analisaram a composição, reatividade, interações superficiais e o modo de ação de três agentes silano disponíveis no comércio. A reatividade dos silanos foi estimada pela quantidade de grupos metoxi por átomo de Si hidrolisados em silanol. Estes grupos silanóis seriam as áreas ativas das moléculas hidrolisadas de silano. Assim, quanto maior a sua quantidade, melhor seria a reatividade do material. Os resultados encontrados pelos autores ${ }^{4}$ mostraram que todos os agentes silanos continham radicais com afinidade ao dimetacrilato. Nos silanos pré-hidrolisados encontrou-se ácido acético que funcionaria como catalisador para a hidrólise e condensação das moléculas de silano. Todos os silanos avaliados mostraram hidrólise parcial dos grupos metoxi, porém os pré-hidrolisados apresentaram um maior índice de hidrólise, quando comparado aos quimicamente ativados.

Neste mesmo ano, REID; SAUNDERS; BAIDAS ${ }^{67}$ avaliaram a adaptação marginal e a microinfiltração de três sistemas adesivos indiretos para incrustações. Cavidades MOD foram preparadas em 67 pré-molares extraídos, sendo que em 34 dentes as paredes cavitárias apresentavam-se com $10^{\circ}$ de divergência oclusal e nos outros 33 dentes com $15^{\circ}$. Os sistemas utilizados foram o EOS, Isosit e Hi-Ceram. 
Todas as restaurações dos grupos confeccionados com a resina Isosit e com a porcelana Hi-Ceram se assentaram sem modificações nas cavidades preparadas tanto com $10^{\circ}$ ou $15^{\circ}$ de divergência oclusal. Já as incrustações feitas pelo sistema EOS necessitaram de modificações na superfície interna para se ajustarem. A análise da microinfiltração mostrou que não houve diferença significante entre os três sistemas após a fixação e que a microinfiltração nas margens de incrustações de resina composta ou porcelana fixadas com uma resina de baixa viscosidade não pôde ser evitada, especialmente nas cavidades com término cervical em cemento.

SULIMAN; SWIFT; PERDIGÃO ${ }^{91}$, em 1993, avaliaram a resistência adesiva entre resina composta e porcelana com a aplicação de quatro diferentes tratamentos da superfície da porcelana e três sistemas adesivos. Sessenta cilindros de porcelana foram divididos em quatro grupos de acordo com o tratamento: (1) ponta diamantada; (2) ácido fluorídrico a 9,6\% por dois minutos; (3) jato de óxido de alumínio com partículas de $50 \mu \mathrm{m}$ por 15 segundos; (4) ponta diamantada + ácido fluorídrico a 9,6\% por dois minutos. Após o tratamento superficial, todos os espécimes foram silanizados. Cada um dos quatro grupos foi dividido em três subgrupos de acordo com a aplicação dos diferentes sistemas adesivos: Amalgambond, All-Bond 2 e Clearfil Porcelain Bond. Uma resina composta foi então, aplicada e polimerizada. Depois de armazenados por sete dias, os espécimes foram submetidos à termociclagem e ao teste de resistência adesiva ao cisalhamento. Os resultados apontaram falhas predominantemente coesivas na porcelana e na resina composta. 
STACEY ${ }^{90}$, em 1993 comparou a resistência adesiva de um sistema de fixação resinoso ao esmalte e à porcelana e também avaliou a influência da termociclagem na resistência das ligações entre estes substratos. Cem espécimes foram divididos em cinco grupos: (1) agente de fixação resinoso + porcelana condicionada; (2) agente de fixação resinoso + porcelana condicionada e silanizada; (3) agente de fixação resinoso + esmalte condicionado; (4) esmalte condicionado + agente de fixação resinoso + porcelana condicionada e (5) esmalte condicionado + agente de fixação resinoso + porcelana condicionada e silanizada. Metade dos espécimes de cada grupo foi submetida à termociclagem e os testes de cisalhamento conduzidos em uma máquina de testes universal. Os resultados mostraram que a aplicação do silano à porcelana condicionada aumentou significantemente a resistência adesiva entre a porcelana e o sistema de fixação. A resistência dos espécimes combinados de esmalte e porcelana foi significantemente menor do que a dos espécimes individualizados esmalte/agente de fixação e agente de fixação/porcelana. A termociclagem não teve influência significante na resistência adesiva do grupo esmalte condicionado/agente de fixação/porcelana condicionada, quando a porcelana foi tratada com silano.

WHITE; YU ${ }^{106}$, em 1993, avaliaram a resistência à compressão e à tração de diversos sistemas de fixação adesiva e compararam com as do cimento fosfato de zinco. Sete marcas comerciais foram manipuladas de acordo com as recomendações dos respectivos fabricantes e os testes conduzidos conforme as normas da American National Standards/American Dental Association. Os dados obtidos foram tabulados e submetidos à análise estatística. Pôde-se concluir que os 
agentes de fixação resinosos possuem maior resistência à tração e à compressão que o cimento fosfato de zinco.

BARGHI $^{6}$, em 1994, comparou a resistência ao cisalhamento de uma resina composta e uma porcelana aderida à dentina utilizando quatro sistemas adesivos. Oitenta e seis dentes humanos extraídos foram divididos em dois grupos e tratados da seguinte forma: (1) porcelana condicionada, silanizada e fixada com sistema de fixação resinoso, (2) resina composta silanizada e fixada com sistema de fixação resinoso. Antes da fixação, cada grupo foi dividido em quatro subgrupos, os quais foram tratados com os seguintes sistemas adesivos: All-Bond, Gluma 2000, Mirage ABC e Scotchbond Multi-Purpose. A resistência adesiva ao cisalhamento foi testada em uma máquina de testes universal Instron. Os resultados indicaram que o mesmo adesivo pode produzir resistências significantemente diferentes quando usado para aderir porcelana ou resina composta à dentina.

DRAUGHN; DAVIS ${ }^{21}$, em 1994, verificaram os efeitos da vibração ultra-sônica na espessura da película de um cimento de ionômero de vidro e de um agente de fixação resinoso. Espécimes dos agentes cimentantes foram preparados e submetidos à aplicação de forças estáticas por 30 segundos. A vibração ultra-sônica também foi aplicada por 5, 15 e 25 segundos e a espessura da película foi medida com um micrômetro de precisão. Os resultados mostraram diferenças significantes na espessura dos agentes cimentantes. Com o cimento de ionômero de vidro, a espessura da película após a vibração ultra-sônica foi de $38 \mu \mathrm{m}$ e sem a vibração a película apresentou espessura de $46 \mu \mathrm{m}$. O agente de fixação resinoso mostrou uma espessura de $63 \mu \mathrm{m}$ após a aplicação de uma carga de 1,0Kgf sem vibração e $52 \mu \mathrm{m}$ 
com vibração. A espessura do agente de fixação resinoso, com ou sem vibração ultra-sônica, diminuiu a um valor mínimo de $41 \mu \mathrm{m}$ com a aplicação de carga de $6 \mathrm{kgf}$. Concluiu-se com este estudo, que a aplicação de vibração ultra-sônica para esses agentes cimentantes produziu películas mais finas que a aplicação de pequenas cargas.

Devido a limitações na interpretação dos testes laboratoriais, GALE; DARVELL; CHEUNG ${ }^{28}$, em 1994, desenvolveram um método de avaliação tridimensional do padrão de penetração do nitrato de prata. Cavidades de classe $\mathrm{V}$ foram realizadas e restauradas com sistema adesivo e resina composta. Os espécimes foram termociclados e preparados para a penetração e evidenciação do nitrato de prata. A seguir, cada espécime foi seccionado em aproximadamente 30 secções de $0,15 \mathrm{~mm}$ cada. Estas foram digitalizadas e uma imagem tridimensional do padrão de penetração foi obtida. Os autores ${ }^{28}$ concluíram que este método reproduziria com mais fidelidade a microinfiltração que os métodos tradicionais.

LATTA; BARKMEIER ${ }^{47}$, em 1994, avaliaram a resistência ao cisalhamento de um sistema de fixação resinoso à resina composta para incrustações. Sessenta espécimes de resina composta foram confeccionados e divididos em seis grupos. Os seguintes tratamentos de superfície foram utilizados: (1) controle; (2) ácido fluorídrico a $20 \%$ por 60 segundos; (3) bifluoreto de amônia por 60 segundos; (4)

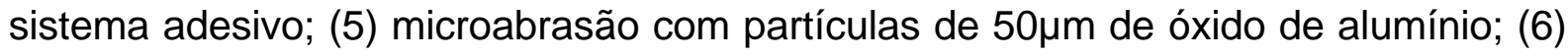
microabrasão + sistema adesivo. As incrustações foram fixadas com um sistema resinoso de dupla polimerização, armazenadas em água destilada por 24 horas e 
em seguida testadas. Os resultados mostraram que a microabrasão da superfície interna da incrustação aumentou a adesão do sistema de fixação à resina composta.

ÖZDEN; AKALTAN; CAN ${ }^{59}$, em 1994, avaliaram a resistência adesiva ao cisalhamento entre a porcelana e um agente de fixação resinoso de dupla polimerização. Confeccionaram-se 77 corpos-de-prova que foram divididos em sete grupos de acordo com o tratamento de superfície: (1) silanização; (2) ácido fluorídrico; (3) abrasão com ponta diamantada; (4) silanização após abrasão e condicionamento com ácido fluorídrico; (5) silanização após abrasão; (6) silanização após condicionamento com ácido fluorídrico; (7) ácido fluorídrico após abrasão. Efetuado o tratamento de superfície, as incrustações foram fixadas com um agente resinoso de dupla polimerização e armazenadas em água a $37^{\circ} \mathrm{C}$ por 24 horas. Em seguida, os corpos-de-prova foram termociclados e testados na máquina de ensaios. O tratamento com silano resultou num aumento da resistência ao cisalhamento se comparado com os demais grupos. Contudo, o uso de dois sistemas de adesão juntos (mecânico e químico) não melhorou a resistência ao cisalhamento dos espécimes testados.

Em 1994, RETIEF; RUSSELL; MANDRAS ${ }^{69}$ relacionaram a resistência adesiva ao cisalhamento de sete sistemas adesivos com a microinfiltração quantitativa de restaurações com término cervical em dentina. Para os testes de resistência ao cisalhamento, os autores ${ }^{69}$ prepararam 15 molares para cada grupo. A superfície oclusal de cada espécime foi desgastada até expor a dentina. Esta foi delimitada com uma fita isolante deixando exposta uma área de $3 \mathrm{~mm}$ que foi tratada com os respectivos sistemas adesivos e restaurada com resina composta. Os testes 
foram conduzidos em uma máquina de testes universal Instron e os resultados tabulados. Para os testes de microinfiltração quantitativa foram utilizados caninos e pré-molares, num total de 15 dentes para cada grupo. Os ápices foram obturados e preparos de classe $\mathrm{V}$ foram realizados. Os sistemas adesivos foram então, aplicados e os dentes restaurados com resina composta. Os espécimes foram cobertos com esmalte de unha deixando $1 \mathrm{~mm}$ livre em torno da restauração, termociclados, imersos em solução de azul de metileno a $2 \%$ e depois lavados. Os corpos-de-prova foram avaliados em um espectofotômetro e os dados tabulados e analisados

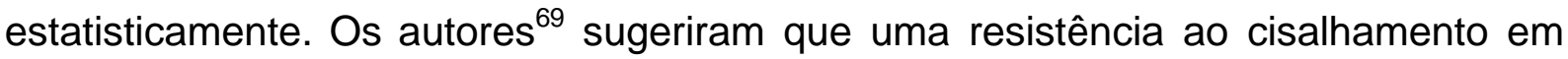
torno de 21MPa poderia reduzir a microinfiltração próximo a zero.

A importância da integridade marginal das restaurações na prevenção de cárie secundária foi relatada por ROULET $^{74}$, em 1994. O autor ${ }^{74}$ ressaltou a dificuldade de se realizar testes in vivo e que os testes in vitro para a avaliação da qualidade marginal são, na maioria das vezes, realizados em dentes extraídos sob condições de simulação clínica ou sob condições padronizadas. Tais testes teriam limitações devido à interação e má interpretação dos resultados, o que poderia resultar em má avaliação do material restaurador.

GRIGGS, SHEN, ANUSAVICE ${ }^{31}$, em 1994, investigaram a influência da variação na proporção das pastas base e catalisadora no tempo de trabalho e de presa de três agentes de fixação resinosos de dupla polimerização. Quinze espécimes de cada grupo tiveram seu tempo de trabalho avaliado espatulando diferentes proporções do agente de fixação por 30 segundos a $23^{\circ} \mathrm{C}$. O tempo desde o início da espatulação até o momento do aumento da temperatura era registrado. 0 
tempo de presa foi avaliado, espatulando os materiais da mesma maneira a $37^{\circ} \mathrm{C}$ e registrando o tempo no qual a temperatura alcançava o valor máximo. Os tempos registrados e as medidas das pastas foram usados para determinar o efeito da proporção da massa no tempo de trabalho e de presa. Os autores ${ }^{31}$ concluíram que as variações na proporção das pastas base e catalisadora não tiveram uma influência significante no tempo de trabalho e de presa dos sistemas avaliados.

Em 1994, SILVA E SOUZA Júnior et al. ${ }^{81}$ avaliaram a resistência adesiva ao cisalhamento de três sistemas adesivos a diferentes substratos e a microinfiltração quantitativa em restaurações de classe V. Para os testes de resistência adesiva foram utilizados 15 espécimes para cada condição. Estes foram tratados com os sistemas adesivos de acordo com as recomendações dos respectivos fabricantes e os testes conduzidos em uma máquina de testes universal Instron. Para a análise da microinfiltração foram realizadas cavidades de classe $V$ com término cervical em cemento. Após a confecção das restaurações, os espécimes foram termociclados em solução de azul de metileno a $2 \%$, e a infiltração quantitativa determinada em um espectofotômetro. Os resultados mostraram uma resistência adesiva ao cisalhamento ao esmalte estatisticamente superior aos demais substratos e um índice reduzido de infiltração na interface sistema adesivo/cemento.

THORDRUP; ISIDOR; HORSTED-BINDSLEV ${ }^{94}$, em 1994, avaliaram a microinfiltração marginal em quatro diferentes sistemas para confecção de incrustações de porcelana e resina composta. Sessenta e três terceiros molares foram divididos aleatoriamente em quatro grupos. Preparos MOD foram realizados e as restaurações confeccionadas conforme as instruções dos fabricantes. Os 
sistemas usados foram Cerec, Brilliant, Kulzer Inlay System e Vitadur. Dez dentes de cada grupo foram termociclados com 2500 ciclos e temperaturas de $12^{\circ} \mathrm{C}$ e $62^{\circ} \mathrm{C}$. Os restantes serviram como grupo controle. Os ápices foram selados com cera e as raízes foram cobertas com duas camadas de esmalte de unha, deixando livre $1 \mathrm{~mm}$ em torno da restauração. Os dentes foram imersos em fucsina básica por 24 horas a $37^{\circ} \mathrm{C}$, lavados e seccionados para a análise. Os resultados mostraram que as incrustações de porcelana apresentaram menor microinfiltração que as de resina composta, sendo que o término cervical em esmalte resultou em menor infiltração que o término em dentina. A termociclagem teve somente uma pequena influência na microinfiltração.

Em 1994, VAN MEERBEEK et al. ${ }^{100}$ avaliaram o comportamento clínico de vários sistemas adesivos e compararam com alguns sistemas adesivos atuais. As causas das falhas foram padronizadas a partir de dados obtidos em pesquisas in vitro. Para tanto, os autores ${ }^{100}$ avaliaram dez sistemas adesivos de diferentes gerações, utilizados em 1177 restaurações de classe $\vee$ de resina composta em dentes de 346 pacientes durante dez anos. Dois tipos de preparos cavitários foram empregados, sendo que no grupo 1 as restaurações situavam-se totalmente em dentina e no grupo 2 as margens oclusais dos preparos estavam localizadas em esmalte. Os pacientes foram avaliados e os resultados mostraram, para o grupo 1, uma proporção crescente de retenção dos sistemas adesivos atuais em relação aos demais, no período de avaliação de um ano. No grupo 2, a retenção das restaurações foi em torno de $92 \%$ no primeiro ano. Para os demais períodos, a proporção de retenção no grupo 1 foi significante menor que no grupo 2. Dois sistemas adesivos (Clearfil Liner Bond System e Scotchbond Multi-Purpose) tiveram 
excelente comportamento clínico independente do preparo situar-se em esmalte ou dentina.

A fim de esclarecer os aspectos relacionados aos testes de laboratório e sua correlação com o comportamento clínico, VAN NOORT ${ }^{101}$, em 1994, teceu vários comentários relevantes. Dentre eles, relatou que o desenvolvimento de um material é associado a vários testes que visam mensurar as suas propriedades mecânicas e físicas. Assim, os resultados encontrados servem, não só para estabelecer as suas propriedades, mas também monitorar os possíveis efeitos das alterações em sua composição. Segundo o autor ${ }^{101}$, as medidas de resistência podem ser efetuadas de várias maneiras e apesar de não concordar com os testes de resistência adesiva ao cisalhamento, enfatizou que eles são importantes para avaliar os efeitos dos diferentes parâmetros na resistência adesiva à dentina.

WALMSLEY; LUMLEY; WILSON ${ }^{102}$, em 1994, compararam a técnica de fixação adesiva de incrustações com ou sem a aplicação de vibração ultra-sônica. Dez clínicos fixaram incrustações de resina composta em dentes conectados a uma célula de carga usando pressão digital ou vibração ultra-sônica. Os resultados mostraram que cargas significantemente maiores foram registradas quando usou-se aplicação manual. O efeito da viscosidade do agente de fixação também foi determinado. Este foi manipulado e posicionado entre duas lâminas de microscópio. Forças estáticas foram aplicadas sobre as duas lâminas várias vezes, durante dois minutos. Após esse período, os agentes de fixação foram polimerizados e a espessura entre as lâminas medida utilizando-se um microscópio. O mesmo foi realizado com vibração ultra-sônica, sendo esta aplicada às lâminas por dez 
segundos. Concluiu-se que a sonda ultra-sônica orientada perpendicularmente à superfície resultou em uma fina espessura do agente de fixação em um período mais curto de tempo e com menor carga que com os métodos manuais.

A dureza dos agentes de fixação resinosos de polimerização química ou dupla e a influência da espessura da incrustação na sua polimerização foram estudados por EL-BADRAWY; EL-MOWAFY ${ }^{22}$, em 1995. Foram confeccionados discos de dimensões padronizadas com sete diferentes agentes de fixação resinosos, sendo oito espécimes para cada grupo. Metade dos espécimes foi polimerizada apenas quimicamente e a outra metade sofreu dupla polimerização para então, serem submetidos aos testes de dureza Knoop nos intervalos de uma hora, 24 horas e uma semana. Na segunda parte da pesquisa, a polimerização foi realizada com a passagem da luz através de diferentes espessuras do material restaurador, sendo este resina composta ou porcelana. Foram confeccionados 24 espécimes do agente de fixação com as mesmas dimensões, sendo que metade foi polimerizada por luz através da resina composta, com espessuras variando de 1 a $6 \mathrm{~mm}$, e a outra metade polimerizada através da porcelana, com as mesmas espessuras. Os dados obtidos foram tabulados e submetidos à análise estatística. Pôde-se concluir que a polimerização química não foi suficiente para alcançar valores máximos de dureza. Houve uma redução significante na dureza quando espessuras de material restaurador superiores a 2 ou $3 \mathrm{~mm}$ foram interpostas.

FRAZIER, SARRET ${ }^{27}$, em 1995, avaliaram a resistência ao desgaste de diferentes marcas comerciais de sistemas de fixação resinosos de dupla polimerização. Seis espécimes de cada material foram confeccionados e testados 
sob três condições: (1) armazenagem em água por seis meses; (2) armazenagem em água por 12 meses; (3) armazenagem a seco. Os espécimes foram analisados e os resultados mostraram diferenças significantes na resistência entre os materiais. Dentre eles, o Insure (Cosmedent) e o Dual Cement (Vivadent) foram os mais resistentes, enquanto o Optec Luting Cement (Jeneric Pentron) e o Mirage LFC (Chameron) demonstraram os menores valores. Os efeitos da armazenagem em água tiveram pouca influência na resistência ao desgaste com exceção do Optec Luting Cement.

GUZMAN, MOORE ${ }^{32}$, em 1995, avaliaram a resistência adesiva entre uma resina composta termopolimerizável e uma resina composta fotopolimerizável. Os espécimes de resina termopolimerizável foram confeccionados e montados sobre uma base para em seguida serem divididos em diferentes grupos de acordo com o tratamento de superfície. O experimento foi conduzido em duas fases. Na primeira fase, a resina composta e o agente adesivo usados eram à base de uretana. $\mathrm{Na}$ segunda fase, foram utilizados uma resina BIS-GMA e um adesivo. As superfícies receberam os seguintes tratamentos: (1) controle; (2) aplicação de um monômero; (3) aplicação de solvente à base de acetona; (4) abrasão + adesivo; (5) condicionamento com ácido fluorídrico a 9,5\% por um minuto + silano + adesivo; (6) adesivo. Na segunda fase, três grupos contendo 20 espécimes cada, receberam os seguintes tratamentos: (7) controle; (8) condicionamento com ácido fluorídrico a 9,5\% por 1 minuto + adesivo; (9) adesivo. A resistência adesiva foi testada em uma máquina de testes universal e os espécimes examinados em um microscópio. Os autores $^{32}$ concluíram que a aplicação do adesivo foi essencial para se alcançar uma resistência adesiva adequada entre as resinas foto e termopolimerizável. Ademais, 
ressaltaram que existe uma relação direta entre as falhas coesivas e a resistência adesiva, ou seja, a medida que uma aumenta, a outra segue na mesma proporção.

MICHELINI et al. ${ }^{53}$, em 1995, compararam a resistência à tração de incrustações de ouro e de porcelana fixadas com três diferentes materiais: agente de fixação resinoso de dupla polimerização, cimento de ionômero de vidro, e cimento fosfato de zinco. Foram utilizados 45 molares que receberam 23 incrustações de ouro e 22 de porcelana, distribuídas em quatro grupos. No grupo 1, com 12 incrustações de ouro, foi utilizado o cimento fosfato de zinco. No grupo 2, as incrustações tiveram sua superfície interna jateada com partículas de óxido de alumínio e depois sofreram eletrodeposição de estanho, sendo cimentadas com cimento de ionômero de vidro. No grupo 3, 11 incrustações de porcelana foram condicionadas, silanizadas e fixadas com agente de fixação resinoso de dupla polimerização. Finalmente, o grupo 4, com 11 incrustações de porcelana, não recebeu nenhum tratamento de superfície e as restaurações foram cimentadas com cimento de ionômero de vidro. O teste de resistência à tração foi realizado e os dados analisados estatisticamente. Os autores ${ }^{53}$ concluíram que não houve diferenças significantes entre as incrustações de ouro cimentadas com cimento de fosfato de zinco ou cimento de ionômero de vidro e as incrustações de porcelana cimentadas com cimento de ionômero de vidro. As incrustações de porcelana fixadas com sistema resinoso de dupla polimerização mostraram uma resistência adesiva duas a três vezes superior que aquelas obtidas pelas incrustações de ouro.

MILLEDING; ÖRTENGREN; KARLSSON ${ }^{4}$, em 1995, avaliaram a freqüência de falhas em incrustações de porcelana, por meio de questionários distribuídos aos 
dentistas participantes, e discutiram alguns aspectos clínicos relevantes. As respostas revelaram que a maioria dos dentistas executavam entre uma e dez restaurações de porcelana por mês e que em $85 \%$ foram observadas complicações clínicas, sendo a sensibilidade pós-operatória a mais freqüente. Outros problemas, tais como fratura do dente ou da restauração, cárie secundária, perda de retenção da restauração, complicações endodônticas e deterioração marginal também ocorreram, porém com menor freqüência. As análises das falhas revelaram como fatores causais a qualidade do preparo cavitário e da restauração, o processo

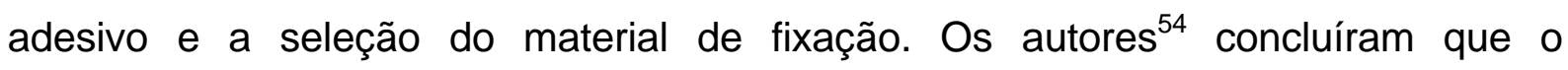
conhecimento dos fundamentos do processo adesivo e o conhecimento do material utilizado são cruciais para o sucesso da restauração.

ROULET; SODERHOLM; LONGMATE ${ }^{75}$, em 1995, testaram vários tratamentos superficiais e também tentaram identificar as variáveis que têm grande influência na resistência adesiva entre a porcelana e a resina composta. Três sistemas cerâmicos (Dicor, Mirage, Vitablock), três tratamentos de superfície (condicionamento com bifluoreto de amônia a 10\% por 90 segundos, jateamento da superfície com óxido de alumínio, abrasão com lixa abrasiva), três tipos de silano (metacriloxipropiltrimetoxisilano, metacriloxipropiltrimetoxisilano dimetil-paratoluidina, viniltriclorosilano), dois tratamento térmicos $\left(20^{\circ} \mathrm{C}\right.$ por 60 segundos, $100^{\circ} \mathrm{C}$ por 60 segundos) e duas condições de armazenamento (24horas a seco, um ano em água a $37^{\circ} \mathrm{C}$ ) foram estudados. Para cada uma das 108 combinações, cinco espécimes foram testados e os resultados mostraram que os métodos de tratamento superficial tiveram mais efeito na resistência adesiva, enquanto a seleção da porcelana teve menor influência. Dentre os tratamentos de superfície, o condicionamento com 
bifluoreto de amônia resultou num alto valor de resistência, assim como o jateamento ou a abrasão. A resistência adesiva permaneceu constante para os espécimes testados com bifluoreto de amônia após a armazenagem em água. Já os espécimes que sofreram jateamento ou abrasão e foram armazenados em água tiveram uma queda em torno de 50 a $75 \%$ da sua resistência quando comparados à armazenagem a seco. $O$ aquecimento dos espécimes tratados com metacriloxipropiltrimetoxisilano a $100^{\circ} \mathrm{C}$ resultou num aumento da resistência duas vezes maior que aqueles sem aquecimento.

ROSSOMANDO; WENDT JUNIOR ${ }^{73}$, em 1995, avaliaram o efeito de diferentes tempos de imersão durante os procedimentos de termociclagem na infiltração marginal de restaurações adesivas. Foram confeccionadas 90 restaurações de classe $\mathrm{V}$ de resina composta ou amálgama adesivo com a margem cervical localizada em cemento. As restaurações foram confeccionadas de acordo com as recomendações dos respectivos fabricantes. Os dentes tiveram seus ápices seccionados e obturados com amálgama e em seguida aplicou-se esmalte de unha em todo o dente, deixando livre $1 \mathrm{~mm}$ em torno da restauração. Os espécimes foram divididos em três grupos que foram imersos em fucsina durante a termociclagem. Após, os dentes foram limpos, inseridos em resina epóxica e seccionados para serem analisados em um estereomicroscópio. Os resultados mostraram que os efeitos do coeficiente de expansão térmica dos materiais envolvidos são dependentes do tempo, sendo que o tempo de imersão abaixo de dez segundos não seria capaz de produzir efeitos significativos em restaurações de resina composta, devido à sua baixa condutibilidade térmica. 
Em 1995, SCHMALZ; FEDERLIN; $\mathrm{REICH}^{77}$ avaliaram a influência da desadaptação inicial e das diferentes composições dos sistemas de fixação na adaptação marginal de incrustações confeccionadas pelo sistema Cerec. Foram realizadas cavidades MOD padronizadas em 72 molares humanos extraídos, sendo que as margens cervicais foram localizadas em esmalte. Após a confecção das incrustações, a desadaptação marginal inicial foi ajustada em 50, 100, 500 e $1000 \mu \mathrm{m}$. As restaurações foram fixadas com três diferentes sistemas (Microfil Pontic C cement, Dual cement e Cerec Duo cement) e cicladas térmica e mecanicamente. Foram feitas avaliações de penetração de corante e análise em microscópio eletrônico de varredura. Pôde-se verificar que uma desadaptação inicial de até $100 \mu \mathrm{m}$ não teria influência na qualidade marginal. Desadaptações iniciais maiores que $100 \mu \mathrm{m}$ poderiam ser parcialmente compensadas pela viscosidade do agente cimentante.

Em 1995, SJÖGREN ${ }^{82}$ avaliou a desadaptação interna e a desadaptação marginal após a fixação de incrustações de porcelana confeccionadas com quatro diferentes materiais. Cavidades MOD padronizadas foram realizadas em 50 prémolares humanos extraídos. As restaurações foram confeccionadas com os sistemas Cerec, Celay, IPS Empress e Vita In-Ceram Spinell. Antes da fixação, a desadaptação foi checada nos espécimes, da mesma maneira como se faz nos procedimentos clínicos. Todas as restaurações foram fixadas com o sistema Kerr Porcelite Dual Cure e a desadaptação marginal foi avaliada em um microscópio com aumento de dez vezes. Após, os espécimes foram seccionados e a desadaptação interna foi medida entre a incrustação e a estrutura dentária, em sete pontos selecionados. Não se verificou diferenças na adaptação marginal dos quatro 
sistemas estudados. A menor desadaptação interna foi obtida com o sistema Celay, não havendo diferenças estatisticamente significante entre os demais sistemas.

Em 1995, SORENSEN; MUNKSGAARD ${ }^{84}$ desenvolveram um método para identificar a presença, localização e extensão da fenda que se forma entre o assoalho cavitário e a restauração após a fixação de incrustações de porcelana. Cavidades cilíndricas com dimensões padronizadas foram preparadas em molares humanos extraídos. Confeccionaram-se incrustações de porcelana, as quais foram condicionadas com ácido fluorídrico e silanizadas. Treze agentes de fixação resinosos foram manipulados de acordo com as recomendações dos respectivos fabricantes e as restaurações foram fixadas. Os espécimes foram incluídos em resina epóxica e seccionados para a mensuração da fenda. Foram realizadas cinco medições para cada secção, totalizando dez por espécime. Os resultados mostraram uma formação de fendas, resultante da contração de polimerização, entre o assoalho cavitário e o agente de fixação, porém não foi observada entre o agente de fixação e a porcelana. Os autores ${ }^{84}$ concluíram que a fenda resultante da utilização de alguns sistemas de fixação pode alcançar um tamanho equivalente à espessura da película multiplicado pela contração volumétrica do cimento.

Em 1995, TUNTIPRAWON; WILSON ${ }^{98}$ determinaram a resistência à fratura de coroas de porcelana cimentadas com cimento fosfato de zinco em diversas espessuras. Para a realização deste trabalho, confeccionaram-se 33 coroas que foram divididas em três grupos. No grupo 1, apenas uma folha de platina foi usada, no grupo 2, duas folhas de platina e no grupo 3, quatro folhas serviram como espaçador e foram aplicadas no troquel antes da moldagem. Cada coroa foi 


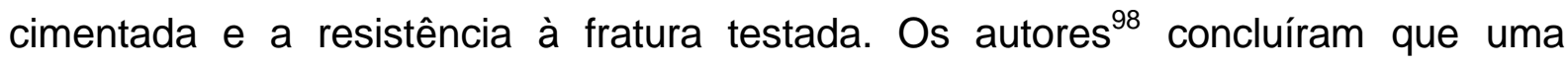
espessura crescente da película do cimento reduz a resistência à fratura das coroas, sendo que ocorreu um declínio significante quando foram utilizadas quatro camadas de espaçadores.

Em 1996, BURROW et al. ${ }^{9}$ avaliaram a resistência à tração de três sistemas de fixação resinosos à dentina bovina variando o tempo de aplicação do teste (10 minutos, 1 hora e 24 horas) e a temperatura ambiente e umidade relativa $\left(23^{\circ} \mathrm{C}\right.$ e $50 \%$ de umidade relativa, e $20^{\circ} \mathrm{C}$ e $80 \%$ de umidade relativa). Foram obtidos espécimes de dentina bovina de incisivos inferiores com uma área adesiva de $4 \mathrm{~mm}$ de diâmetro. Os procedimentos adesivos foram executados e discos de resina foram fixados com os diferentes sistemas. Os corpos-de-prova foram inseridos em uma câmara com temperatura e umidade relativa controladas, sendo que dez espécimes foram testados para cada condição. Os resultados mostraram valores crescentes na resistência à tração durante as primeiras 24 horas, porém a umidade relativa teve pouca influência nos resultados.

DÉJOU; SINDRES; CAMPS $^{18}$, em 1996, compararam diferentes métodos estatísticos empregados na avaliação da infiltração marginal in vitro de 13 sistemas adesivos. Duzentos e sessenta pré-molares receberam preparos padronizados de classe $\mathrm{V}$ e foram restaurados com os sistemas restauradores adesivos. Os dentes foram termociclados, imersos em solução de fucsina básica a 0,5\% por 24 horas, incluídos em resina epóxica e seccionados. Cinco critérios de avaliação foram empregados: (1) média; (2) mediana; (3)modo; (4) penetração máxima; (5)porcentagem de dentes por grupo sem nenhuma penetração. Verificou-se que o 
método de penetração máxima do corante medido em cada dente foi o melhor critério, por permitir uma análise estatística com maior poder.

Em 1996, CARVALHO et al. ${ }^{12}$ realizaram uma revisão de literatura sobre a contração de polimerização das resinas compostas. Relataram que esta seria capaz de gerar forças que poderiam romper a adesão com as paredes cavitárias, sendo uma das principais causas de degradação marginal e conseqüente microinfiltração. Enfatizaram a importância da configuração cavitária, sendo que esta deveria apresentar a menor relação entre superfície aderida e superfície livre, diminuindo assim, a concentração de estresse na interface adesiva. Ademais, comentaram que o módulo de elasticidade da resina também seria decisivo para a geração de estresse. Dentre as possíveis soluções para o problema, sugeriram desenvolvimento de sistemas adesivos capazes de estabelecer valores de resistência adesiva superiores aqueles desenvolvidos pela contração de polimerização.

CORREA $^{16}$, em 1996, avaliou a influência dos diferentes tratamentos da umidade remanescente no preparo cavitário, após a lavagem do condicionador, na infiltração marginal de restaurações de resina composta. Para tanto, realizou 50 cavidades MOD em pré-molares com término cervical em cemento. As cavidades foram condicionadas com ácido fosfórico a $37 \%$ e em seguida receberam os seguintes tratamentos: (1) aplicação de jatos de ar por dez segundos; (2)aplicação de jatos de ar por três segundos (grupo controle); (3) emprego de papel absorvente; (4) aplicação de jatos de ar por dez segundos, seguido de reumedecimento e jatos de ar por três segundos; (5) aplicação de jatos de ar por dez segundos, seguido de reumedecimento e emprego de papel absorvente. Após, aplicou-se o sistema 
adesivo e a resina composta foi inserida e polimerizada. Os espécimes foram submetidos à ciclagem térmica e imersos em fucsina básica a 0,5\% por 24 horas. Para a análise da microinfiltração, os corpos-de-prova foram seccionados no sentido mesiodistal, obtendo-se quatro a cinco fatias de cada espécime que foram analisadas em um estereomicroscópio com aumento de 40X. Pôde-se concluir que nenhum dos grupos experimentais foi capaz de bloquear totalmente a infiltração nas margens de cemento e apesar de não haver diferença estatisticamente significante entre os cinco grupos, verificou-se que as cavidades que permaneceram úmidas apresentaram uma maior quantidade de índice zero de infiltração.

Os sistemas de fixação resinosos têm sido objeto de estudo de vários autores $^{5,6,7,9,13,22,27,31,35,38,47,66,102}$. Assim, em 1996, SÖDERHOLM, REETZ ${ }^{83}$ relataram que estes sistemas são menos solúveis na cavidade oral que a maioria dos cimentos odontológicos e que associados aos resultados clínicos e laboratoriais alcançados, permitem sua crescente difusão. Além disso, salientaram que na fixação de incrustações, onde a espessura e a opacidade da restauração dificultam a difusão da luz, os agentes de fixação de eleição deveriam ser aqueles de polimerização dupla. Comentaram que o sucesso de uma fixação adesiva depende da união química com a superfície interna da restauração, que seria melhorada com o uso de um agente silano. Ressaltaram também, a importância da configuração cavitária (fator C) na contração de polimerização e na geração de estresse na interface adesiva.

Em 1996, SORENSEN; MUNKSGAARD ${ }^{85}$ avaliaram diversos sistemas adesivos quanto à possibilidade de redução ou eliminação de fendas na interface 
adesiva de incrustações de porcelana. Molares humanos foram incluídos em resina acrílica e preparados para receberem incrustações cilíndricas. Foram feitas moldagens com silicona de adição e a partir dos modelos obtidos, confeccionaramse as incrustações. Estas foram condicionadas com ácido fluorídrico e silanizadas. Doze sistemas adesivos foram utilizados e as incrustações fixadas com o agente de fixação Dual. Os espécimes foram armazenados em água e seccionados para serem examinados em um microscópio quanto à presença, localização e extensão das fendas resultantes da contração. Pôde-se observar um comportamento diferente entre os diversos sistemas adesivos e embora, alguns conseguissem diminuir substancialmente, nenhum deles foi capaz de eliminar totalmente as fendas resultantes da contração de polimerização.

A fim de comparar a infiltração marginal em restaurações adesivas, em 1996, HASANREISOGLU et al. ${ }^{34}$ realizaram um estudo com diversos materiais de uso direto e indireto. Cavidades MOD foram confeccionadas em 60 pré-molares humanos extraídos, sendo que uma margem cervical do preparo foi estabelecida em esmalte e a outra em dentina. As restaurações de resina composta de uso direto foram realizadas e aquelas de uso indireto foram fixadas com sistemas de fixação resinosos de acordo com as recomendações dos fabricantes. Os corpos-de-prova obtidos foram termociclados e imersos em solução de fucsina por 24 horas. Em seguida, estes foram lavados, seccionados no sentido mesiodistal e então, avaliados em um estereomicroscópio quanto à penetração do corante. As restaurações de uso direto infiltraram menos que as de uso indireto, porém todas tiveram maior infiltração quando as margens estavam localizadas em dentina. 
A evolução dos agentes de fixação resinosos conjuntamente com os sistemas adesivos permitiu a utilização mais segura das incrustações de porcelana, mas não foi capaz de eliminar totalmente a fenda marginal. Assim, em 1996, SORENSEN; MUNKSGAARD $^{86}$, mediram as fendas resultantes da contração de polimerização, após a fixação de incrustações. Foram realizadas cavidades cilíndricas padronizadas em molares humanos que foram moldadas para a confecção das incrustações. As cavidades foram tratadas com diferentes sistemas adesivos e as restaurações fixadas com os sistemas de fixação. Os espécimes foram seccionados e avaliados em um microscópio com aumento de $800 X$. Os autores ${ }^{86}$ observaram que nenhuma das combinações entre sistema adesivo e agente de fixação foi capaz de eliminar completamente a fenda, porém houve redução com alguns materiais utilizados.

A fim de elucidar alguns aspectos relacionados com a microinfiltração marginal, em 1997, ALANI; $\mathrm{TOH}^{2}$ realizaram uma revisão de literatura descrevendo as diversas metodologias empregadas. Dentre elas, podiam ser incluídas o uso de corantes, traçadores químicos, isótopos radioativos, pressão de ar, bactérias, microscopia eletrônica de varredura, cárie artificial e condutibilidade elétrica. A penetração de corantes foi citada como uma das técnicas mais utilizadas sendo que sua concentração pode variar entre 0,5 e 10\% e o tempo de imersão dos espécimes entre 4 e 72 horas. Como desvantagens desta técnica citaram a subjetividade da análise e a necessidade de destruição do espécime o que impediria um estudo longitudinal. Concluíram que todas as metodologias apresentam vantagens e desvantagens e nenhuma poderia ser considerada ideal. 
CHANA et al. ${ }^{13}$, em 1997, avaliaram a influência da espessura do agente de fixação na resistência à tração de espécimes cilíndricos de níquel-crômio. Os cimentos utilizados foram o Panavia Ex e o Panavia 21 e os testes foram conduzidos em uma máquina de testes universal. Os autores ${ }^{13}$ observaram que a espessura do cimento tinha uma relação inversamente proporcional à resistência à tração. Isto poderia ser explicado, em parte, pela formação de bolhas nas películas mais espessas que poderiam induzir a propagação de fendas com menor aplicação de força.

GEMALMAZ et al. ${ }^{29}$, em 1997, avaliaram a integridade marginal de incrustações de porcelana antes e após a fixação. Dez molares humanos extraídos foram preparados para receber incrustações MOD de porcelana. Os preparos foram moldados e sobre os modelos foram confeccionadas as restaurações. Foram obtidas moldagens do espaço existente entre a incrustação e o dente que foram analisadas em um microscópio. As incrustações foram então, fixadas com um sistema de fixação resinoso de dupla polimerização (Enforce) e seccionadas no sentido vestibulolingual e mesiodistal para a mensuração da fenda marginal, da espessura do agente de fixação e da discrepância horizontal. Os resultados mostraram uma desadaptação marginal média na margem oclusal antes e após a fixação de $71,83 \mu \mathrm{m}$ e $78,77 \mu \mathrm{m}$, respectivamente. Nas margens cervicais, os valores médios foram $105,6 \mu \mathrm{m}$ e $128,85 \mu \mathrm{m}$.

MELLO et al. ${ }^{52}$, em 1997, verificaram a influência da ciclagem mecânica no comportamento de oito sistemas adesivos. Cavidades de classe II, com término cervical em dentina, foram preparadas em 80 pré-molares superiores. Os dentes 
foram divididos em oito grupos e restaurados com diferentes sistemas adesivos e resinas compostas. Metade dos espécimes de cada grupo foi submetida à ciclagem mecânica e todos os espécimes foram imersos em solução de azul de metileno por 48 horas. Em seguida, foram limpos e seccionados no sentido mesiodistal para a análise da microinfiltração. Dentre os resultados obtidos, os autores ${ }^{52}$ ressaltaram que o sistema adesivo Syntac apresentou maior porcentagem de infiltração marginal nas paredes cervicais que o sistema adesivo Scotchbond Multi-Uso. Este fato foi mais acentuado após a ciclagem mecânica.

PASHLEY; CARVALHO ${ }^{62}$, em 1997, realizaram uma revisão de literatura, a fim de elucidar as características morfológicas da dentina e a sua relação com o processo adesivo. Dentre elas, ressaltaram que a principal característica morfológica da dentina é a sua estrutura rica em túbulos preenchida pelo fluido dentinário. Enfatizaram também a importância da interdifusão da resina na dentina intertubular e peritubular para se conseguir uma boa adesão dentinária.

Em 1997, PATEL; SAUNDERS; BURKE $^{65}$ verificaram a microinfiltração marginal de coroas de porcelana fixadas com três sistemas adesivos. Quarenta e cinco pré-molares extraídos foram divididos em três grupos de 15 dentes cada. Foram realizados preparos MOD padronizados com o término cervical em esmalte em uma das caixas e em dentina na outra. Após as moldagens das cavidades, as restaurações foram confeccionadas sobre modelos refratários, silanizadas e fixadas com os seguintes sistemas: (1)Scotchbond Multi-Purpose Plus/ 3M Ceramic Luting Kit; (2) Mirage ABC/FLC; (3) All-Bond 2/ Duolink. Todos os espécimes foram armazenados em água por duas semanas, termociclados e imersos em solução a 
$2 \%$ de azul de metileno. Realizaram-se cortes no sentido mesiodistal e os espécimes foram avaliados quanto à microinfiltração com o auxílio de uma lupa com aumento de 10X. Os dados obtidos foram submetidos à análise estatística e verificaram-se diferenças estatisticamente significantes entre os grupos com o término cervical em esmalte, porém não se observaram diferenças quando o término cervical foi estabelecido em dentina.

Em 1998, DICKENS; LIAO; REED ${ }^{19}$ tentaram estabelecer uma correlação entre dois testes de resistência ao cisalhamento e um teste de resistência à tração. Para tanto, utilizaram espécimes de dentina de molares humanos que foram tratados com dois diferentes sistemas adesivos: Scotchbond Multi-Purpose e um sistema experimental a base de acetona (P-One). Os materiais foram manipulados seguindo as recomendações dos fabricantes e uma resina composta foi colocada sobre a área adesiva e fotopolimerizada. Os corpos-de-prova foram armazenados em água por 24 horas a $23^{\circ} \mathrm{C}$ e por sete dias a $60^{\circ} \mathrm{C}$ para em seguida serem testados. Concluiu-se que não houve diferenças entre os dois sistemas adesivos utilizados. $O$ envelhecimento a $60^{\circ} \mathrm{C}$ resultou em um ligeiro decréscimo na resistência ao cisalhamento e uma diminuição acentuada na resistência à tração, porém não foi possível correlacionar os dados obtidos nos dois testes.

ROSENSTIEL; LAND; CRISPIN ${ }^{72}$, em 1998, relataram alguns aspectos importantes relacionados aos cimentos de uso odontológico e aos agentes de fixação resinosos. Ressaltaram que o cimento fosfato de zinco é considerado o cimento mais popularmente utilizado, tendo como principais desvantagens a solubilidade e a falta de adesão, e que estes problemas não estariam presentes com 
os sistemas de fixação resinosos. Dentre as propriedades destes sistemas, ressaltaram que sua biocompatibilidade estaria diretamente relacionada ao grau de conversão dos monômeros em polímeros. As causas de irritação pulpar e sensibilidade pós-operatória que ocorrem freqüentemente estariam associadas provavelmente a erros de técnica, como conseqüência de contaminação bacteriana ou ressecamento da dentina. Comentaram ainda, que um agente de fixação ideal deveria prover uma união estável entre a estrutura dentária e a restauração, e através da sua resiliência, aumentar a resistência à fratura da restauração.

A correlação entre a força de cisalhamento e a microinfiltração marginal foi avaliada em 1998, por SILVA et al. ${ }^{79}$. Para esta pesquisa foram selecionados 40 dentes humanos extraídos. Os sistemas adesivos utilizados foram Scotchbond Multi Purpose Plus; Prime \& Bond 2.0; Single Bond Dental Adhesive System; Multi Bond Alpha. Para o teste de cisalhamento utilizaram-se 20 dentes divididos em quatro grupos. Estes foram inseridos em um molde de resina, seccionados na sua superfície oclusal e abrasionados com lixas de granulação decrescente. Cilindros de resina composta com $6 \mathrm{~mm}$ de diâmetro foram unidos à dentina com os respectivos sistemas adesivos. Os corpos-de-prova foram armazenados em solução fisiológica por 30 dias e os testes realizados em uma máquina de testes universal com uma velocidade de $1 \mathrm{~mm} / \mathrm{min}$. Para os testes de microinfiltração, cavidades de classe $\mathrm{V}$ foram realizadas com dimensões padronizadas. Os sistemas adesivos foram aplicados de acordo com as recomendações dos fabricantes e a resina composta inserida e polimerizada. Os espécimes foram então, recobertos com esmalte de unha, deixando $1 \mathrm{~mm}$ de superfície livre em torno da restauração, e imersos por 24 horas em solução de Rodamina B. Em seguida, os corpos-de-prova foram limpos e 
seccionados para a observação em uma lupa estereoscópica com aumento de quatro vezes. Dentre os sistemas adesivos testados, o Scotchbond Multi Purpose Plus mostrou os menores valores de resistência adesiva, porém não apresentou infiltração do corante em nenhum dos espécimes.

TRAITEL $^{95}$, em 1998, testou a resistência à tração de restaurações de porcelana fixadas com dois sistemas resinosos (Enforce e Dualcement). Oito prémolares hígidos foram inseridos em blocos de resina autopolimerizável e em seguida preparados. As restaurações de porcelana foram confeccionadas e fixadas aos preparos com os respectivos sistemas. Elas apresentavam uma forma retangular para que pudessem se adaptar às garras de tracionamento do Sistema Expansor EMIC. Após a análise dos resultados observaram-se valores médios de resistência à tração de $36,91 \mathrm{kgf} / \mathrm{cm}^{2}$ para o Sistema Enforce e $40,59 \mathrm{kgf} / \mathrm{cm}^{2}$ para o Dualcement.

ZARAGOZA VELÁSQUEZ109, em 1998, avaliou a resistência ao cisalhamento de braquetes ortodônticos fixados ao esmalte, porcelana e ligas metálicas de níquelcrômio e cobre-alumínio com os sistemas de fixação Enforce e Concise Ortodôntico. Foram confeccionados 20 corpos-de-prova para cada grupo e como grupo controle foram utilizados 20 pré-molares. A superfície do substrato foi tratada e os braquetes metálicos fixados com os respectivos sistemas. Os corpos-de-prova foram armazenados em ambiente úmido a $37^{\circ} \mathrm{C}$ por uma hora e submetidos aos testes de cisalhamento na máquina de ensaios Kratos a uma velocidade de $0,5 \mathrm{~mm} / \mathrm{min}$. Os resultados mostraram uma força de união do sistema Enforce superior ao sistema Concise para todos os substratos empregados, porém sem diferença estatisticamente significante. 
3-PROPOSIÇÃO 


\section{3- PROPOSIÇÃO}

Tendo em vista a possível influência dos sistemas adesivos e dos agentes de fixação resinosos de dupla polimerização no comportamento clínico das incrustações de porcelana, propusemo-nos a:

- avaliar a resistência adesiva, por meio de testes de cisalhamento, de porcelana fixada à dentina com três diferentes sistemas de dupla polimerização;

- determinar o tipo de fratura ocorrido após a realização dos testes de resistência adesiva;

- avaliar a microinfiltração marginal em incrustações de porcelana fixadas com três diferentes sistemas de dupla polimerização. 
4-MATERIAL E MÉTODOS 


\section{4- MATERIAL E MÉTODOS}

\section{1- Considerações gerais}

Foram selecionados 30 pré-molares e 30 molares hígidos ou com pequenas cáries, que apresentassem tamanhos coronários semelhantes. Após a exodontia, os dentes foram limpos cuidadosamente com curetas periodontais (Hu-Friedy, Chicago, IL, USA) e polidos com escovas tipo Robinson (Viking, Barueri, SP, Brasil) montadas em micromotor e embebidas em pasta de pedra-pomes e água. Todos os dentes foram armazenados em solução fisiológica a $9 \%$ em refrigerador a $5^{\circ} \mathrm{C}$ até o momento da confecção dos corpos-de-prova. Estes foram realizados em um período inferior a seis meses após a exodontia.

Os sistemas utilizados para a fixação adesiva encontram-se na Tabela 1 e são ilustrados na Figura 1. Estes sistemas foram empregados segundo as recomendações dos respectivos fabricantes e polimerizados com a unidade fotopolimerizadora Optilux (Demetron Research Corporation, E.U.A.). A potência da unidade fotopolimerizadora foi verificada, após a polimerização de cinco espécimes com o auxílio de um radiômetro (Demetron Research Corporation, E.U.A.). 
TABELA 1 - Sistemas de fixação adesiva avaliados e seus respectivos fabricantes e números de lote

\begin{tabular}{|c|c|c|c|c|c|}
\hline Grupo & $\begin{array}{c}\text { Sistema de } \\
\text { Fixação }\end{array}$ & $\begin{array}{l}\text { Agente de } \\
\text { Fixação }\end{array}$ & $\begin{array}{l}\text { Sistema } \\
\text { Adesivo }\end{array}$ & Fabricante & Lote \\
\hline 1 & Enforce & Enforce & Probond & $\begin{array}{l}\text { Dentsply Ind. } \\
\text { e Com. Itda }\end{array}$ & 27561 \\
\hline 2 & $\begin{array}{c}\text { Scotchbond } \\
\text { Resin } \\
\text { Cement }\end{array}$ & $\begin{array}{c}\text { Scotchbond } \\
\text { Resin } \\
\text { Cement }\end{array}$ & $\begin{array}{c}\text { Scotchbond } \\
\text { Multi-Uso } \\
\text { Plus }\end{array}$ & 3M do Brasil & 19951121 \\
\hline 3 & $\begin{array}{c}\text { Variolink } \\
\text { Professional } \\
\text { Set }\end{array}$ & Variolink & $\begin{array}{c}\text { Syntac } \\
\text { Primer/ } \\
\text { Syntac } \\
\text { Adhesive }\end{array}$ & Vivadent Ets. & 806400 \\
\hline
\end{tabular}



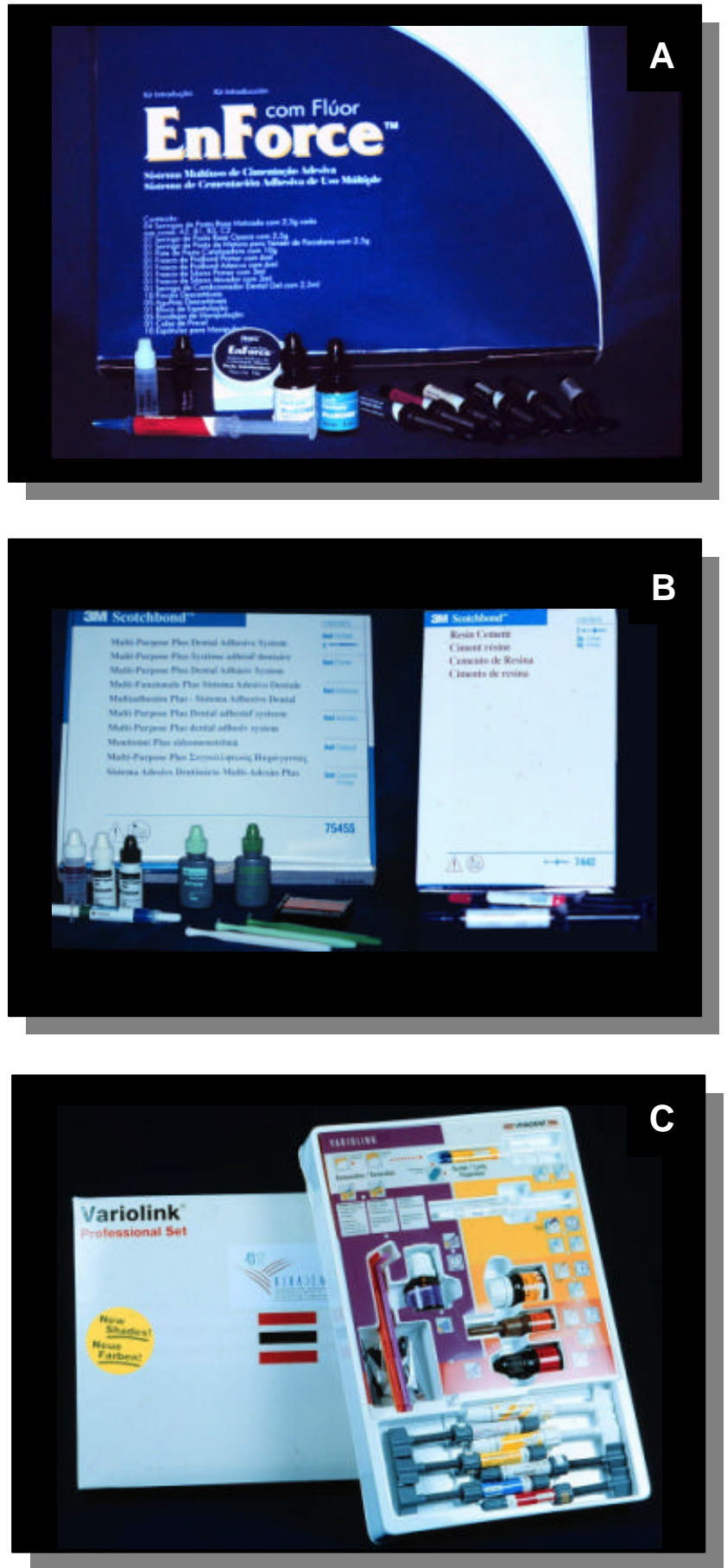

FIGURA 1- Sistemas de fixação adesiva dedupla polimerização. A - Sistema de Fixação Enforce; B - Sistema de fixação Scotchbond Multi-Uso Plus/Scotchbond Resin Cement; C - Sistema de Fixação Variolink Professional Set 


\section{2- Resistência adesiva ao cisalhamento}

\subsection{1- Obtenção dos corpos-de-prova}

Para esta parte do experimento foram utilizados 30 molares que tiveram suas raízes seccionadas e foram incluídos em cilindros de PVC de 3/4 de polegada (Tigre do Brasil) com resina acrílica quimicamente ativada (Artigos Odontológicos Clássico, S.P., Brasil). A superfície oclusal, que dispunha-se paralelamente à base do cilindro, foi desgastada com pontas diamantadas cilíndricas número 4103 (K.G.Sorensen, S.P., Brasil) montada em alta rotação sob refrigeração água/ar até a completa remoção do esmalte. Cada ponta diamantada foi trocada após o desgaste de cinco dentes. Em seguida, a superfície oclusal foi abrasionada com lixas em ordem decrescente de granulação 180, 320 e 600 respectivamente, procurando sempre deixar a estrutura dentária $2 \mathrm{~mm}$ acima do nível da resina (Figura 2). Cilindros de porcelana para dentina (Duceram Metalkeramik, Ducera, Dental Gesellschaft mbH, Germany), na cor A2, medindo aproximadamente 5,4mm de diâmetro e 7,0mm de comprimento foram confeccionados por um técnico em prótese dentária, de acordo com as instruções do fabricante. As superfícies a serem aderidas dos cilindros de porcelana foram jateadas com partículas de óxido de alumínio com partículas de $50 \mu \mathrm{m}$, no aparelho microetcher (Danville Engineering, CA, USA) por cinco segundos a uma distância de aproximadamente $5 \mathrm{~cm}$. A pressão utilizada no aparelho foi de 80l/pol ${ }^{2}$. Os corpos-de-prova foram divididos aleatoriamente em três grupos e posteriormente fixados com os respectivos sistemas de fixação. 


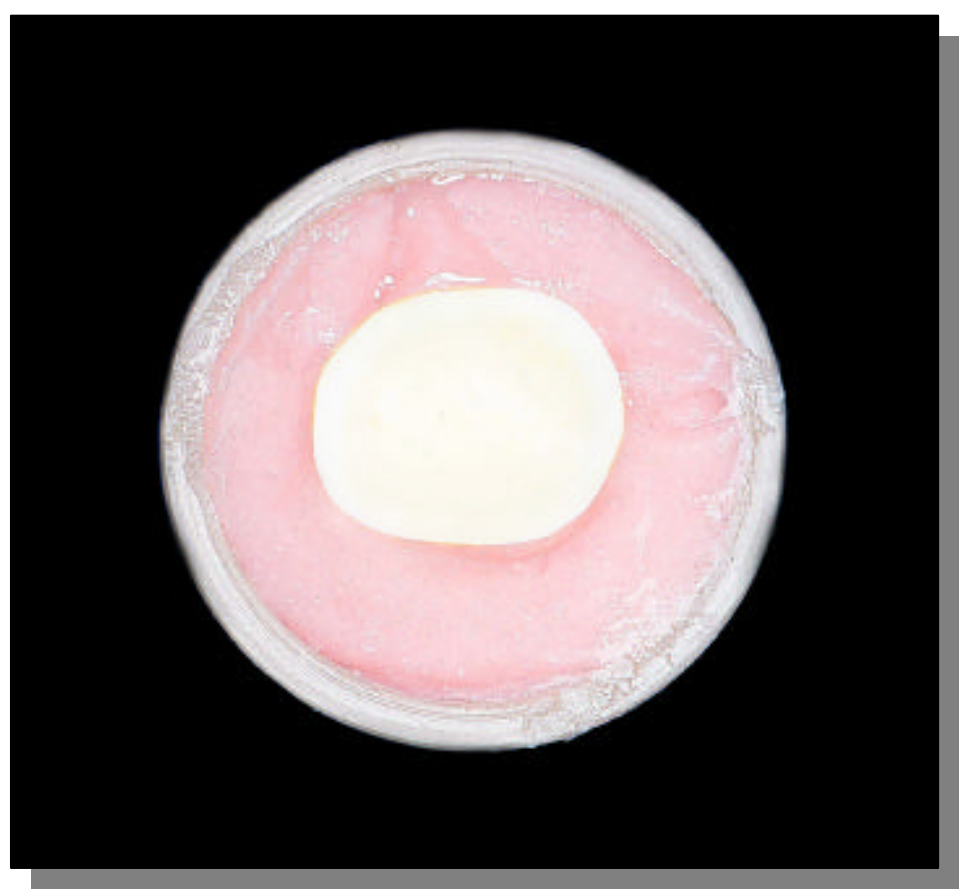

FIGURA 2 - Corpo-de-prova fixado ao cilindro de PVC com resina acrílica quimicamente polimerizável

\subsection{2- Técnica de fixação}

\subsubsection{1- Grupo 1 (Sistema de fixação Enforce)}

A superfície da porcelana a ser aderida foi condicionada com ácido fluorídrico a $8 \%$ em gel (condicionador de porcelanas Dentsply, Dentsply Industria e Comércio Ltda, Petrópolis, RJ, Brasil) por quatro minutos, seguido de lavagem em água corrente por 30 segundos e secagem por cinco segundos com jatos de ar. Em um pote Dappen foram dispensadas uma gota de Silano Ativador e uma gota de Silano Primer, sendo misturadas por 15 segundos e a supefície do pote tampada com uma placa de vidro para evitar sua evaporação. A mistura permaneceu intacta por cinco minutos e em seguida foi aplicada uma fina camada sobre a superfície condicionada 
da porcelana. Esta foi seca com jatos de ar. Uma segunda camada foi reaplicada com os mesmos cuidados. Após o tratamento da superfície da porcelana, iniciou-se o tratamento da dentina. Uma tira de fita isolante (3M do Brasil, Sumaré S.P., Brasil) foi perfurada, sendo que o orifício apresentava um diâmetro de 5,4mm. Esta foi cuidadosamente fixada sobre a superfície dentinária permitindo somente a exposição da área a ser tratada. A dentina delimitada foi condicionada com ácido fosfórico a 37\% sob a forma de gel (Caulk Tooth Conditioner Gel) por 15 segundos e em seguida lavada com água por 30 segundos. Os excessos de água foram removidos com papel absorvente, sem contudo ressecá-la. Aplicou-se o Probond Primer, mantendo a superfície dentinária umedecida por 30 segundos, e em seguida secou-se por cinco segundos com jatos de ar. Uma camada de Probond Adesivo foi aplicada seguindo-se a remoção dos excessos com um pincel e sua fotopolimerização por dez segundos. Partes iguais de pasta base e pasta catalisadora do agente de fixação, na cor A2 foram dispensadas em um bloco para manipulação e espatuladas por 20 segundos, com o auxílio de um instrumento plástico, até sua completa homogeneização e uma fina camada foi aplicada sobre a superfície tratada da porcelana. O cilindro de porcelana foi posicionado na área da dentina demarcada e tratada, e sobre este foi aplicada pressão digital. Os excessos foram removidos com o auxílio de uma sonda exploradora número 5 e a fotopolimerização realizada por 60 segundos em quatro pontos eqüidistantes na base do cilindro. $\mathrm{O}$ cilindro de porcelana fixado à dentina pode ser visto na Figura 3. 


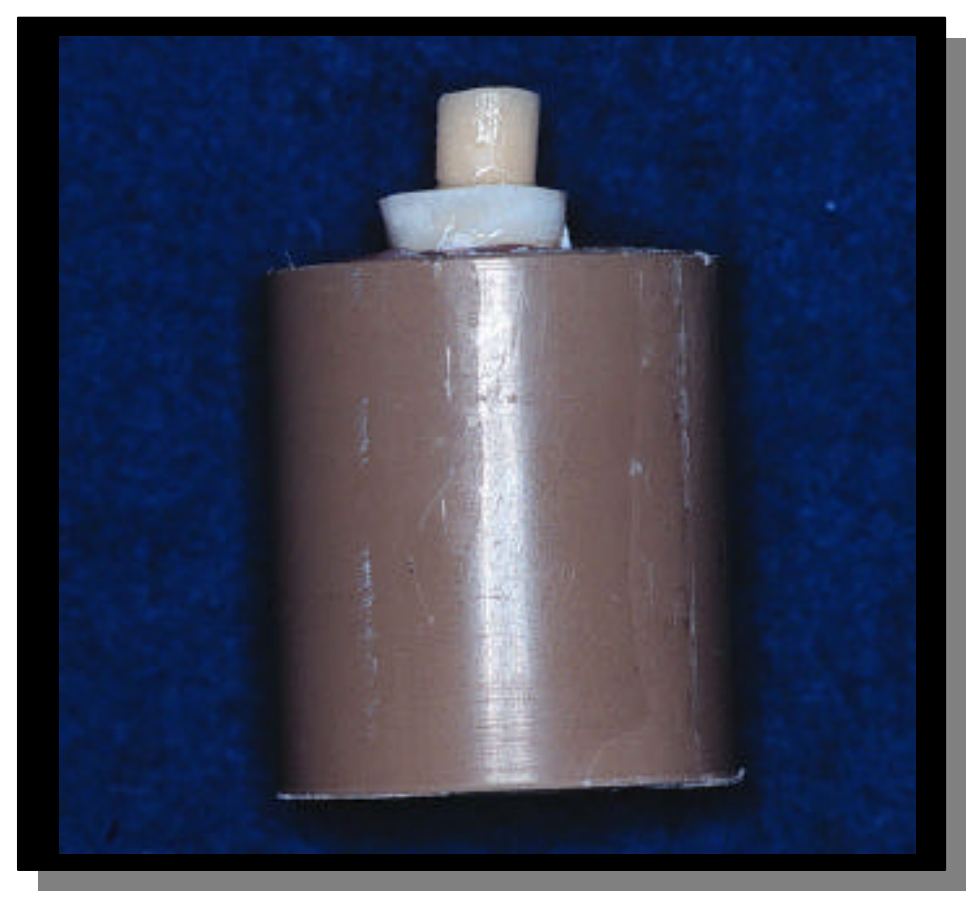

FIGURA 3 - Cilindro de porcelana fixado à dentina do espécime

\subsubsection{2- Grupo 2 (Sistema de fixação Scotchbond Resin Cement / Scotchbond Multi Uso Plus)}

O condicionamento da superfície da porcelana a ser fixada foi feito com ácido fluorídrico a $8 \%$ em gel(Condicionador de porcelanas Dentsply) por quatro minutos e em seguida lavada por 30 segundos e seca por cinco segundos com jatos de ar. Sobre esta, aplicou-se o Scotchbond Ceramic Primer, o qual foi seco com ar por cinco segundos. Da mesma forma como descrita para o grupo 1, a superfície dentinária foi delimitada com uma tira de fita isolante (3M do Brasil, Sumaré S.P., Brasil) com uma perfuração apresentando $5,4 \mathrm{~mm}$ de diâmetro. A dentina foi condicionada com ácido fosfórico a 37\% (Scotchbond, 3M do Brasil) sob a forma de gel por 15 segundos, lavada por 30 segundos e os excessos de umidade removidos com papel absorvente, mantendo-se a superfície úmida. Em seguida, aplicou-se o 
Scotchbond Multi-Uso Plus Activator e secou por cinco segundos com jatos de ar. $\mathrm{O}$ Primer Scotchbond Multi-Uso Plus também foi aplicado e seco por cinco segundos. O catalisador (Scotchbond Catalist) foi então, aplicado tanto na superfície dentinária quanto na superfície da porcelana. Partes iguais do agente de fixação Scotchbond Resin Cement foram espatuladas por 20 segundos, com um instrumento plástico, até a completa homogeneização. Este foi aplicado sobre a superfície tratada da porcelana e o cilindro foi posicionado sobre a área delimitada e tratada da dentina. Aplicou-se uma pressão digital para o seu assentamento, removeram-se os excessos do agente de fixação com o auxílio de uma sonda exploradora número 5 e então procedeu-se a fotopolimerização por 60 segundos em quatro pontos eqüidistantes na base do cilindro de porcelana.

\subsubsection{3- Grupo 3 (Sistema de fixação Variolink Professional Set)}

Condicionou-se a superfície da porcelana por quatro minutos com ácido fluorídrico em gel a 8\% (Condicionador de porcelana Dentsply). Em seguida, esta foi lavada por 30 segundos e seca por cinco segundos com jatos de ar. Procedeu-se à silanização através da aplicação, com um pincel, de uma camada do silano Monobond S. Este permaneceu intacto por 60 segundos e em seguida, foi seco com jatos de ar. Uma tira de fita isolante (3M do Brasil, Sumaré S.P., Brasil) perfurada com 5,4mm de diâmetro foi posicionada sobre a dentina. Sobre a área de dentina demarcada, realizou-se o condicionamento com ácido fosfórico a 37\% (Email Preparator GS, Vivadent Ets., Liechtenstein) por 15 segundos, seguido de lavagem abundante com água e remoção do excesso de umidade. O Syntac Primer foi aplicado, com o auxílio de um pincel, sobre a dentina por 15 segundos antes de ser 
seca com ar. Sobre este, aplicou-se o Syntac Adhesive e deixou-o intacto por dez segundos. Em seguida, secou-se com jatos de ar. Uma fina camada de Heliobond foi pincelada sobre a superfície dentinária e sobre a porcelana condicionada e silanizada. Partes iguais da pasta base e catalisadora do agente de fixação Variolink, na cor amarela, foram espatuladas com um instrumento plástico por 20 segundos, até sua completa homogeneização. $O$ agente de fixação foi aplicado à porcelana e posicionado sobre a dentina tratada. Aplicou-se uma pressão digital, removeram-se os excessos das margens com uma sonda exploradora número $5 \mathrm{e}$ realizou-se a polimerização por 60 segundos em quatro pontos eqüidistantes na base do cilindro de porcelana.

\subsection{3- Testes de resistência adesiva}

Após a confecção dos corpos-de-prova, aguardaram-se dez minutos e depois, estes foram armazenados em água destilada a $37^{\circ} \mathrm{C}$ por 24 horas. Decorrido este tempo, os corpos-de-prova foram adaptados a um dispositivo metálico com uma abertura para o posicionamento dos cilindros de PVC. Com o auxílio de um parafuso, o cilindro foi fixado e o conjunto posicionado na máquina de testes universal Kratos (Kratos Equipamentos S.A., S.P., Brasil). Esta máquina trabalhou com uma célula de carga número 2 e uma velocidade de $0,5 \mathrm{~mm} / \mathrm{min}$. A força de cisalhamento foi aplicada por meio de uma haste em forma de cunha e espessura de 0,5mm na base da interface adesiva (Figura 4). Os valores de resistência adesiva foram registrados em Kgf, transformados em MPa e submetidos à análise estatística.

A análise do tipo de fratura foi realizada por meio de uma lupa (Neitz BL, Neitz Instruments Co., Ltd, Tokyo, Japan) com aumento de dez vezes. A fratura ocorrida 
foi classificada em adesiva entre a dentina e o agente de fixação, adesiva entre o agente de fixação e a porcelana, coesiva da porcelana, coesiva da dentina e mista. A falha foi considerada adesiva quando ocorria o rompimento na interface adesiva. A falha coesiva envolvia somente a fratura do substrato envolvido, seja ele porcelana ou dentina e a falha mista ocorria quando dois ou mais substratos estavam envolvidos.

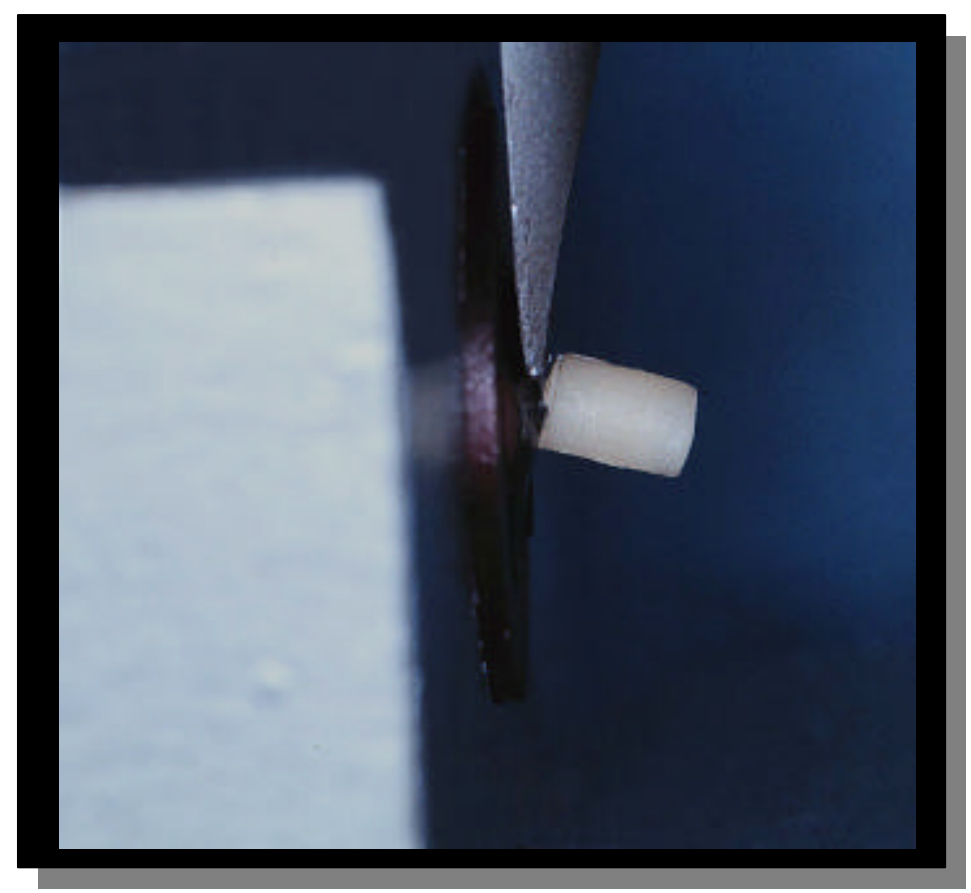

FIGURA 4 - Corpo-de-prova fraturado após a aplicação da força de cisalhamento na base adesiva 


\section{3- Microinfiltração marginal}

\subsection{1- Obtenção dos corpos-de-prova}

Nesta parte da pesquisa foram utilizados 30 pré-molares superiores humanos. Todos os dentes foram analisados, com o auxílio de uma lupa com aumento de dez vezes (Neitz BL, Neitz Instruments Co., Ltd, Tokyo, Japan), quanto à presença de trincas ou defeitos que pudessem interferir na qualidade da restauração ou na penetração do corante. Cavidades padronizadas MOD para incrustação de porcelana foram confeccionadas por um único operador com pontas diamantadas troncocônicas de extremo arredondado número 4138 (K.G.Sorensen, S.P. Brasil) em alta rotação sob refrigeração água/ar. Cada ponta diamantada foi substituída após a realização de três preparos. As cavidades recebiam um refinamento com uma ponta diamantada de granulação fina número 2135F (K.G.Sorensen, S.P. Brasil) montada em micromotor e recortadores de margem gengival números 28 e 29 . Ao término, as cavidades apresentavam as seguintes características: profundidade da caixa oclusal de $2 \mathrm{~mm}$, istmo com distância vestibulolingual igual a $2 \mathrm{~mm}$, paredes com divergência no sentido proximoproximal e cervicoclusal de aproximadamente 100, ângulos internos arredondados, ângulo cavo-superficial nítido e sem bisel ${ }^{67}$. Todas as cavidades apresentavam o término cervical localizado em esmalte (Figura 5). 

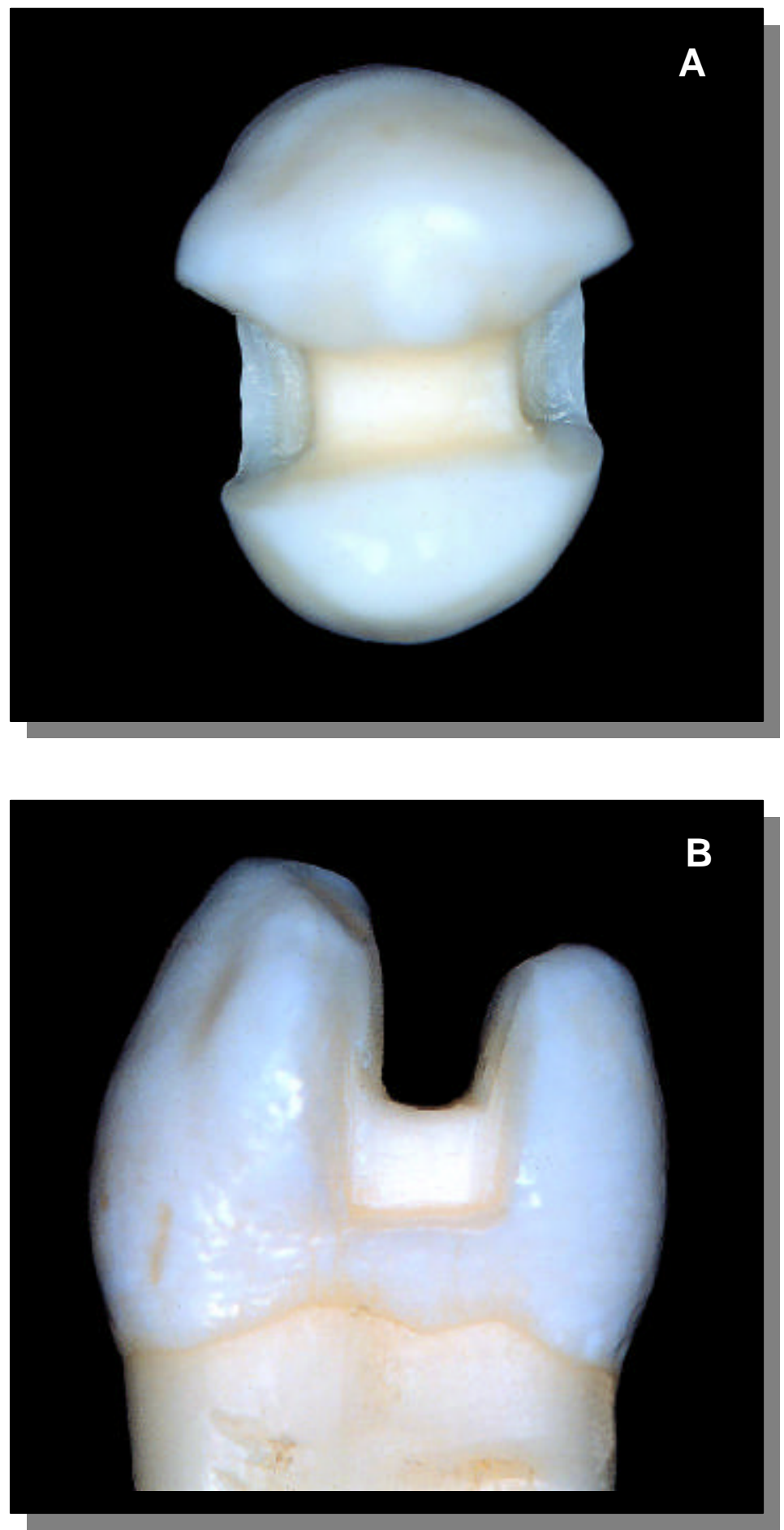

FIGURA 5 - Cavidade MOD para incrustação de porcelana realizada em um prémolar superior. A - vista oclusal; B - vista proximal 
As cavidades foram moldadas uma a uma com silicona de adição (Provil, Bayer Dental, Germany), seguindo a técnica da dupla moldagem. Sobre os moldes, foi vertido revestimento refratário Superfit (Feuerfestes Stumpfmaterial refractory material) na proporção de $30 \mathrm{~g}$ de pó para $10,5 \mathrm{~g}$ de líquido. Estes foram manipulados a vácuo por 45 segundos. Após a presa, os modelos refratários foram analisados com relação à cópia de detalhes. As margens foram delimitadas com lápis dermográfico e os troquéis levados ao forno a $1040^{\circ} \mathrm{C}$ para a sinterização. Após, os troquéis foram imersos em líquido saturador, para a eliminação dos gases de amônia que se formam no interior do revestimento. Foi aplicado o conector (Connector Paste, Ducera, Dental Gesellschaft mbH, Germany), e novamente foram levados ao forno a $970^{\circ} \mathrm{C}$ a vácuo por um minuto, para em seguida ser aplicada a porcelana de alta fusão Duceram (Ducera, Dental Gesellschaft mbH, Germany) para dentina, na cor A2. Todas as restaurações foram realizadas por um técnico em prótese dental. Para a queima da porcelana, foi utilizado o programa 059 do forno EDG (EDG Equipamentos e Controles Ltda, São Paulo, Brasil). Cada camada foi aplicada no troquel e inserida no forno à temperatura de $650^{\circ} \mathrm{C}$. Em seguida, a temperatura foi elevada a $940^{\circ} \mathrm{C}$ com velocidade de $56^{\circ} \mathrm{C}$ por minuto, permanecendo nesta temperatura por 30 segundos a vácuo. Foram realizadas três queimas para cada restauração. Terminada a última queima da porcelana, as incrustações foram glazeadas utilizando-se o programa 077 do forno EDG. A incrustação foi inserida no forno a $650^{\circ} \mathrm{C}$ permanecendo por dez minutos. Em seguida, a temperatura foi elevada a $890^{\circ} \mathrm{C}$ sem vácuo, com velocidade de $56^{\circ} \mathrm{C}$ por minuto, permanecendo nesta temperatura por três minutos. Todas as incrustações foram analisadas quanto à fidelidade marginal com o auxílio de uma lupa com aumento de dez vezes (Neitz BL, Neitz Instruments Co., Ltd, Tokyo, Japan). O troquel refratário foi destruído com 
o auxílio de brocas esféricas montadas em peça de mão. As superfícies internas das incrustações foram jateadas por cinco segundos com partículas de óxido de alumínio de 50 $\mu \mathrm{m}$, utilizando o aparelho microetcher (Danville Engineering, CA, USA) com pressão de $80 \mathrm{l} / \mathrm{pol}^{2}$ e uma distância de $5 \mathrm{~cm}$. Em seguida, as restaurações foram posicionadas sobre os respectivos dentes e os ajustes internos foram realizados. Para uma melhor visualização dos locais de interferência no assentamento das incrustações, utilizou-se um carbono líquido (Super Filme Kota, Kota Indústria e Comércio Itda, São Paulo, Brasil). As incrustações foram novamente analisadas com o auxílio de uma lupa e uma sonda exploradora número 5 quanto à integridade marginal e divididas aleatoriamente em três grupos de dez espécimes cada. As incrustações que apresentassem uma desadaptação marginal inicial capaz de permitir a penetração da ponta da sonda exploradora eram dispensadas.

\subsection{2- Técnica de fixação}

\subsubsection{1- Grupo 1 (Sistema de fixação Enforce)}

Cada incrustação foi protegida externamente com cera utilidade (Polidental Indústria e Comércio Itda, São Paulo, Brasil) e condicionada internamente com ácido fluorídrico em gel a $8 \%$ (Condicionador de porcelana Dentsply) por quatro minutos. Depois, esta foi lavada em água corrente por 30 segundos e seca por cinco segundos com jatos de ar. Foram dispensadas, em um pote Dappen, uma gota de Silano Ativador e uma gota de Silano Primer e misturadas por 15 segundos. A supefície do pote foi tampada com uma placa de vidro para evitar sua evaporação. A mistura permaneceu intacta por cinco minutos para em seguida ser aplicada uma 
fina camada sobre a superfície interna da incrustação. Esta foi seca com jatos de ar e uma segunda camada foi reaplicada com os mesmos cuidados. Após o tratamento da superfície da porcelana, iniciou-se o tratamento da superfície dentária. Condicionou-se o esmalte das margens do preparo com ácido fosfórico a 37\% sob a forma de gel (Caulk Tooth Conditioner Gel) por 30 segundos e a dentina por 15 segundos. A cavidade foi lavada com água por 30 segundos e os excessos removidos com papel absorvente, sem contudo ressecar a dentina. Aplicou-se o Probond Primer, mantendo a superfície dentinária umedecida por 30 segundos, e em seguida secou-se por cinco segundos com jatos de ar. Uma camada de Probond Adesivo foi aplicada seguindo-se a remoção dos excessos com um pincel e sua fotopolimerização por dez segundos. Partes iguais de pasta base e pasta catalisadora do agente de fixação, na cor A2 foram dispensadas em um bloco para manipulação e espatuladas por 20 segundos, com o auxílio de um instrumento plástico, até sua completa homogeneização e uma fina camada foi aplicada à superfície interna da incrustação. A incrustação foi posicionada na cavidade e aplicou-se pressão digital. Os excessos foram removidos com o auxílio de uma sonda exploradora número 5 e a fotopolimerização realizada por meio de uma unidade fotopolimerizadora por 60 segundos em cada superfície. Inicialmente foi realizada a polimerização através das superfícies proximais, seguida das superfícies vestibular e lingual e concluída pela superfície oclusal. As incrustações fixadas aos dentes preparados podem ser visualizadas na Figura 6. 


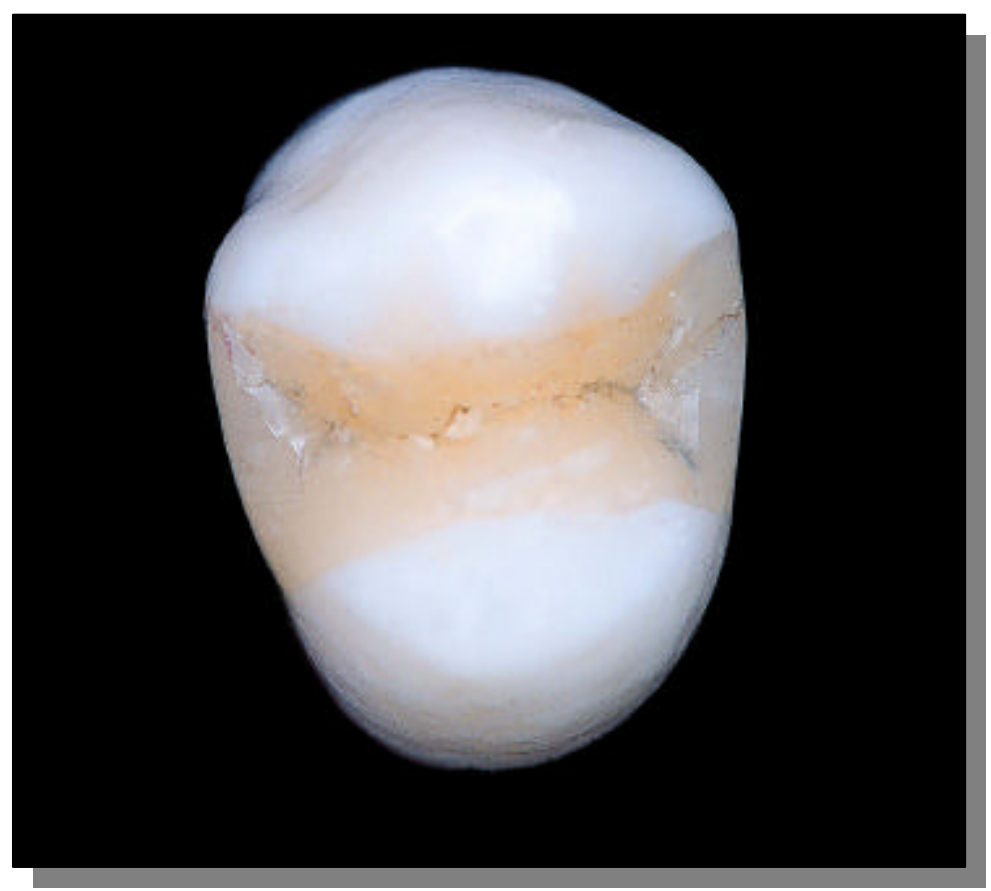

FIGURA 6 - Incrustação de porcelana fixada com agente de fixação resinoso de dupla polimerização

\subsubsection{2- Grupo 2 (Sistema de fixação Scotchbond Resin Cement / Scotchbond Multi Uso Plus)}

A superfície externa de cada incrustação foi protegida com cera utilidade (Polidental Indústria e Comércio Itda, São Paulo, Brasil) e a superfície interna foi condicionada com ácido fluorídrico em gel a 8\% (Condicionador de porcelana Dentsply) por quatro minutos. As incrustações foram lavadas em água corrente por 30 segundos e secas por cinco segundos com jatos de ar. Sobre esta superfície condicionada, aplicou-se o Scotchbond Ceramic Primer, o qual foi seco com ar por cinco segundos. O esmalte circundade à cavidade foi condicionado com ácido fosfórico a 37\% (Scotchbond, 3M do Brasil) sob a forma de gel por 30 segundos e a dentina por 15 segundos, e em seguida a cavidade foi lavada por 30 segundos e os 
excessos de umidade removidos com papel absorvente, mantendo-se a superfície dentinária úmida. Sobre a estrutura dentária, aplicou-se o Scotchbond Multi-Uso Plus Activator que foi seco por cinco segundos com jatos de ar. O Primer Scotchbond Multi-Uso Plus também foi aplicado e seco por cinco segundos. O catalisador (Scotchbond Catalist) foi então, aplicado tanto no dente quanto na superfície interna da incrustação. Partes iguais do agente de fixação Scotchbond Resin Cement foram espatuladas por 20 segundos, com um instrumento plástico, até a completa homogeneização. Este foi inserido na superfície interna da incrustação e então posicionada à cavidade. Aplicou-se uma pressão digital para o seu assentamento, removeram-se os excessos do agente de fixação com o auxílio de uma sonda exploradora número 5 e então procedeu-se a fotopolimerização por 60 segundos em cada superfície, começando pelas superfícies proximais, seguida das superfícies vestibular e lingual e concluída pela superfície oclusal.

\subsubsection{3- Grupo 3 (Sistema de fixação Variolink Professional Set)}

Protegeu-se a superfície externa das incrustações com cera utilidade (Polidental Indústria e Comércio Itda, São Paulo, Brasil) e condicionou-se a superfície interna com ácido fluorídrico em gel a 8\% (Condicionador de porcelana Dentsply) por quatro minutos. As incrustações foram lavadas em água corrente por 30 segundos e secas por cinco segundos com jatos de ar. As incrustações foram silanizadas por meio da aplicação, com um pincel, de uma camada do silano Monobond S. Este permaneceu intacto por 60 segundos e em seguida, foi seco com jatos de ar. Realizou-se o condicionamento com ácido fosfórico a 37\% (Email Preparator GS, Vivadent Ets., Liechtenstein) por 30 segundos no esmalte e 15 
segundos na dentina, seguido de lavagem abundante com água e secagem com suaves jatos de ar. O Syntac Primer foi aplicado, com o auxílio de um pincel, à estrutura dentária por 15 segundos antes de ser seco com ar. Sobre este, aplicou-se o Syntac Adhesive e deixou-o intacto por dez segundos. Em seguida, secou-se com jatos de ar. Uma fina camada de Heliobond foi pincelada sobre a estrutura dentária e sobre a superfície interna da incrustação de porcelana condicionada e silanizada. Partes iguais da pasta base e catalisadora do agente de fixação Variolink, na cor amarela, foram espatuladas com um instrumento plástico por 20 segundos, até sua completa homogeneização. O agente de fixação foi inserido na parte interna da incrustação e esta foi posicionada sobre a cavidade. Aplicou-se uma pressão digital, removeram-se os excessos das margens da restauração com uma sonda exploradora número 5 e realizou-se a polimerização por 60 segundos em cada superfície, começando pelas superfícies proximais, seguida das superfícies vestibular e lingual e concluída pela superfície oclusal.

\subsection{3- Ciclagem térmica}

Após a fixação das incrustações, aguardaram-se dez minutos e então, os corpos-de-prova foram armazenados em água destilada a $37^{\circ} \mathrm{C}$ por 24 horas. Posteriormente, foi dado o acabamento com pontas Enhance (Dentsply Indústria e Comércio Itda, Petrópolis, R.J., Brasil) e discos Sof-flex de granulação fina (3M do Brasil, Sumaré, SP, Brasil).

Para evitar que houvesse a penetração do corante pelo ápice dos dentes, estes foram preparados com brocas cone invertido número 35 (KG Sorensen, S.P. Brasil) e duas camadas de verniz Copalite (Cooley \& Cooley Itd., Houston, Texas, E.U.A.) foram aplicadas e secas com jatos de ar, para em seguida serem obturados 
com amálgama (Velvalloy, S.S. White Artigos Dentários Itda, Rio de Janeiro, R.J., Brasil). Após, os dentes foram cobertos com duas camadas de esmalte de unha (Colorama, Com. Exp. Ind. Itda, São Paulo, S.P., Brasil) deixando apenas $1 \mathrm{~mm}$ livre em torno das margens da restauração (Figura 7).

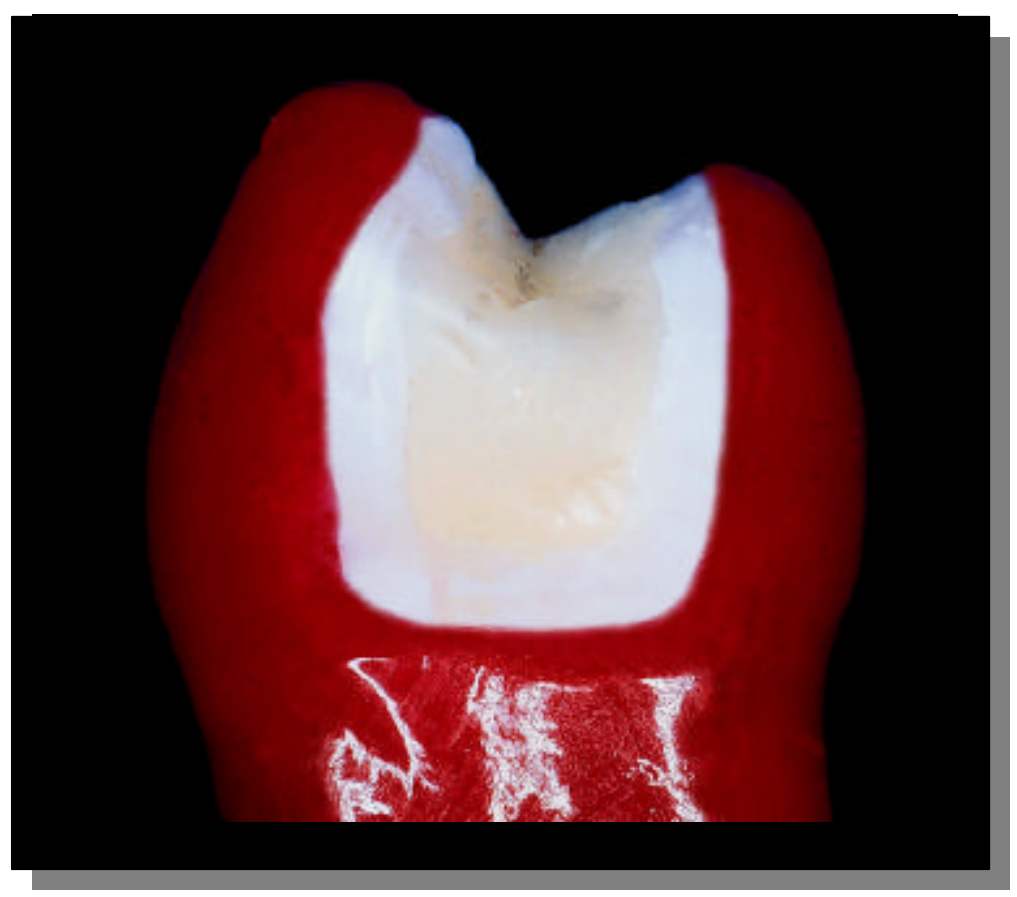

FIGURA 7 - Corpo-de-prova coberto com esmalte de unha deixando apenas $1 \mathrm{~mm}$ livre em torno da restauração

Em seguida, os espécimes foram armazenados em água destilada a $37^{\circ} \mathrm{C}$ por uma hora e termociclados em um aparelho específico desenvolvido pelo departamento de Materiais Dentários da Faculdade de Odontologia da Universidade de São Paulo e pela Ética Equipamentos Científicos. A ciclagem térmica foi realizada em água destilada num total de 500 ciclos com temperatura variando entre $5^{\circ} \mathrm{C} \pm$ $3^{\circ} \mathrm{C}$ e $55^{\circ} \mathrm{C} \pm 3^{\circ} \mathrm{C}$ e tempos de imersão de 15 segundos em cada banho. Terminada 
a ciclagem térmica, os dentes foram imersos em solução de fucsina básica a $0,5 \%$ por 24 horas, e em seguida lavados em água corrente por três horas.

\subsection{4- Seccionamento dos dentes e método de avaliação}

Todo o esmalte de unha foi eliminado com o auxílio de lâminas de bisturi. Os dentes foram limpos em um torno para polimento (Nevoni, Fábrica nacional de motores monofásicos, São Paulo, S.P., Brasil) e os dois terços radiculares foram seccionados. Os corpos-de-prova foram incluídos em resina acrílica autopolimerizável transparente Resapol T-208 (Difibra Com. de Prod. p/ Fiberglass Ltda., São Paulo, SP, Brasil) e seccionados na máquina de cortes EXTEC modelo 1010 (Excel Technologies Inc., Enfield, Connecticut, USA), no sentido mesiodistal, seguindo o longo eixo do dente. Foram obtidas três secções de 0,5mm cada. Três examinadores previamente calibrados fizeram as avaliações dos espécimes em uma lupa estereoscópica (D.F. Vasconcelos, São Paulo, S.P., Brasil) com aumento de 40X seguindo os seguintes índices:

0- nenhuma infiltração;

1- infiltração do corante na parede gengival;

2- infiltração do corante na parede axial;

3- infiltração do corante na parede axial e em direção à polpa.

Foram avaliadas todas as seis superfícies das secções obtidas, sendo que foi atribuído o maior índice de penetração em cada espécime. Quando havia discordância entre os examinadores, os resultados eram confrontados. Os dados obtidos foram então, tabulados e submetidos à análise estatística. 
5-RESULTADOS 


\section{5- RESULTADOS}

\section{1- Resistência adesiva ao cisalhamento}

A partir do conhecimento do diâmetro da superfície adesiva foi calculado o raio em centímetros e de posse do seu valor, foi aplicada a fórmula $\pi r^{2}$ para se saber a área adesiva. Os valores de resistência adesiva registrados em Kgf foram divididos pela área e estabelecidos em $\mathrm{Kgf} / \mathrm{cm}^{2}$. Estes valores foram multiplicados pelo coeficiente de conversão $(0,09807)$ para que fossem transformados em $\mathrm{MPa}$ (Tabela 2). As respectivas médias e desvios-padrão são mostrados na Tabela 3, sendo as médias também ilustradas na Figura 8.

TABELA 2 - Valores individuais em Kgf e MPa dos corpos-de-prova submetidos ao teste de resistência adesiva ao cisalhamento

\begin{tabular}{c|c|c|c|c|c|c}
\hline \multirow{2}{*}{ Corpo-de-prova } & \multicolumn{2}{|c|}{$\begin{array}{c}\text { Grupo 1 } \\
\text { Enforce }\end{array}$} & \multicolumn{2}{c|}{$\begin{array}{c}\text { Grupo 2 } \\
\text { Soctchbond }\end{array}$} & \multicolumn{2}{c}{$\begin{array}{c}\text { Grupo 3 } \\
\text { Variolink }\end{array}$} \\
\cline { 2 - 7 } & Kgf & $\mathbf{M P a}$ & Kgf & $\mathbf{M P a}$ & Kgf & MPa \\
\hline $\mathbf{1}$ & 36,20 & 15,50 & 25,00 & 10,71 & 3,70 & 1,58 \\
\hline $\mathbf{2}$ & 18,40 & 7,88 & 31,00 & 13,27 & 0,30 & 0,10 \\
\hline $\mathbf{3}$ & 9,80 & 4,37 & 27,70 & 11,86 & 5,90 & 2,53 \\
\hline $\mathbf{4}$ & 24,80 & 10,62 & 26,90 & 11,52 & 13,40 & 5,74 \\
\hline $\mathbf{5}$ & 20,90 & 8,95 & 26,50 & 10,96 & 7,90 & 2,33 \\
\hline $\mathbf{6}$ & 10,90 & 4,67 & 25,50 & 10,92 & 1,00 & 0,43 \\
\hline $\mathbf{7}$ & 25,60 & 10,96 & 20,30 & 8,69 & 3,20 & 1,37 \\
\hline $\mathbf{8}$ & 7,30 & 3,13 & 34,20 & 14,65 & 19,20 & 8,22 \\
\hline $\mathbf{9}$ & 23,10 & 9,89 & 19,60 & 8,39 & 0,40 & 0,17 \\
\hline $\mathbf{1 0}$ & 14,50 & 6,21 & 16,50 & 6,83 & 17,80 & 7,62 \\
\hline
\end{tabular}


TABELA 3 - Valores médios e desvios-padrão dos grupos submetidos ao teste de resistência adesiva ao cisalhamento

\begin{tabular}{l|c|c}
\multicolumn{1}{c|}{ Grupo } & Média & Desvio-Padrão \\
\hline Enforce (1) & 8,22 & 3,76 \\
\hline Scotchbond (2) & 10,78 & 2,32 \\
\hline Variolink (3) & 3,01 & 3,06 \\
\hline
\end{tabular}

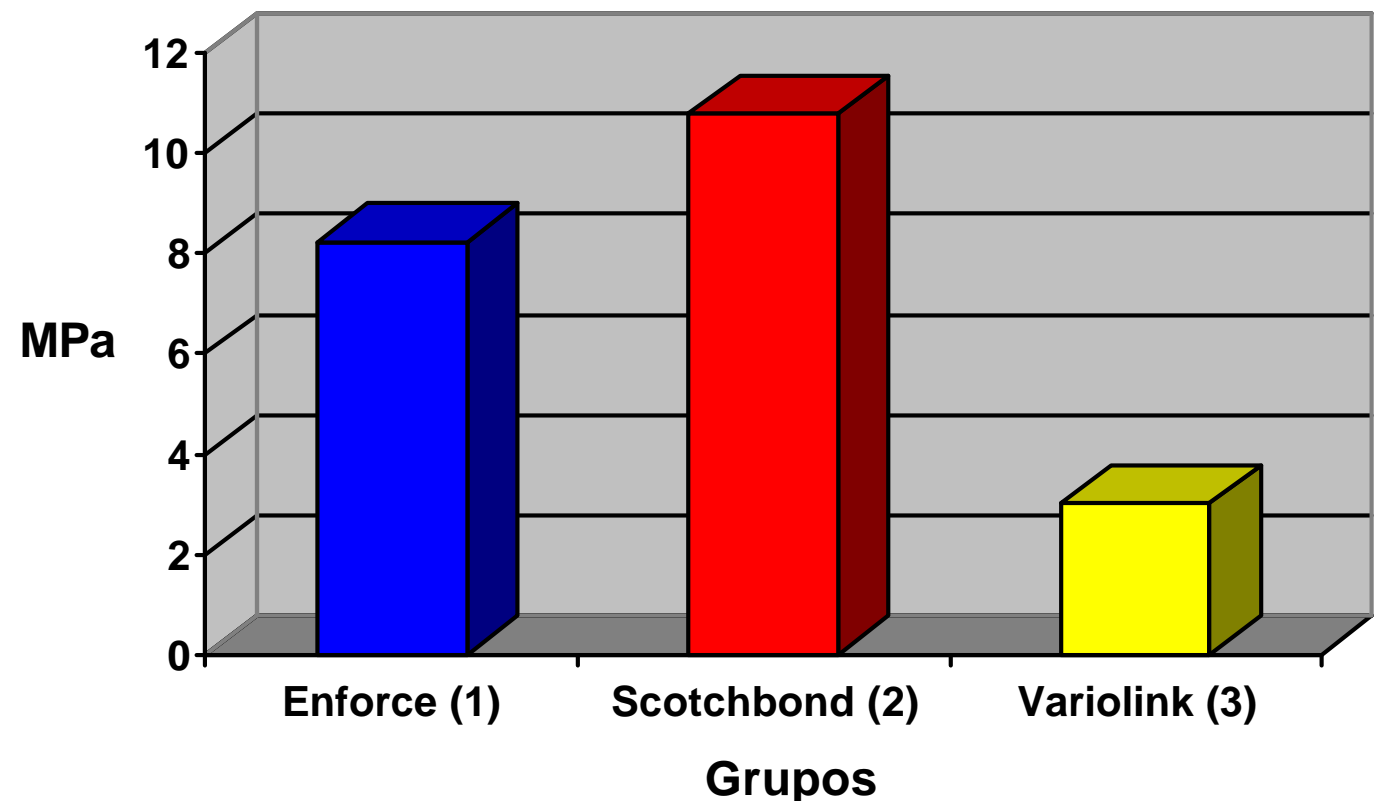

FIGURA 8 - Representação gráfica dos valores médios dos corpos-de-prova submetidos à força de cisalhamento

Os valores individuais mostram que houve uma distribuição mais homogênea dos resultados dos grupos 1 e 2 em relação ao grupo 3. Os valores médios dos grupos 1 e 2 foram 8,22MPa e 10,78MPa respectivamente. O grupo 3 apresentou uma média de 3,01MPa, sendo o desvio-padrão maior que a sua média, o que mostra uma maior variabilidade nos resultados. 
Para a análise estatística dos dados, foi utilizado o software SigmaStat 2.0 (SPSS Inc., Chicago, IL, USA). Após a verificação de uma distribuição normal ( $P=0,8239)$ e de igualdade de variância dos valores $(P=0,3514)$, aplicou-se $\circ$ teste de Análise de Variância a um critério (ANOVA). Este método revelou a presença de diferenças estatisticamente significantes entre os grupos com um poder de teste de 0,9992 $(p<0,05)$, como mostra a Tabela 4.

TABELA 4 - Resultados de análise de variância a um critério (ANOVA) aplicado aos valores obtidos após o teste de resistência adesiva ao cisalhamento

\begin{tabular}{cccccc}
\hline $\begin{array}{c}\text { Fonte de } \\
\text { variação }\end{array}$ & $\begin{array}{c}\text { Soma dos } \\
\text { quadrados }\end{array}$ & $\begin{array}{c}\text { Graus de } \\
\text { liberdade }\end{array}$ & $\begin{array}{c}\text { Quadrado } \\
\text { médio }\end{array}$ & $\mathbf{F}$ & $\mathbf{P}$ \\
\hline Entre grupos & 313,6 & 2 & 156,81 & 16,3 & $<0,0001$ \\
Residual & 260,2 & 27 & 9,64 & & \\
Total & 573,8 & 29 & & & \\
\hline
\end{tabular}

Após detectadas diferenças significantes entre os grupos, os valores médios foram submetidos a um teste de comparações múltiplas (Student-Newman-Keuls). Pôde-se verificar diferenças estatisticamente significantes entre os grupos 1 e 3 e entre os grupos 2 e 3, conforme mostra a Tabela 5. 
TABELA 5 - Resultados do teste de comparações múltiplas (Student-NewmanKeuls) entre os grupos experimentais submetidos ao teste de resistência adesiva ao cisalhamento $(p<0,05)$

\begin{tabular}{c|c|c|}
\hline $\begin{array}{c}\text { Comparações } \\
\text { entre grupos }\end{array}$ & $\begin{array}{c}\text { Diferença das } \\
\text { médias }\end{array}$ & $\begin{array}{c}\text { Diferenças } \\
\text { estatísticas }\end{array}$ \\
\hline $\mathbf{2} \times \mathbf{3}$ & 7,77 & sim \\
\hline $\mathbf{2} \times \mathbf{1}$ & 2,56 & não \\
\hline $\mathbf{1} \times \mathbf{3}$ & 5,21 & sim \\
\hline
\end{tabular}

A fratura ocorrida após a aplicação da força de cisalhamento ocorreu de forma diferente entre os espécimes, sendo que poderiam ser classificadas como adesiva entre a dentina e o agente de fixação, adesiva entre o agente de fixação e a porcelana, coesiva da dentina, coesiva da porcelana ou mista. Alguns exemplos podem ser visualizados na Figura 9. Para verificar o modo de fratura ocorrido, os espécimes foram analisados e os resultados são mostrados de forma percentual na Tabela 6. 

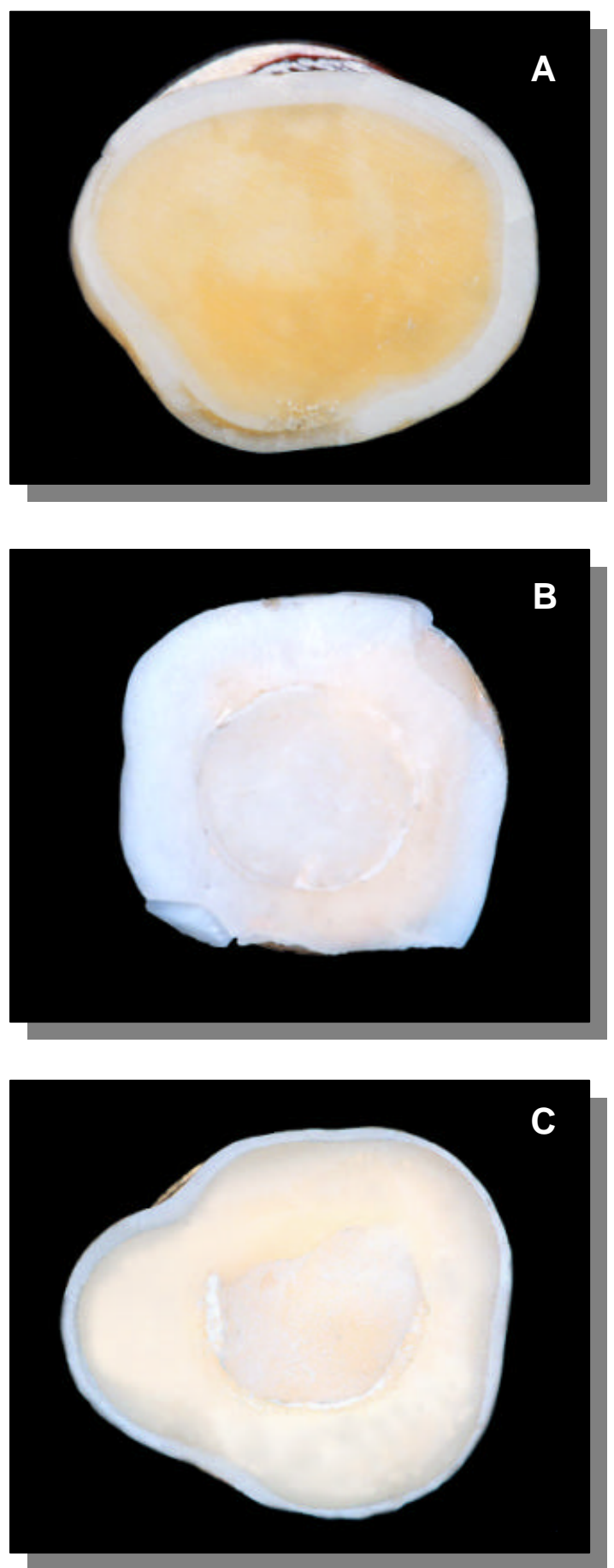

FIGURA 9 - Exemplos de modos de fratura dos corpos-de-prova submetidos à força de cisalhamento. A - fratura adesiva entre a dentina e o agente de fixação; B - fratura adesiva entre o agente de fixação e a porcelana; C - fratura mista 
TABELA 6 - Valores percentuais do modo de fratura ocorrido nos corpos-de-prova submetidos à resistência adesiva ao cisalhamento (\%)

\begin{tabular}{c|c|c|c}
\hline Modo de fratura & $\begin{array}{c}\text { Grupo 1 } \\
\text { Enforce }\end{array}$ & $\begin{array}{c}\text { Grupo 2 } \\
\text { Scotchbond }\end{array}$ & $\begin{array}{c}\text { Grupo 3 } \\
\text { Variolink }\end{array}$ \\
\hline $\begin{array}{c}\text { adesiva entre a dentina e o } \\
\text { agente de fixação }\end{array}$ & $0 \%$ & $0 \%$ & $100 \%$ \\
\hline $\begin{array}{c}\text { adesiva entre o agente de } \\
\text { fixação e a porcelana }\end{array}$ & $30 \%$ & $40 \%$ & $0 \%$ \\
\hline coesiva da dentina & $0 \%$ & $0 \%$ & $0 \%$ \\
\hline coesiva da porcelana & $0 \%$ & $0 \%$ & $0 \%$ \\
\hline mista & $70 \%$ & $60 \%$ & $0 \%$ \\
\hline
\end{tabular}

Estes valores mostram que os grupos 1 e 2 apresentaram fraturas predominantemente do tipo mista (70\% e 60\% respectivamente), enquanto o grupo 3 apresentou fratura adesiva entre a dentina e o agente de fixação em todos os espécimes avaliados. 


\section{2- Microinfiltração marginal}

Os índices individuais de infiltração marginal dos espécimes fixados com os três diferentes sistemas de fixação adesiva de dupla polimerização encontram-se na Tabela 7. Estes índices são ilustrados na Figura 10.

TABELA 7 - Índices individuais de infiltração marginal dos espécimes fixados com três sistemas de fixação adesiva de dupla polimerização

\begin{tabular}{c|c|c|c}
\hline \multirow{2}{*}{ Espécime } & \multicolumn{3}{|c}{ Grupo } \\
\cline { 2 - 4 } & Enforce (1) & Scotchbond (2) & Variolink (3) \\
\hline $\mathbf{1}$ & 1 & 0 & 2 \\
\hline 3 & 0 & 1 & 3 \\
\hline 4 & 1 & 1 & 1 \\
\hline 5 & 1 & 0 & 2 \\
\hline 6 & 1 & 1 & 3 \\
\hline 7 & 0 & 1 & 1 \\
\hline 8 & 0 & 1 & 3 \\
\hline 9 & 0 & 0 & 3 \\
\hline 10 & 1 & & 3 \\
\hline
\end{tabular}



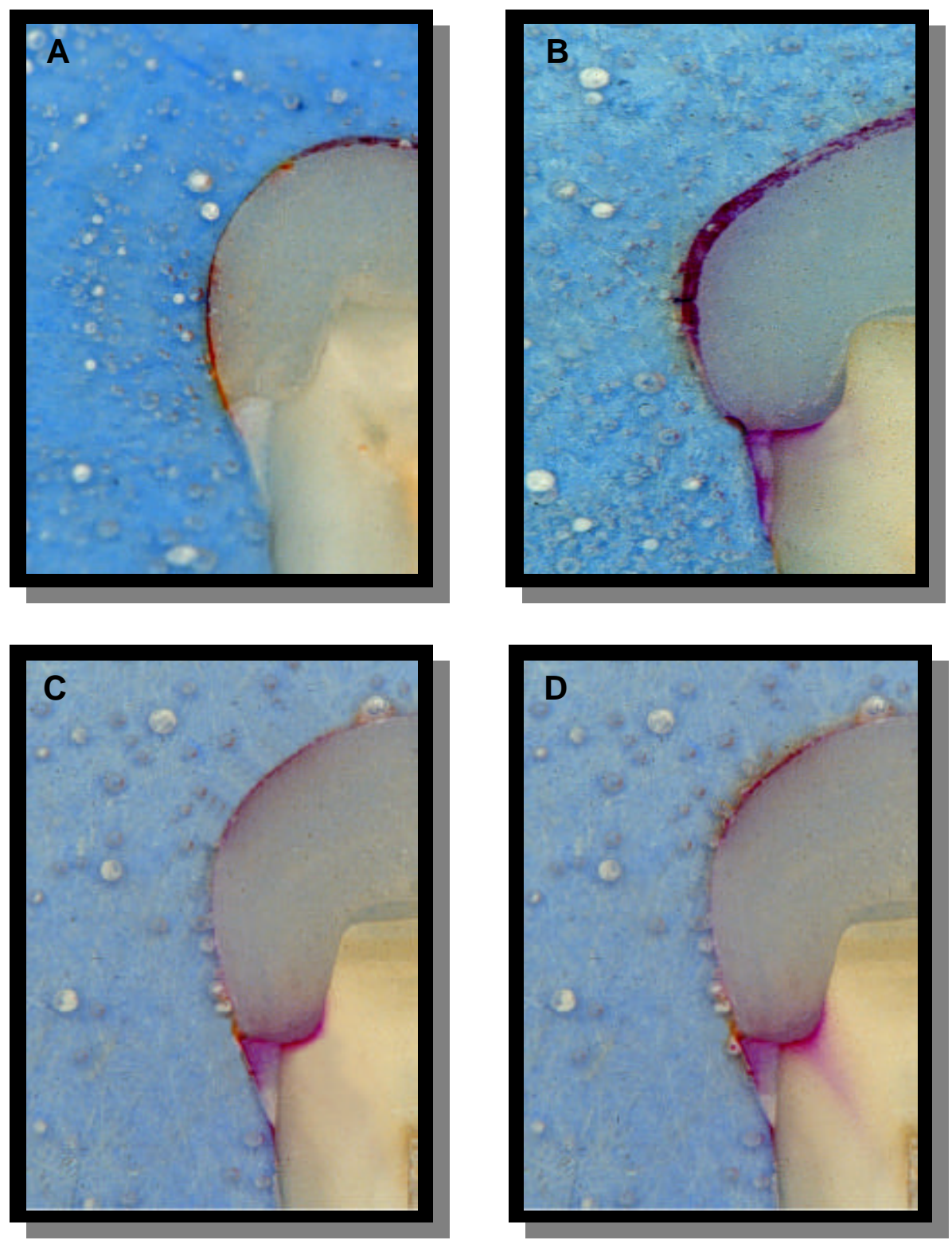

FIGURA 10 - Índices de infiltração marginal dos espécimes fixados com três sistemas de fixação adesiva de dupla polimerização: A - índice 0; B - índice 1; C - índice 2; D - índice 3 
Para a análise estatística, utilizou-se o software SigmaStat 2.0 (SPSS Inc., Chicago, IL, USA). Os índices foram submetidos ao teste estatístico pela análise de variância não paramétrica, método Kruskal-Wallis. Assim, pôde-se verificar que houve uma diferença estatisticamente significante $(p<0,01)$. A Tabela 8 ilustra a análise estatística realizada, tendo em vista os valores de mediana dos índices atribuídos aos 3 grupos experimentais.

TABELA 8 - Análise de variância não paramétrica, método Kruskal-Wallis dos índices de infiltração marginal dos espécimes fixados com três sistemas de fixação adesiva de dupla polimerização

\begin{tabular}{c|c}
\hline Grupo & Mediana \\
\hline Enforce (1) & 1,00 \\
\hline Scotchbond (2) & 1,00 \\
\hline Variolink (3) & 2,50 \\
\hline
\end{tabular}

As comparações individuais foram feitas pelo teste de Miller e observaram-se diferenças estatisticamente significante entre os grupos $1 \times 3$ e $2 \times 3(p<0,05)$, conforme mostra a Tabela 9.

TABELA 9 - Teste de Miller para comparações individuais entre os grupos

\begin{tabular}{c|c|c}
\hline $\begin{array}{c}\text { Comparações } \\
\text { entre grupos }\end{array}$ & $\begin{array}{c}\text { Diferença do } \\
\text { posto médio }\end{array}$ & $\begin{array}{c}\text { Diferenças } \\
\text { estatísticas }\end{array}$ \\
\hline $\mathbf{1} \times \mathbf{2}$ & 1,75 & não \\
\hline $\mathbf{1} \times 3$ & 11,60 & $\operatorname{sim}$ \\
\hline $\mathbf{2} \times 3$ & 9,85 & $\operatorname{sim}$ \\
\hline
\end{tabular}


Em uma análise dos índices individuais pode-se observar um discrepância entre os 3 grupos que foram tabulados de forma percentual, conforme mostra a Tabela 10 e a Figura 11.

TABELA 10 - Valores percentuais dos índices de infiltração marginal dos espécimes fixados com três sistemas de fixação adesiva de dupla polimerização (\%)

\begin{tabular}{c|c|c|c}
\hline \multirow{2}{*}{$\begin{array}{c}\text { Índice de } \\
\text { infiltração } \\
\text { marginal }\end{array}$} & Enforce (1) & Scotchbond (2) & Variolink (3) \\
\cline { 2 - 4 } & 40 & 30 & 0 \\
\hline $\mathbf{0}$ & 50 & 50 & 20 \\
\hline $\mathbf{1}$ & 0 & 10 & 30 \\
\hline $\mathbf{3}$ & 10 & 10 & 50 \\
\hline
\end{tabular}

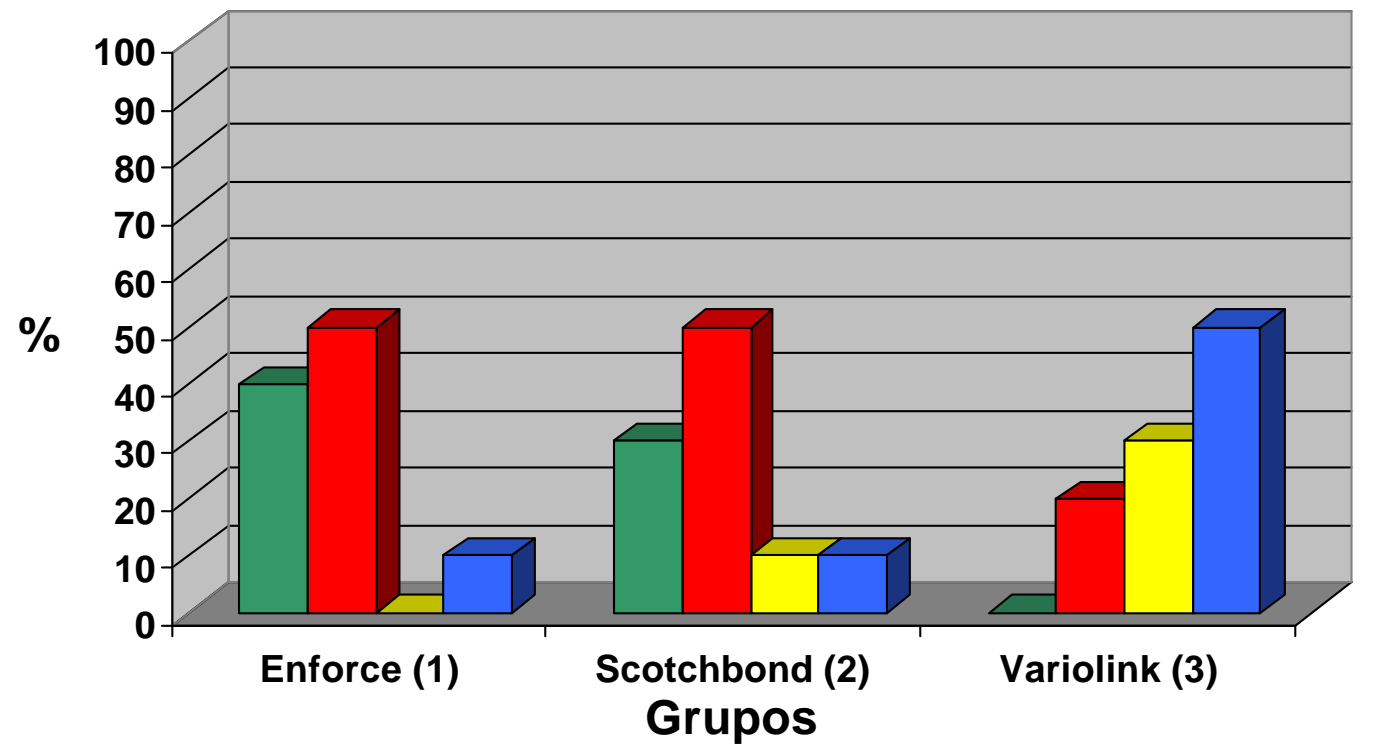

Índices de infiltração marginal : \begin{aligned}$\square 0 \quad \square 1 \quad \square 2 \quad \square 3 \\$\hline\end{aligned}

FIGURA 11 - Representação gráfica dos valores percentuais dos índices de infiltração marginal dos três grupos experimentais (\%) 
A observação dos índices individuais na Tabela 7 e percentuais na Tabela 10 mostra que nenhum dos três grupos experimentais foi capaz de impedir totalmente a microinfiltração marginal. Os grupos 1 e 2 mostraram uma porcentagem de $40 \%$ e $30 \%$ respectivamente de espécimes livres de infiltração marginal. Em um total de $90 \%$ e $80 \%$ dos espécimes dos grupos 1 e 2 , respectivamente, a infiltração não excedeu o índice 1, ou seja, quando ela ocorria, limitava-se à parede gengival. $\mathrm{O}$ grupo três foi o que apresentou o maior percentual de infiltração marginal, sendo que $80 \%$ dos espécimes apresentaram índices 2 e 3 . Também verificou-se que este grupo foi o único que não apresentou nenhum espécime livre de infiltração. Desta forma, os grupos 1 e 2 tiveram comportamento similar e superior estatisticamente ao grupo 3. 
6-DISCUSSÃO 


\section{6- DISCUSSÃO}

Vários testes laboratoriais são freqüentemente realizados para avaliar a eficácia de um sistema restaurador experimental ou predizer o comportamento clínico de um sistema já disponível no comércio ${ }^{68}$. Dentre eles, os mais utilizados são a avaliação da resistência adesiva à tração e ao cisalhamento ${ }^{58}$, avaliação das fendas marginais e da microinfiltração marginal ${ }^{68,100}$. Estes testes laboratoriais geralmente fornecem valores que são diretamente dependentes do tipo de teste aplicado, da qualidade do substrato, condições de armazenamento dos espécimes, além das propriedades manipulativas do material $^{58}$. De acordo com PASHLEY; CARVALHO ${ }^{62}$, a efetividade da união de um sistema adesivo pode ser medida pela sua capacidade de adesão e selamento da superfície. No presente trabalho, realizamos dois testes com três diferentes sistemas de fixação de dupla polimerização: resistência adesiva, por meio de testes de cisalhamento, da porcelana fixada à dentina e microinfiltração marginal, utilizando a penetração de corante, em restaurações de porcelana com término cervical em esmalte.

A composição do esmalte, contendo aproximadamente $97 \%$ de compostos minerais, bem como características particulares na sua distribuição, permite que, através do seu tratamento químico, se promova uma desmineralização seletiva, criando porosidades e permitindo a infiltração do sistema adesivo, resultando em uma retenção micromecânica ${ }^{11}$. Este princípio foi desenvolvido por Buonocore ${ }^{8}$, em 1955, quando propôs a técnica de condicionamento ácido do esmalte. Já na dentina, encontramos uma estrutura mais sujeita a alterações, cuja efetividade de adesão é dependente de alguns fatores, dentre eles, a profundidade, disposição dos túbulos e tipo de substrato (dentina fraturada, desgastada, esclerosada ou cariada). 
SÖDERHOLM; REETZ ${ }^{83}$ relacionaram alguns fatores que determinam a qualidade da união adesiva, como a capacidade de molhamento da superfície do substrato pela resina; qualidade da retenção mecânica entre a resina e o substrato; resistência coesiva da resina; estresse gerado na resina durante a contração de polimerização e a resistência coesiva da dentina. Estes aspectos relacionados à adesão dentinária são difíceis de serem padronizados clinicamente, uma vez que o sistema adesivo necessita adaptar-se a um substrato morfologicamente heterogêneo. Desta forma, a eficácia de um sistema adesivo estaria diretamente relacionada à sua sensibilidade a essas variações $^{11}$, o que estimulou a realização do teste de resistência adesiva em dentina.

Apesar da presença de um substrato heterogêneo como a dentina estar envolvido no processo adesivo de restaurações indiretas, o estabelecimento das margens cervicais em esmalte poderia resultar em uma adesão mais estável $^{34,46,67,94,108,110}$, limitando a infiltração na interface dente/restauração, o que foi realizado no teste de microinfiltração marginal.

Apesar de não haver um consenso quanto ao tamanho ideal da fenda marginal inicial de uma incrustação ${ }^{29}$, tem sido sugerido que uma boa adaptação reduziria a exposição das margens, diminuindo a possibilidade de deterioração do agente de fixação ${ }^{13,82}$. Ademais, uma película de cimento muito espessa poderia resultar em uma maior magnitude da contração de polimerização ${ }^{13}$. Porém, alguns trabalhos ${ }^{72,107}$ têm relatado que a adaptação marginal inicial da restauração teria pouca influência na infiltração marginal, provavelmente porque esta ocorre, na maioria das vezes, na interface entre o assoalho cavitário e o agente de fixação ${ }^{84}$. REES; JACOBSEN ${ }^{66}$ e SCHMALZ; FEDERLIN; REICH ${ }^{77}$ sugeriram que uma fenda marginal inicial não deveria exceder $100 \mu \mathrm{m}$. Os valores médios de discrepância marginal em restaurações de 
porcelana observados por $\mathrm{ROCHA}^{71}$ foram $68,27 \mu \mathrm{m}$. No presente trabalho, não foi mensurada a desadaptação marginal antes e após a fixação das incrustações. Antes da fixação, as incrustações foram posicionadas na cavidade e a desadaptação checada com o auxílio de uma lupa com aumento de $10 \mathrm{X}^{7}$ e uma sonda exploradora número $5^{65}$, a semelhança dos critérios clínicos empregados durante o ajuste de incrustações na clínica diária ${ }^{7,65}$.

A medição da desadaptação das incrustações de porcelana após a fixação oferece alguns problemas, pois existe uma dificuldade em determinar a linha divisória entre o agente de fixação e a incrustação e entre o agente de fixação e o esmalte. Na análise, embora se padronize o máximo possível, pode ocorrer uma mudança na relação entre a posição do espécime e a luz do microscópio, e isso poderia influenciar nos valores mensurados ${ }^{82}$. Comparações entre os valores das fendas marginais ou discrepâncias internas antes da fixação e os valores correspondentes obtidos após a fixação também poderiam ser mal interpretados, uma vez que é complicado reproduzir as duas situações com exatidão, pois existem dificuldades em fixar as restaurações nas cavidades sem nenhuma alteração no posicionamento após a colocação do agente de fixação ${ }^{82}$. Além disso, variações no tipo de preparo, técnica de mensuração, localização e número de pontos de análise também poderiam influenciar nos resultados ${ }^{82}$.

Segundo RETIEF; MANDRAS RUSSELL ${ }^{69}$ a resistência ao cisalhamento e a microinfiltração marginal estão fortemente associadas, conforme pôde-se verificar no presente trabalho, em que os grupos avaliados se comportaram de forma similar nos dois testes. Apesar disto, não foi possível estabelecer uma correlação estatística, uma vez que a avaliação da resistência adesiva emprega testes paramétricos e a de microinfiltração marginal utiliza testes não paramétricos. Os mesmos autores ${ }^{69}$ 
sugeriram que uma resistência ao cisalhamento em torno de $21 \mathrm{MPa}$ poderia reduzir a microinfiltração a níveis próximos a zero. Outros $^{43}$ sugeriram que estes valores seriam de 20MPa. Sabe-se que estes valores são resultantes de testes laboratoriais executados sem a interação complexa dos diversos fatores envolvidos no processo de adesão, responsáveis pela resistência adesiva e o bom selamento marginal ${ }^{20}$.

No presente trabalho, a força de cisalhamento resultou em valores médios de 8,22MPa para o grupo 1 e 10,78MPa para o grupo 2. Os baixos valores de desviopadrão (3,76MPa e 2,32MPa respectivamente) comprovam uma uniformidade dos resultados destes grupos. O mesmo não ocorreu com o grupo 3, o qual apresentou valores médios de 3,01MPa, sendo o desvio-padrão ainda maior (3,06MPa), resultante de uma maior variação nos resultados.

Alguns trabalhos encontrados na literatura ${ }^{23,37,100}$ avaliaram a resistência adesiva dos sistemas Scotchbond Multi-Uso plus, Syntac e Probond. A resistência adesiva do sistema adesivo Scotchbond Multi-Uso plus à dentina encontrada na literatura variou entre $15,9 \mathrm{MPa}^{37}, 18,9 \mathrm{MPa}{ }^{23}$ e $22,5 \mathrm{MPa}{ }^{50}$. Os trabalhos que compararam a adesão deste sistema com o adesivo Syntac mostraram uma superioridade estatisticamente significante do primeiro $^{14,37}$, sendo que o Syntac apresentou valores médios de adesão à dentina na ordem de $13,5 \mathrm{MPa}{ }^{37}$. Retief et al. ${ }^{70}$ verificaram que a resistência adesiva do adesivo Syntac à dentina foi de 10,14MPa após 15 minutos e 15,9MPa após 24 horas. TRIOLO JUNIOR; SWIFT JUNIOR; BARKMEIER ${ }^{97}$ ao comparar a resistência adesiva do adesivo Scotchbond Multi-Uso Plus com o adesivo Probond, verificaram que o Scotchbond Multi-Uso Plus apresentou valores estatisticamente superiores. Segundo VAN MEERBEEK et $\mathrm{al}^{100}$, a viscosidade do adesivo do Scotchbond Multi-Uso Plus poderia resultar em uma camada intermediária com uma possível capacidade 
neutralizadora da contração de polimerização. Porém, nenhum dos trabalhos que analisaram a resistência adesiva do adesivo $\operatorname{Syntac}^{14,37,70}$ encontrou valores tão baixos de resistência quanto os encontrados neste trabalho.

As características manipulativas do sistema de fixação Variolink dificultaram a padronização dos procedimentos. Após o condicionamento ácido da dentina, foi aplicado o Syntac Primer e em seguida o Syntac adesivo. Sobre este, uma resina sem carga (Heliobond) foi aplicada e a porcelana fixada com o cimento resinoso. Neste momento é que realizou-se a polimerização. Isto poderia resultar em uma polimerização incompleta dos componentes ${ }^{99}$, com conseqüente rompimento da adesão, o que seria confirmada também pelo alto índice de infiltração marginal encontrado neste grupo.

Os corpos-de-prova fraturados foram analisados com o auxílio de uma lupa para verificação do tipo de fratura. Esta análise mostrou que a fratura dos espécimes dos grupos 1 e 2 foi predominantemente mista ( $70 \%$ e $60 \%$ respectivamente). 0 grupo 3 apresentou fratura adesiva entre a dentina e o agente de fixação em todos os espécimes, o que está em concordância com os achados de CHAPPELL; EICK ${ }^{14}$. O comportamento dos espécimes nos testes de cisalhamento está de acordo com GUZMAN, MOORE ${ }^{32}$ que verificaram uma relação direta entre a resistência adesiva e as falhas coesivas, ou seja, a medida que uma aumenta, a outra segue na mesma proporção.

$\mathrm{Na}$ fixação adesiva existe uma união da porcelana com o agente de fixação resinoso e deste com a estrutura dentária, por meio de um sistema adesivo. As características físicas, químicas e morfológicas da interface resina-dentina são fundamentais para um melhor entendimento dos mecanismos envolvidos na adesão à dentina ${ }^{100}$. O condicionamento ácido remove a camada mineral da sua superfície 
expondo a rede de fibras colágenas permitindo a difusão do primer e do adesivo na dentina peritubular e intertubular. Deste modo, a porção mineral é substituída por uma resina formando um novo composto chamado de camada híbrida. Esta camada foi inicialmente descrita por NAKABAYASHI ${ }^{56}$ em 1982, sendo sua formação fundamental para se alcançar uma boa adesão dentinária, pois acredita-se que a adesão dos sistemas adesivos atuais seja resultante de uma união micromecânica à rede de fibras colágenas $^{56,62,99}$. Os novos sistemas adesivos necessitam penetrar somente alguns micrometros no interior dos túbulos para formar os prolongamentos de resina, os quais, se aderidos às paredes dos túbulos, os selam prevenindo a microinfiltração e contribuindo para a retenção da resina ${ }^{61}$.

Os sistemas adesivos Scotchbond Multi-Uso plus e Probond preconizam a desmineralização da dentina com a utilização do ácido fosfórico para a formação da camada híbrida. Por outro lado, o sistema adesivo Syntac utiliza o primer para dissolver completamente ou remover a smear layer ${ }^{99}$, promovendo uma desmineralização somente da dentina intertubular, sem afetar a dentina peritubular. Este tratamento da superfície dentinária é conseguido à custa do ácido maleico existente na composição do primer $^{99}$. Nesta pesquisa foi realizado o condicionamento ácido da dentina por 15 segundos, conforme a técnica alternativa recomendada pelo fabricante do sistema adesivo Syntac. GWINNETT; DICKERSON; YU ${ }^{33}$ avaliaram a resistência adesiva ao cisalhamento e a microinfiltração do adesivo Syntac com ou sem o condicionamento ácido da dentina. Verificaram que este não resultou em valores estatisticamente diferentes, mas observou uma redução na microinfiltração marginal dos espécimes que tiveram a dentina condicionada. Os autores ${ }^{33}$ sugeriram que esta redução seria oriunda da formação da camada híbrida. MELLO et al ${ }^{52}$ ao compararem a microinfiltração 
marginal em cavidades restauradas com resina composta utilizando diversos sistemas adesivos, verificaram uma maior porcentagem de infiltração do sistema adesivo Syntac, quando comparada com o sistema Scotchbond Multi-Uso.

Após o condicionamento ácido, a superfície dentinária foi lavada abundantemente com água e os excessos removidos, contudo evitando-se o seu ressecamento ${ }^{40}$. Este ressecamento poderia levar a uma contração de até $65 \%$ do seu volume, limitando o tamanho dos espaços em torno das fibras colágenas e dificultando a difusão do sistema adesivo. Caso isto ocorresse, a resistência adesiva na dentina intertubular estaria limitada à resistência da superfície de $\operatorname{adesão~}^{62}$ e poderia influenciar negativamente 0 selamento marginal ${ }^{16}$.

Na outra interface, a adesão do agente de fixação à porcelana é dada à custa de uma retenção mecânica promovida pelo condicionamento da superfície interna da incrustação associado à união química proporcionada pelo agente silano ${ }^{36,48,83,87,90}$. Apesar de não existir na literatura uma concordância a respeito do tempo de condicionamento $^{1,5,32,36}$, é um consenso a criação de microrretenções por meio da aplicação do ácido fluorídrico ${ }^{32,66}$. Este condicionamento aumentaria a área de superfície e criaria um embricamento micromecânico entre o agente de fixação e a porcelana ${ }^{48}$.

Os silanos são agentes de ligação anfóteros ou bifuncionais. A sua molécula pode reagir com diferentes superfícies, uma inorgânica e outra orgânica ${ }^{3}$. PAFFENBARGER; SWEENEY; BOWEN ${ }^{60}$, em 1967, foram os primeiros autores a estudar a união de adesivos à porcelana. Utilizando testes de resistência adesiva, eles verificaram que o agente de ligação silano aumentou a união entre dentes de porcelana e a base de resina acrílica de próteses totais. Estes silanos se desenvolveram e hoje são encontrados 
diferentes tipos para o tratamento químico da porcelana: (a) silanos quimicamente ativados; (b) silanos ácido ativados; (c) silanos pré-ativados ${ }^{80}$.

No presente trabalho, foram utilizados dois agentes silanizadores pré-ativados (Scotchbond Ceramic Primer, 3M; Monobond - S, Vivadent) e um silano quimicamente ativado (Silano - Agente de ligação, Dentsply).

Segundo ANAGNOSTOPOULOS; ELIADES; PALAGHIAS ${ }^{4}$ o potencial reativo destes materiais poderia ser estimado pela quantidade de grupos metoxi por átomo de Si hidrolisados em silanol. Os grupos silanóis são sítios ativos das moléculas hidrolisadas do silano. Desta forma, quanto maior a sua quantidade, maior seria a reatividade do material. Os mesmos autores ${ }^{4}$ encontraram um maior índice de hidrólise dos silanos pré-ativados, o que resultaria em melhores ligações, quando comparados aos quimicamente ativados. No presente estudo, a proposta foi verificar o comportamento do sistema de fixação como um todo. Portanto, não se pode afirmar que um silano teve maior influência na resistência adesiva e na microinfiltração que o outro. O sistema Scotchbond Multi-Uso Plus / Scotchbond Resin Cement e o sistema Variolink Professional Set, que utilizam silanos pré-ativados apresentaram valores de resistência adesiva e índices de infiltração marginal diferentes estatisticamente entre si. Além disso, o sistema Variolink Professional Set também apresentou um comportamento inferior ao sistema Enforce, o qual utiliza um agente silanizador quimicamente ativado.

Quando as pastas base e catalisadora do agente de fixação resinoso são manipuladas, se inicia o processo de polimerização. Porém, ao contrário das resinas compostas quimicamente ativadas, esta reação é menos pronunciada. Com a ativação da luz, um grande número de radicais livres é adicionado aos radicais livres da reação química, acelerando a reação de polimerização. Assim, após a reação inicial ter sido 
deflagrada, a polimerização química continua nas regiões inacessíveis à luz ${ }^{83}$. Entretanto, tem sido sugerido que a luz não seria capaz de atingir a resina através da restauração, quando a sua espessura fosse maior que $2 \mathrm{~mm}$, o que poderia afetar sua microdureza $^{10,22}$. Segundo alguns autores ${ }^{35,103}$, um aumento no tempo de polimerização, nestas situações, poderia ser vantajoso. No presente trabalho, realizou-se a polimerização em diversas áreas, sendo a luz ativada por 60 segundos em cada uma. Nos espécimes utilizados no teste de microinfiltração marginal, optou-se pela polimerização através das superfícies proximais, vestibular, lingual e oclusal. Por outro lado, os testes de resistência adesiva foram realizados com cilindros de porcelana, o que impediu este tipo de procedimento. Assim, optou-se pela polimerização em quatro pontos eqüidistantes localizados na base dos cilindros. Desta forma, uma maior área do agente de fixação pôde ser atingida pela luz. Ademais, para que a polimerização química se completasse, foram aguardadas 24 horas entre a confecção dos corpos-deprova e a realização dos testes.

Logo no início do processo de polimerização, o agente de fixação resinoso começa a sofrer uma contração. O escoamento, que é maior inicialmente, diminui à medida que a polimerização continua, enquanto a resistência do agente de fixação aumenta $^{83}$. Assim, a competição entre as forças de contração durante a polimerização de uma resina composta e a união dos adesivos às paredes cavitárias geraria um estresse, que poderia resultar em uma ruptura da adesão às paredes da cavidade $^{12,25,110}$, com conseqüente microinfiltração marginal ${ }^{12}$. Além disso, existe uma relação muito importante a ser considerada entre a velocidade da reação de conversão e a acomodação da rede molecular do polímero em formação. Quanto maior a 
velocidade desta reação, mais difícil se torna a acomodação molecular, podendo resultar em uma tensão residual, que seria um fator adicional ao estresse gerado ${ }^{104}$.

A influência da configuração cavitária na contração de polimerização de uma resina composta foi inicialmente estudada por DAVIDSON; DE GEE; FEILZER ${ }^{17}$. Neste estudo, constatou-se que a contração da resina ocorria em uma só direção quando uma boa união resina composta/dentina era formada, porém quando a resina está unida a várias paredes, as forças de contração poderiam superar a força de união. Assim, foi estabelecido que quanto maior a relação entre superfícies aderidas e superfícies livres, maior seria a dificuldade de relaxamento do estresse de contração de polimerização. Este modelo foi chamado de Fator $C^{24}$. À medida que este fator aumenta, a contração volumétrica, que é normalmente distribuída em três dimensões, é gradualmente convertida em uma única direção. Este fato também acontece com finas camadas de resina composta ${ }^{25}$, como na fixação de incrustações ou coroas totais. Nestas situações, os agentes de fixação resinosos formariam uma união às paredes opostas e direcionariam o estresse da contração de polimerização quase perpendicularmente, criando uma competição entre a união à cerâmica condicionada e às paredes dentinárias $^{85}$. O estudo de FEILZER; DE GEE; DAVIDSON ${ }^{25}$ foi contestado por MAHLER ${ }^{49}$, o qual ressaltou que o estresse gerado no processo adesivo de fixação de incrustações seria na ordem de 7MPa. Afirmou ainda, que as forças geradas durante a fixação de incrustações teriam uma magnitude menor que aquela das restaurações de resina composta de uso direto, as quais teriam valores na ordem de 53MPa. FEILZER; DE GEE; DAVIDSON ${ }^{26}$ publicaram uma resposta à afirmação de MAHLER ${ }^{49}$, enfatizando que a contração do agente de fixação poderia ser em torno de 7,0\% do seu volume e gerar forças entre $17,6 \mathrm{MPa}$ e $27,6 \mathrm{MPa}$. Segundo estes autores ${ }^{26}$, estaria 
errado o conceito de que a contração de polimerização de finas camadas de agente de fixação resinoso causaria apenas pequenas conseqüências, o que foi confirmado por outros estudos ${ }^{77,86}$.

Porém, a configuração cavitária não é a única responsável pelo estresse gerado na interface adesiva. Quando se utilizam agentes de fixação resinosos existe uma interação entre a contração de polimerização, a capacidade de escoamento e a dureza do material de fixação ${ }^{83}$. Se o agente resinoso apresentar uma baixa viscosidade, o estresse resultante da contração poderá ser menor que a resistência adesiva à estrutura dentária devido à sua elasticidade, e assim, a integridade marginal poderia ser preservada $^{83,110}$.

A presença de uma fenda marginal poderia resultar na passagem de bactérias, fluidos, substâncias químicas, moléculas e íons através da interface dente/restauração ${ }^{42}$. As conseqüências clínicas desta infiltração estariam relacionadas ao manchamento das margens da restauração, cárie secundária, sensibilidade e desenvolvimento de patologia pulpar ${ }^{30}$. Na presente pesquisa, nenhum dos grupos avaliados foi capaz de impedir totalmente a infiltração marginal, o que está de acordo com outros trabalhos ${ }^{7,67,85}$. Os grupos 1 e 2 mostraram uma porcentagem de $40 \%$ e $30 \%$, respectivamente, de espécimes livres de infiltração marginal e o grupo 3 não apresentou nenhum espécime livre de infiltração. Os grupos 1 e 2 também apresentaram um número maior de espécimes (50\%) com índice 1 de infiltração marginal. Este fato mostra que na maioria dos espécimes, quando a infiltração ocorreu, ela limitou-se à parede gengival. O mesmo não ocorreu com o grupo 3 que apresentou um alto índice de infiltração na maioria do espécimes. 
ALANI; $\mathrm{TOH}^{2}$ realizaram uma revisão de literatura descrevendo as diversas metodologias empregadas para a avaliação da microinfiltração marginal. Dentre elas, podiam ser incluídas o uso de corantes, traçadores químicos, isótopos radioativos, pressão de ar, bactérias, microscopia eletrônica de varredura, cárie artificial e condutibilidade elétrica. Os mesmos autores ${ }^{2}$ ressaltaram que, apesar de cada metodologia apresentar vantagens e desvantagens, nenhuma delas poderia ser considerada ideal. Contudo, a penetração de corantes, principalmente a fucsina, tem sido referida como uma das técnicas mais utilizadas ${ }^{2,18,93}$. Esta técnica apresenta uma metodologia relativamente simples que não necessita de reações químicas adicionais ou exposição a radiações, apenas utilizando seç̧ões da interface dente/restauração coradas $^{93}$. Porém, é uma metodologia tecnicamente sensível, tendo como principal desvantagem a utilização de índices para a avaliação. Embora, os espécimes sejam geralmente avaliados por mais de um avaliador, pode existir alguma variação na interpretação resultante da subjetividade do método. Além disso, uma margem de erro pode estar associada com a possibilidade do corante penetrar na estrutura dentária ou na restauração dificultando a visualização da área infiltrada.

Os diversos problemas relacionados com a interpretação dos resultados ${ }^{74}$, oriundos da falta de padronização entre as diversas metodologias ${ }^{93}$ e a subjetividade destes tipos de testes poderiam resultar em uma má avaliação do material restaurador $^{74}$, dificultando a comparação com outros trabalhos ${ }^{93}$. Porém, DÉJOU; SINDRES; CAMPS $^{18}$ ao comparar diferentes métodos estatísticos empregados na avaliação da infiltração marginal, verificaram que o método de penetração máxima do corante medido em cada dente foi considerado o melhor critério, por permitir uma análise estatística com maior poder. 
Outro fator que deve ser levado em consideração é o tamanho das partículas do corante empregado, não sendo desejável utilizar corantes cujas partículas sejam maiores que o diâmetro interno dos túbulos dentinários ${ }^{2}$. A utilização do nitrato de prata como corante tem sido considerado um teste severo devido ao tamanho extremamente pequeno das suas partículas, com aproximadamente $0,059 \mathrm{~nm}$, quando comparado ao tamanho médio das bactérias $(0,5$ a 1,0 $\mu \mathrm{m})$. Consequentemente, a invasão bacteriana deveria ser esperada somente quando as fendas marginais apresentassem uma discrepância entre 0,5 a $1,0 \mu \mathrm{m}$ ou maiores ${ }^{2}$.

As variações térmicas, mecânicas e químicas podem causar uma deterioração na adaptação marginal das restaurações ${ }^{45}$. Nas pesquisas laboratoriais, a termociclagem tem sido utilizada para simular uma condição oral, submetendo a restauração a temperaturas extremas que poderiam resultar em uma fadiga da interface adesiva $a^{39,73}$ como consequência da diferença do coeficiente de expansão térmica entre o dente e a restauração ${ }^{2}$. De acordo com ROSSOMANDO; WENDT JUNIOR ${ }^{73}$ as temperaturas utilizadas na termociclagem podem variar de $0^{\circ} \mathrm{C}$ a $68^{\circ} \mathrm{C}$. Retief ${ }^{68}$ considera que estas temperaturas devem situar entre $8^{\circ} \mathrm{C}$ e $50^{\circ} \mathrm{C}$, pois seriam temperaturas encontradas na cavidade oral. O tempo de imersão e a quantidade de ciclos variam de acordo com o material restaurador a ser testado, sendo que as resinas compostas, por apresentarem baixa condutibilidade térmica deveriam ter um tempo de imersão maior que dez segundos em cada temperatura para produzir efeitos significativos ${ }^{73}$. Tempo de imersão máximo de 15 segundos em cada temperatura tem sido preconizado por RETIEF ${ }^{68}$ já que estas alterações térmicas não ocorrem por períodos prolongados na cavidade oral.

Finalmente, é importante ressaltar que os sistemas de fixação adesiva contribuem para uma união mais estável entre as restaurações de porcelana e a estrutura dentária, 
o que possibilita a realização de preparos mais conservadores, eliminando a necessidade de retenções adicionais. Por outro lado, o uso de sistemas adesivos e agentes de fixação resinosos também permite que se compense, em parte, a discrepância marginal inicial característica destas restaurações. Entretanto, este fato não elimina a possibilidade de ocorrerem falhas, uma vez que a utilização de um material sensível a diferentes substratos pode resultar no comprometimento da longevidade da restauração. Além disso, o número de etapas operatórias existentes nos procedimentos de fixação adesiva poderia aumentar a discrepância entre o desempenho destes materiais em testes laboratoriais e seu desempenho na prática clínica ${ }^{72}$. Desta forma, o desenvolvimento de materiais com maiores valores de adesão e menor sensibilidade aos diversos substratos, associado à uma menor contração de polimerização e um comportamento dimensional semelhante aos das estruturas dentárias são fundamentais para sua longevidade. Assim, a fase clínica de fixação de restaurações de porcelana é considerada uma etapa crucial para o sucesso do procedimento restaurador. 
7-CONCLUSÕES 


\section{7- CONCLUSÕES}

Com base nos resultados obtidos nesta pesquisa pode-se concluir que:

-Não houve diferença estatisticamente significante na resistência adesiva ao cisalhamento entre o Sistema de fixação Enforce e o Sistema de fixação Scotchbond Resin Cement / Scotchbond Multi Uso Plus, porém estes foram estatisticamente superiores ao Sistema de fixação Variolink Professional Set;

-O modo de fratura dos corpos-de-prova submetidos à força de cisalhamento foi predominantemente do tipo mista para o Sistema de fixação Enforce (70\%) e para o Sistema de fixação Scotchbond Resin Cement / Scotchbond Multi Uso Plus (60\%), enquanto o Sistema de fixação Variolink apresentou fratura adesiva entre a dentina e o sistema de fixação em todos os espécimes;

-Nenhum dos grupos experimentais foi capaz de evitar a microinfiltração marginal;

-Os Sistemas de fixação Enforce e Sotchbond Resin Cement / Scotchbond Multi Uso Plus apresentaram os menores índices de infiltração marginal e foram estatisticamente superiores ao Sistema de fixação Variolink Professional Set. 
REFERÊNCIAS BIBLIOGRÁFICAS 


\section{REFERÊNCIAS BIBLIOGRÁFICAS*}

1 - ABBATE, M.F.; TJAN, A.H.L.; FOX, W.M. Comparison of the marginal fit of various ceramic crown systems. J. prosth. Dent., v.61, n.5, p.527-31, May 1989.

2 - ALANI, A.H.; TOH, C.G. Detection of microleakage around dental restorations: a review. Oper. Dent., v.22, n.4, p.173-85, July 1997.

3 - ALBERS, H.F. Esthetic treatment planning, in pertinent information on cosmetic, adhesives and restorative dentistry. Adept Report, v.3, p.45-52, Fall 1992.

4 - ANAGNOStOPOULOS, T.; ELIADES, G.; PALAGHIAS, G. Composition, reactivity and surface interactions of three dental silane primers Dent. Mat., v.9, n.3, p.182-90, May 1993.

5 - ARIYARATNAM, M. et al. Variation in the thickness of the composite lute with an indirect composite inlay system. Restorat. Dent., v.6, n.4, p.16-8, Nov. 1990.

6 - BARGHI, N. Comparison of bond strength of porcelain and composite to dentin. $\underline{\mathrm{J}}$. dent. Res., v.73, p.319, 1994. Special issue. /Abstract n.1739/.

7 - BLAIR, K. et al. Microleakage associated with resin composite-cemented, cast glass ceramic restoration. Int. J. Prosthodont., v.6, n.6, p. 579-84, Nov./Dec. 1993.

\footnotetext{
* Normas recomendadas para uso no âmbito da Universidade de São Paulo, com base no documento "Referências Bibliográficas: exemplos", emanado do Conselho Supervisor do Sistema Integrado de Bibliotecas da USP, em reunião de 20 de setembro de 1990.
} 
8 - BUONOCORE, M.G. A simple method of increasing the adhesion of acrylic filling materials to enamel surfaces. J. dent. Res., v.34, n.6, p.849-53, Dec. 1955.

9 - BURROW, M.F. et al. Early bonding of resin cements to dentin - Effect of bonding environment. Oper. Dent., v.21, n.5, p.196-202, Sept./Oct. 1996.

10 - CARDASH, H.S. et al. The effect of porcelain color on the hardness of luting composite resin cement. J. prosthet. Dent., v.69, n.6, p. 620-3, June. 1993.

11 - CARVALHO, R. M. Adesivos dentinários. Fundamentos para aplicação clínica. Rev. Dent. restaur., v.1, n.2, p.62-96, abr./jun. 1998.

12 - CARVALHO, R.M. et al. A review of polymerization contraction: the influence of stress development versus stress relief. Oper. Dent., v.21,n.1, p.17-24, Jan. /Feb. 1996.

13 - CHANA, H.S. et al. The influence of cement thickness on the tensile strength of two resin cements. Int. J. Prosthodont., v.10, n.4, p.340-4, July/Aug. 1997.

14 - CHAPPELL, R.P.; EICK, J.D. Shear bond strength and scanning electron microscopic observation of six current dentinal adhesives. Quintessence Int., v.25, n.5, p.359-68, May 1994. 
15 - CHARLTON, D.G.; MOORE, B.K. Effect of age of sample on the shear bond strength of dentin bonding agents to dentin. J. Indiana dent. Ass., v.70, n.5, p.23-6, Sept. 1991.

16 - CORREA, I.L.V. Influência na infiltração marginal de diferentes formas de tratamento da umidade em cavidades restauradas com Scotchbond MultiUso/Z100. Bauru, 1996. 140p. Dissertação (Mestrado) - Faculdade de Odontologia de Bauru, Universidade de São Paulo.

17 - DAVIDSON, C.L.; DE GEE, A.J.; FEILZER,A. The competition between the composite-dentin bonding strength and polymerization contraction stress. $\underline{\mathrm{J}}$ dent. Res., v.63, n.12, p.1396-9, Dec. 1984.

18 - DÉJOU, J.; SINDRES, V.; CAMPS, J. Influence of criteria on the results of in vitro evaluation of microleakage. Dent. Mat., v.12, n.6, p.342-9, Nov. 1996.

19 - DICKENS, S.H.; LIAO, N.S.; REED, B.B. Comparison of a micro and two shear dentin bond tests. J. dent. Res., v.77, p.657, 1998. Special issue. / Abstract n. 202/

20 - DONOVAN, T.E.; CHEE, W.W.L. Conservative indirect restorations for posterior teeth. Dent. Clin. N. Amer., v.37, n.3, p. 433-43, July. 1993.

21 - DRAUGHN, R. A.; DAVIS, T. N. Effect of vibration on film thickness of two cements. J. dent. Res., v.73, p. 182, 1994. Special issue. /Abstract n. 644/ 
22 - EL-BADRAWY, W.A.; EL-MOWAFY, O. M. Chemical versus dual curing of resin inlay cements. J. prosth. Dent., v.73, n.6, p. 515-24, June 1995.

23 - EL KALLA, I.H.; GARCIA GODOY, F. Bond strength and interfacial micromorphology of four adhesive systems in primary and permanent teeth. $\underline{J}$. Dent. Child., v.65, n.3, p.169-73, May/June. 1998.

24 - FEILZER, A.J.; DE GEE, A.J.; DAVIDSON, C.L. Setting stress in composite resin in relation to configuration of the restoration. J. dent. Res., v.66, n.11, p.1636-9, Nov. 1987.

25 - FEILZER, A.J.; DE GEE, A.J.; DAVIDSON, C.L. Increased wall-to-wall curing contraction in thin bonded resin layers. J. dent. Res., v.68, n.1, p.48-50, Jan. 1989.

26 - FEILZER, A.J.; DE GEE, A.J.; DAVIDSON, C.L. Letters to the Editor J. dent. Res., v.69, n.3, p.914, Mar. 1990.

27 - FRAZIER, B.K.; SARRET, D.C. Wear resistance of dual-cured resin luting agents. Amer. J. Dent., v.8, n.4, p.161-4, Aug. 1995.

28 - GALE, M.S.; DARVELL, B.W.; CHEUNG, G.S.P. Three-dimensional reconstruction of microleakage pattern using a sequential grinding technique. J. Dent., v.22, n.6, p.370-5, Dec. 1994. 
29 - GEMALMAZ, D. et al. Marginal adaptation of sintered ceramic inlay system before and after cementation J. oral Rehab., v.24, n.9, p.646-51, Sept. 1997.

30 - GOING, R.E. Microleakage around dental restorations: a summarizing review. J. Amer. dent. Ass., v.84, n.6, p.1349-57, Jun. 1972.

31 - GRIGGS, J.A.; SHEN, C.; ANUSAVICE, K. J. Sensitivity of catalist/base ratio on curing of resin luting agents: polymerization exotherm analysis. Dent. Mat., v. 10, n.5, p.314-8, Sept. 1994.

32 - GUZMAN, A.; MOORE, B.K. Influence of surface treatment on bond strength between a heat-activated and a light-activated resin composite. Int. J. Prosthodont., v.8, n.2, p.179-86, Mar./Apr. 1995.

33 - GWINNETT, A.J.; DICKERSON, W.G.; YU, S. Denting bond strength and microleakage for Syntac/Heliomolar: a comparison between the manufacturer's and total etch technique. J. Esthet. Dent., v.4, n.5, p.164-8, Sept./Oct. 1992.

34 - HASANREISOGLU, U. et al. Microleakage of direct and indirect inlay/onlay systems. J. oral Rehab., v.23, n.1, p.66-71, Jan. 1996.

35 - HASEGAWA, E. A.; BOYER, D. B.; CHAN, D. C. N. Hardening of dual-cured cements under composite resin inlays. J. prosth. Dent.; v.66, n.2, p.187-92, Aug. 1991. 
36 - HAYAKAWA, T. et al. The influence of surface conditions and silane agents on the bond of resin to dental porcelain. Dent. Mat., v.8, n.4, p.238-40, July 1992.

37 - HOLTAN, J.R. et al. Bond strength of six dentinal adhesives. J. Dent., v.22, n.2, p.92-6, Apr. 1994.

38 - IONOKOSHI, S. et al. Dual-cure luting composites. Part I: filler particle distribution. J. oral Rehab., v.20, n.2, p.133-46, Mar.1993.

39 - JENSEN, M.E.; CHAN, D.C.N. Polymerization shrinkage and microleakage. In: VANHERLE, G.; SMITH, D.C., eds. International symposium on posterior composite resin dental restorative materials. St. Paul, Minnesota Mining 1985. p.243-62.

40 - KANCA III, J. Resin bonding to wet substrate. I: bonding to dentin. Quintessence Int., v.23, n. 1, p.39-41, Jan. 1992.

41 - KARAAGACLIOGLU, L.; ZAIMOGLU, A.; AKOREN, A. C. Microleakage of indirect inlays placed on different kinds of glass ionomer cement linings. J. oral Rehab., v.19, n.5, p.457-69, Sept. 1992.

42 - KIDD, E.A.M. Microleakage: a review. J. Dent., v.4, n.5, p.199-206, Sept. 1976.

43 - KOMATSU, M.; FINGER, W. Dentin bonding agents: correlation of early bond strength with marginal gap. Dent. Mat., v.2, n.6, p.257-62, Dec. 1986. 
$44-\mathrm{KREJCl}$, ,I. ; KREJCI, D.; LUTZ,F. Clinical evaluation of a new pressed glass ceramic inlay material over 1.5 years. Quintessence Int., v.23, n.3, p.181-6, Mar. 1992.

45 - KREJCI, I.; LUTZ, F. ; REIMER, M. Marginal adaptation and fit of adhesive ceramic inlays. J. Dent., v.21, n.1, p.39-46, Feb. 1993.

46 - LACY, A.M. et al. In vitro microleakage at the gengival margin of porcelain and resin veneers. J. prosth. Dent., v. 67, n.1, p.7-10, Jan. 1992.

47 - LATTA, M.A.; BARKMEIER, W.W. Bond strength of a resin cement to a cured composite inlay material. J. prosth. Dent., v.72, n.2, p. 189-93, Aug. 1994.

48 - LU,R. et al. An investigation of the composite resin/porcelain interface. Aust. dent. J., v.37, n.1, p.12-9, Feb. 1992.

49 - MAHLER, D.B. Letters to the Editor J. dent. Res., v.69, n.3, p.913, Mar. 1990

50 - MAY JUNIOR, K.N.; SWIFT JUNIOR, E.J.; BAYNE, S.C. Bond Strengths of a new dentin adhesive system. Amer. J. Dent., v.10, n.4, p.195-8, Aug. 1997.

51 - MCINTYRE, F.M. ; BOCHIECHIO, R. A. ; JOHNSON, R. Marginal gap width of a new refractory porcelain system. J. prosth. Dent., v.69, n.6, p.564-7, June 1993. 
52 - MELLO, F.S.T.C. et al. Sealing ability of eight resin bonding systems in a class II restoration after mechanical fatiguing. Dent. Mat., v.13, n.5/6, p. 372-6, Nov. 1997.

53 - MICHELINI, F.S. et al. Tensile bond strength of gold and porcelain inlays to extracted teeth using three cements. Int. J. Prosthodont., v.8, n.4, p.324-31, July/Aug. 1995.

54 - MILLEDING, P.; ÖRTENGREN, U.; KARLSSON, S. Ceramic inlay systems: some clinical aspects. J. oral Rehab., v.22, n.8, p.571-80, Aug. 1995.

55 - MOLIN, M. ; KARLSSON, S. The fit of gold inlays and three ceramic inlays systems. A clinical and in vitro study. Acta odont. scand., v.51, n.4, p.201-6, Aug. 1993.

56 - NAKABAYASHI, N.; KOJIMA, K.; MASUHARA, E. The promotion of adhesion by the infiltration of monomers into tooth substrates. J. Biomed. Mater. Res., v.16, p.265-73, 1982.

57 - NELSEN, R.J.; WOLCOTT, R.B.; PAFFENBARGER, G.C. Fluid exchange at the margin of dental restoration. J. Amer. dent. Ass., v.44, n.3, p. 288-95, Mar. 1952.

58 - ØILO, G. Bond Strength testing. What does it means? Int. dent. J., v.43, n.5, p.4928, Oct. 1993. 
59 - ÖZDEN, A.N.; AKALTAN, F.; CAN, G. Effect of surface treatment of a porcelain on the shear bond strength of applied dual-cured cement. J. prosth. Dent., v.72, n.1, p.85-8, July 1994.

60 - PAFFENBARGER,G.C.; SWEENEY, W.T.; BOWEN,R.L. Bonding porcelain teeth to acrylic resin denture bases. J. Amer. dent. Ass.,v.74, n.5, p.1018-23, Apr. 1967.

61 - PASHLEY, D.H. Clinical considerations of microleakage, J. Endod., v.16,n.2, p. 707, Feb. 1990.

62 - PASHLEY, D.H., CARVALHO, R.M. Dentine permeability and dentine adhesion. J. Dent., v.25, n.5, p.355-72, Sept. 1997.

63 - PASHLEY, D.H.; PASHLEY, E.L. Dentin permeability and restorative dentistry: A status report for the American Journal of Dentistry. Amer. J. Dent., v.4, n.1, p.5-9, Feb. 1991.

64 - PASHLEY, D.H. et al. Permeability of dentin to adhesive agents. Quintessence Int., v.24, n.9, p.618-31, Sept. 1993.

65 - PATEL, S.; SAUNDERS, W.P.; BURKE, F.J.T. Microleakage of dentin-bonded crowns placed with different luting materials. Amer. J. Dent., v. 10, n. 4, p.17983, Sept. 1997. 
66 - REES, J. S.; JACOBSEN, P. H. Stresses generated by luting resins during cementation of composite and ceramic inlays. J. oral Rehab., v.19, n.2, p.11522, Mar. 1992.

67 - REID, J. S.; SAUNDERS, W. P.; BAIDAS, K. M. Marginal fit and microleakage of indirect inlay systems. Amer. J. Dent., v.6, n.2, p.81-4, Apr. 1993.

68 - RETIEF, D.H. Standardizing laboratory adhesion tests. Amer. J. Dent., v.4, n.5, p.231-6, Oct. 1991.

69 - RETIEF, D.H.; MANDRAS, R.S.; RUSSELL, C.M. Shear bond strength required to prevent microleakage at dentin/restoration interface. Amer. J. Dent., v.7, n.1, p.43-6, Feb. 1994.

70 - RETIEF, D.H. et al. Evaluation of the Syntac bonding system. Amer. J. Dent., v.6, n.1, p.17-21, Feb. 1993.

71 - ROCHA, P.V.B. Avaliação "in vitro" da fenda e da infiltração marginal de restaurações "inlays" de cerâmicas puras. Bauru, 1997. 206p. Tese (Doutorado) - Faculdade de Odontologia de Bauru, Universidade de São Paulo.

72 - ROSENSTIEL, S.F.; LAND, M.F.; CRISPIN, B.J. Dental luting agents: a review of the current literature. J. prosth. Dent., v.80, n.3, p.280-301, Sept. 1998. 
73 - ROSSOMANDO, K.J.; WENDT JUNIOR, S.L. Thermocycling and dwell times in microleakage evaluation for bonded restorations. Dent. Mat., v.11, n.1, p.47-51, Jan. 1995.

74 - ROULET, J. F. Marginal integrity: clinical significance. J. Dent., v.22, p. S9-12, 1994. Suppl. n.1.

75 - ROULET, J.K.; SODERHOLM, K.J.M.; LONGMATE, J. Effects of treatment and storage conditions on ceramic/composite bond strength. J. dent. Res., v.74, n.1, p.381-7, Jan. 1995.

76 - SAUNDERS, W.P.; MUIRHEAD, J.M. Microleakage of composite restorations with Syntac Bond and Denthesive. Amer. J. Dent., v.5, n.5, p.255-7, Oct. 1992.

77 - SCHMALZ, G.; FEDERLIN, M.; REICH, E. Effect of dimension of luting space and luting composite on marginal adaptation of a class II ceramic inlay. J. prosth. Dent., v.73, n.4, p.392-9, Apr. 1995.

78 - SHORTALL, A. C. et al. Marginal seal comparisons between resin-bonded class II porcelain inlays, posterior composite restorations, and direct composite resin inlays. Int. J. Prosthodont., v.2, n.3, p.217-23, May/June 1989.

79 - SILVA, F.B.C. et al. Análise da força de cisalhamento: aspectos qualitativos da formação de camada híbrida e macroscópicos da microinfiltração. Rev. bras. Odont., v.55, n.3, p.184-91, mai./jun. 1998. 
80 - SILVA E SOUZA JÚNIOR, M.H. Facetas laminadas em porcelana Maxi-Odonto: Dentística, v.1, n.6, p. 38-9, Nov./Dez. 1995.

81 - SILVA E SOUZA JÚNIOR, M.H. et al. Laboratory evaluation of phosphate ester bonding agents. Amer. J. Dent., v.7, n.2, p.67-73, Apr. 1994.

82 - SJÖGREN, G. Marginal and internal fit of four different types of ceramic inlays after luting. Acta odont. scand., v.53, n.1, p. 24-8, Feb. 1995.

83 - SÖDERHOLM, K. M.; REETZ, E. A. Factors affecting reliability of a resin-based cement joint. Gen. Dent., v.44, n.4, p.296-302, July/Aug. 1996.

84 - SORENSEN, J.A.; MUNSKSGAARD, E.C. Interfacial gaps of resin cemented ceramic inlays. Eur. J. Oral Sci., v.103, n.2, p. 116-20, Apr. 1995.

85 - SORENSEN, J.A.; MUNKSGAARD, E.C. Relative gap formation of resin-cemented ceramic inlays and dentin bonding agents. J. prosth Dent., v.76, n.4, p.374-8, Oct. 1996.

86 - SORENSEN, J.A.; MUNKSGAARD, E.C. Relative gap formation adjacent to ceramic inlays with combination of resin cements and dentin bonding agents. J. prosth. Dent., v.76, n.5, p.472-6, Nov. 1996. 
87 - SORENSEN,J.A.; KANG,S.K.; AVERA,S.P. Porcelain-composite interface microleakage with various porcelain surface treatments. Dent. Mat., v.7, n.2, p.118-23, Apr. 1991.

88 - SORENSEN,J.A. et al. Shear bond strength of composite resin to porcelain. Int. J. Prosthodont., v.4, n.1, p.17-23, Jan./Feb. 1991.

89 - SORENSEN, J.A. et al. Marginal fidelity and microleakage of porcelain veneers made by two techniques. J. prosth. Dent., v.67, n.1, p.16-22, Jan. 1992.

90 - STACEY, G.D. A shear stress analysis of the bonding of porcelain veneers to enamel. J. prosth. Dent., v.70, n.5, p.395-402, Nov.1993.

91 - SULIMAN, A.A.; SWIFT, E.J.; PERDIGAO, J. Effects of surface treatment and bonding agents on bond strength of composite resin to porcelain. J. prosth. Dent., v.70, n.2, p.118-20, Aug. 1993.

92 - SWIFT JUNIOR, E.J.; TRIOLO JUNIOR, P.T. Bond strength of Scotchbond MultiPurpose to moist dentin and enamel. Amer. J. Dent., v.5, n. 6, p.318-20, Dec.1992.

93 - TAYLOR, M.J.; LYNCH, E. Microleakage. J. Dent., v.20, n.1, p.3-10, Feb. 1992. 
94 - THORDRUP, M. ; ISIDOR, F.; HORSTED-BINDSLEV, P. Comparison of marginal fit and microleakage of ceramic and composite inlays: an in vitro study. J. Dent., v. 22, n.3, p.147-53, July 1994 .

95 - TRAITEL, M. Avaliação dos cimentos resinosos Enforce e Dualcement na cimentação de restaurações de porcelana pura através de teste de tracionamento pelo sistema Expansor EMIC. Rev. bras. Odont., v.55, n.2, p.100-3, mar./abr. 1998.

96 - TRIADAN, H. When is microleakage a real clinical problem? Oper. Dent., v.12, n.4, p.153-7, Autumn 1987.

97 - TRIOLO JUNIOR, P.T.; SWIFT JUNIOR, E.J.; BARKMEIER, W.W. Shear bond strengths of composite to dentin using six dental adhesive systems. Oper. Dent., v.20, n.2, p.46-50, Mar. 1995.

98 - TUNTIPRAWON, M.; WILSON, P.R. The effect of cement thickness on the fracture strength of all-ceramic crowns. Aust. dent. J., v.40, n.1, p.17-21, Feb. 1995.

99 - VAN MEERBEEK, B. et al. Morphological aspects of the resin-dentin interdiffusion zone with different dentin adhesive systems. J. dent. Res., v.71, n.8, p.1530-40, Aug. 1992.

100 - VAN MEERBEEK, B. et al. Clinical status of ten dentin adhesive systems. J. dent. Res., v.7, n.11, p.1690-1702, Nov. 1994. 
101 - VAN NOORT, R. Clinical relevance of laboratory studies on dental material: strength determination - a personal view. J. Dent., v.22, p.S 4-8, 1994. Suppl. n.1.

102 - WALMSLEY, A. D.; LUMLEY, P. J.; WILSON, H. J. Composite cement thickness after either ultrasonic or manual application. J. dent. Res., v.73, p.182, 1994. Special issue. /Abstract n.643/

103 - WARREN,K. An investigation into the microhardness of a light-cured composite when cured through varying thickness of porcelain. J. oral Rehab., v.17, n.4, p.327-34, July. 1990.

104 - WATTS, D.C.; AL-HINDI, A. "Soft-start" photo-polymerization effects in resincomposite restoratives. J. dent. Res., v.77, p.658, 1998. Special issue. / Abstract n. 216/

105 - WENDT, S.L.; MCINNES, P.M.; DICKINSON, G.L. The effect of thermocycling in microleakage analysis. Dent. Mat., v.8, n.3, p.181-4, May 1992.

106 - WHITE,S.N.; YU, Z. Compressive and diametral tensile strengths of current adhesive luting agents. J. prosth. Dent., v.69, n.6, p.568-72, June 1993.

107 - WHITE, S.N.; INGLES, S.; KIPNINS, V. Influence of marginal opening on microleakage of cemented artificial crowns. J. prosth. Dent., v.71, n.3, p.25764, Mar. 1994. 
108 - ZAIMOGLU,A.; KARAAGAÇLIOGLU,L.; ÜÇTASLI. Influence of porcelain material and composite luting resin on microleakage of porcelain laminate veneers. $\underline{\mathrm{J}}$ oral Rehab., v.19, n.4, p.319-27, Jul. 1992.

109 - ZARAGOZA VELÁSQUEZ, Z. Estudo comparativo das uniões bráqueteresina-esmalte;bráquete-resina-cobre-alumínio;bráquete-resina-níquelcrômio;bráquete-resina-porcelana, mediante testes de cisalhamento utilizando as resinas Enforce e Concise. Bauru, 1998. 147p. Dissertação (Mestrado) - Faculdade de Odontologia de Bauru, Universidade de São Paulo.

110 - ZUELLIG-SINGER, R.; KREJCI, I.; LUTZ, F. Effects of cement-curing modes on dentin bonding of inlays. J. dent. Res., v.71, n.11, p.184-6, Nov. 1992. 
ABSTRACT 


\section{ABSTRACT}

The shear bond strength of porcelain discs bonded to dentin and the microleakage of porcelain inlays with 3 different dual resin cement systems were evaluated. The systems used were Enforce, Scotchbond Resin Cement/Scotchbond Multi-Uso Plus and Variolink Professional Set.

In the first part of the experiment, 30 extracted human molars were embedded in PVC cylinders and their occlusal surfaces were abraded to expose the dentin. Porcelain cylinders were manufactured, abraded with $50 \mu \mathrm{m}$ aluminum oxide particles and etched with $8 \%$ hydrofluoric acid for 4 minutes. The specimens were divided randomly in 3 groups and bonded with one of the dual resin cements. All the specimens were stored in distilled water at $37^{\circ} \mathrm{C}$ for 24 hours and the shear bond strength test performed in a Kratos Universal Machine. The resulted bond strength values were recorded and submitted to a statistical analysis. The mode of fracture of the specimens was also evaluated.

In the second part of the experiment, MOD cavity preparations with enamel margins were made in 30 extracted human premolars. Impressions were taken and porcelain inlays manufactured on refractory dies. The inlays were seated on the respective prepared teeth, internally adapted and then, the specimens were randomly divided in 3 groups. The internal surfaces of the inlays were etched with $8 \%$ hydrofluoric acid for 4 minutes and then bonded into the preparations with one of the dual resin cements. The specimens were stored in distilled water at $37^{\circ} \mathrm{C}$ for 24 hours, covered with nail varnish, leaving $1 \mathrm{~mm}$ around the restoration margins uncovered, and finally thermocycled. Then, the specimens were immersed in $0.5 \%$ basic fuchsin for 24 hours, washed and cut in a mesio-distal direction, resulting in 3 
sections for each specimen. The microleakage scores were attributed by 3 previously calibrated examiners using a stereomicroscope (40X magnification). The adopted criteria was maximum penetration of the die in each specimen, according to the following scores: 0 - no leakage; 1 - leakage at the gingival wall; 2 - leakage at the axial wall; 3 - leakage at the axial wall, toward the pulp. The data was statistically analyzed.

Based on the results, it was concluded that there was no significant difference on shear bond strength between Enforce and Scotchbond Resin Cement / Scotchbond Multi-Uso Plus, but both were statistically superior than Variolink Professional Set. The mode of fracture of the specimens submitted to shear load was predominantly combined for the Enforce and Scotchbond Resin Cement / Scotchbond Multi-Uso Plus, while the Variolink Professional Set presented adhesive failures between dentin and the resin cement in all of the specimens. Although none of the dual resin cement systems had been able to prevent microleakage, Enforce and Scotchbond Resin Cement / Scotchbond Multi-Uso Plus system performed similarly and were statistically superior than the Variolink Professional Set system. 